https://doi.org/10.15388/vu.thesis.211

VILNIUS UNIVERSITY

NORTHWESTERN ITALIAN PHILOSOPHY CONSORTIUM - FINO

Ruslanas

BARANOVAS

THE PROBLEM OF DETERMINATION IN

KANT, HEGEL AND FERRARIS' NEW

REALISM

DOCTORAL DISSERTATION

Philosophy,

Humanities (H 001)

VILNIUS 2021 
The dissertation was written between 2016 and 2021 at Vilnius and Turin Universities.

\section{Academic supervisors:}

Prof. Rita Šerpytytė (Vilnius University, Humanities, Philosophy - H 001).

Prof. Gianluca Cuozzo (Turin University, Humanities, Philosophy - H 001). 
VILNIAUS UNIVERSITETAS

ŠIAURĖS ITALIJOS FILOSOFIJOS KONSORCIUMAS - FINO

Ruslanas

BARANOVAS

DETERMINACIJOS PROBLEMA KANTO

IR HEGELIO FILOSOFIJOSE BEI

FERRARIO NAUJAJAME REALIZME

\section{DAKTARO DISERTACIJA}

Filosofija,

Humanitariniai mokslai (H 001)

VILNIUS 2021 
Disertacija rengta 2016-2021 metais Vilniaus ir Turino universitetuose.

\section{Moksliniai vadovai:}

Prof. Rita Šerpytytė (Vilniaus Universitetas, Humanitariniai mokslai, Filosofija-H 001).

Prof. Gianluca Cuozzo (Turino Universitetas, Humanitariniai mokslai, Filosofija- H 001). 


\section{TABLE OF CONTENTS}

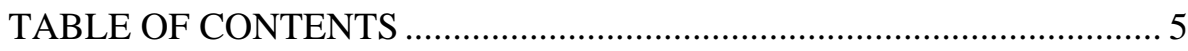

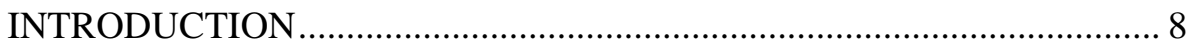

THE KANTIAN REVOLUTION AND THE PROBLEM OF

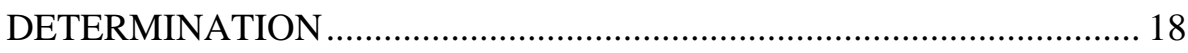

1. The Fundamental Alternative............................................................ 19

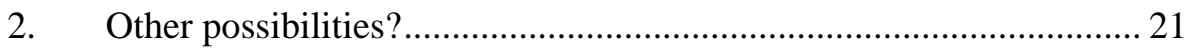

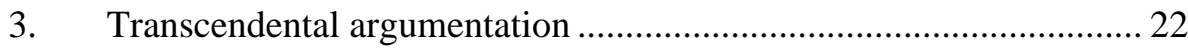

4. The alternative of the object................................................................ 23

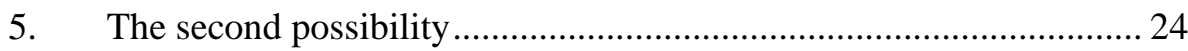

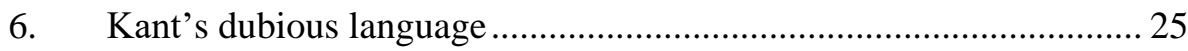

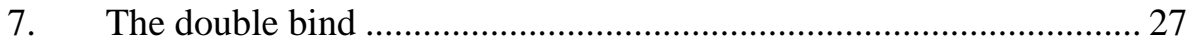

8. The source of determination: subjectivity or the subject?..................29

9. The two formulations of the principle................................................. 32

10. The anticipations and the broadening of experience .......................... 34

11. To the table of categories: the negation and the limit ........................ 35

12. Kant's Dynamic Notion of Determination ......................................... 37

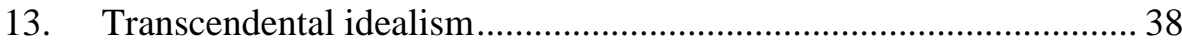

14. The Copernican or Ptolemaic Revolution? .......................................... 40

15. Conclusions and further investigation............................................... 42

UNRAVELING HEGEL'S REALISM: THE PLAN ................................. 44

16. With what must we begin? The path of phenomenology .................... 44

17. Cognition as seizing the hold of the absolute..................................... 45

18. The error, the fear of error and the possibility of science …............... 47

19. The absolute which is always with us ............................................... 49

20. What is the absolute? The First clues................................................. 50

21. The absolute in the absolute idealism ............................................... 51 
22. The absolute in early Hegel ……………..................................... 53

23. The True and The Absolute in preface of Phenomenology .................54

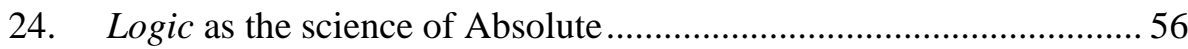

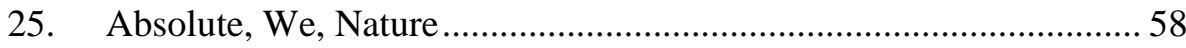

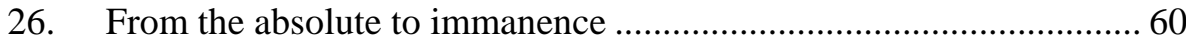

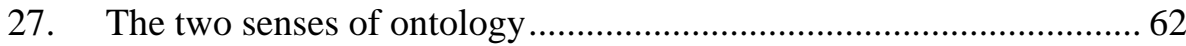

28. Reality, existence and the rise of determination ................................. 63

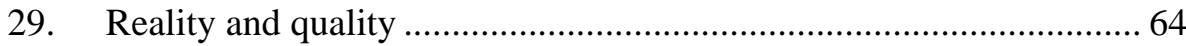

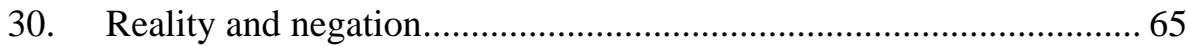

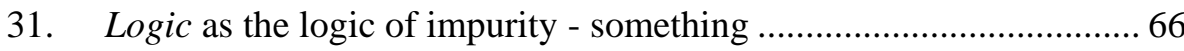

32. What gets lost in reality? The beginning of the individuation ........... 67

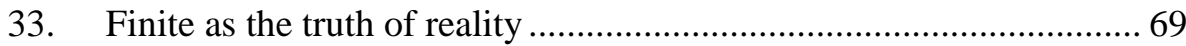

34. What is idealism? Hegel's answer ................................................... 70

35. The night of reflection and the noonday of realism ........................... 71

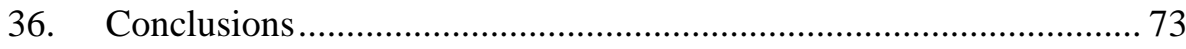

FERRARIS' NEW REALISM AND THE QUESTION OF THE SOURCE

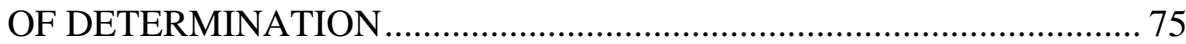

37. Ferraris and Kant's ontological theses ................................................ 75

38. Ferraris and Kant's epistemological theses........................................ 77

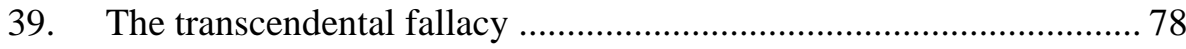

40. Meillassoux notion of correlationism................................................. 81

41. Ferraris and Meillassoux on what went wrong with modern philosophy

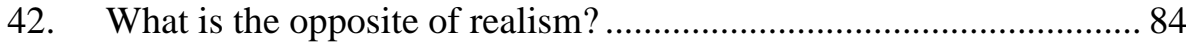

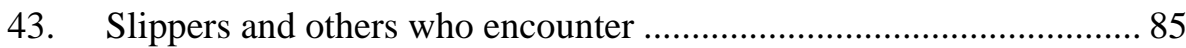

44. Possible critiques: slippers, atoms and anthropocentrism.................. 86

45. Agamben, encounters, determinations .............................................. 87

46. Realism and the question of the source of determination ................... 88

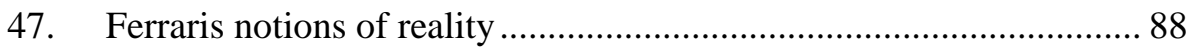

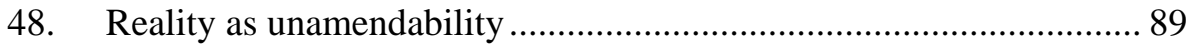




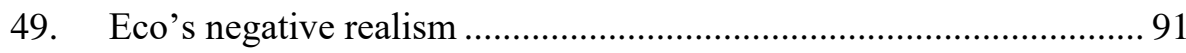

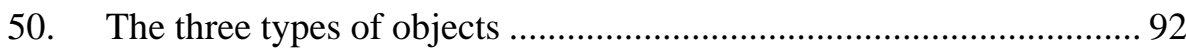

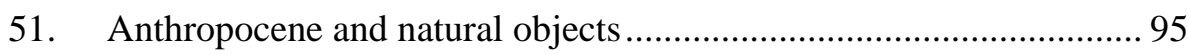

52. The three types of objects and unamendability ................................. 95

53. Positive realism and affordances...................................................... 97

54. Gibson's theory of affordances and a lack of ontological considerations 97

55. Affordances in Ferraris' realism ...................................................... 99

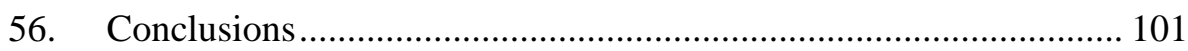

THE QUESTION OF THE SOURCE OF DETERMINATION AS THE PROBLEM OF REALISM: TWO PARADIGMS, TWO PROBLEMS.... 103

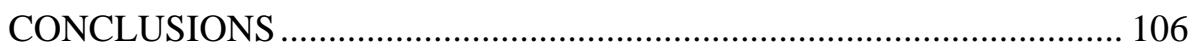

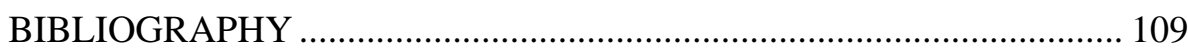

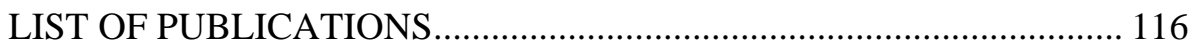




\section{INTRODUCTION}

The problem of realism is a modern problem in its essence. For modernity, the problem of realism is central because it stems from three foundational ideas of modern philosophy: 1) the understanding of the human being as a subject, 2) the understanding of philosophy as a quest for certainty, 3) the understanding of nature as the sphere of lifeless deterministic matter. All three ideas can be traced back to Descartes, but for the problem of realism to truly become central one further development was needed. Kant serves as a proper name for this development in most of the contemporary accounts of the problem. He develops the first idea further claiming that not only a human being is a subject different from everything else, but that he is also an active constructor of his own experience. Simultaneously, Kant transcends vulgar subjectivism because for him transcendental subjectivity as an activity of constructing experience is prior to a consciousness of a concrete human subject. After Kant, the question of whether or not we can know or experience any reality independent of our role as active subjectivity becomes urgent. Kant's own answer to this question is that we can only know what appears to us under the synthesizing power of the "I think", not the things in themselves.

Paradoxically, almost all post-Kantian continental philosophers claimed to be a more and more radical critics of Kant, while being absolutely faithful to Kant's fundamental insight of the central role of an active subjectivity in the constitution of experience. Although for more than a hundred years, Nietzscheans, Hermeneuts, Phenomenologists, and Postmodernists denounced Kant, they all held true the claim that it is impossible to reach mind-independent reality. Nietzsche, for his part, famously claimed that there are no facts, only interpretations and that the real world finally became a fable. Phenomenologists confined the sphere of meaningful investigations to the sphere of the contents of consciousness. His entire philosophical life, Heidegger adhered to the claim that ontology is possible only as phenomenology and that it is the meaning of being that we should be after. His student Gadamer famously stated that "being that could be understood is language", which marks the further development of the Kantian idea which now evolves into a philosophy of language. Although today it is heatedly contested if Derrida falls into the same paradigm, Foucault's The Order of Things is clearly unimaginable without the Kantian revolution. Finally, Vattimo announced that not only we are inescapably Kantian but that we should be delighted about that. According to him, "the weakening of thought" will lead to political and ethical emancipation. 
As matters stand today, all aforementioned radical critics of Kant are today proclaimed to be Kantians themselves. This is the case because the frame of reference has shifted. For most of the thinkers in post-Kantian paradigm, the critique (or destruction) of metaphysics was the horizon in which they judged their own work, as well as the work of others. Yet, today, metaphysics is regaining its previous importance and prestige while the project of destruction of metaphysics is no longer central to the philosophical thinking.

This brief retelling of the history of continental philosophy makes sense only from the perspective of the contemporary critique of the former delivered by the new and speculative realists. Of many different diagnoses of the antirealist character of continental philosophy after Kant, Quentin's Meillassoux's seminal After Finitude (2008) is probably the most influential. According to Meillassoux, Kant's fundamental claim is that both the subject and the object can only be given in correlation and never apart (Meillassoux, 2006: 13). Put differently, one cannot think the object (for example, nature) without thinking the subject at the same time and vice versa. Starting from this, Meillassoux proposes to reread the entire development of post-Kantian philosophy as the development of Kant's correlationist thesis.

Most scholarly works that investigate new and speculative realisms uphold the aforementioned schema according to which Kant is considered to be the founder of the new anti-realist philosophical epoch. One of the most notable examples of this approach is Lee Braver's A Thing of This World: A History of Continental Anti-realism (2007). Braver sees the history of post-Kantian thought as ever-increasing anti-realism, beginning with the Kantian paradigm (Kant, Hegel, Nietzsche) and further developing into the Heideggerian paradigm (early and later Heidegger, Foucault and Derrida). The same schema, with some subtle differences, is presupposed in the wonderful collection of papers Speculative Turn: Continental Materialism and Realism (2011), edited by Bryant, Harman, Srnicek. Following all this work done by the new and speculative realists, I will analyze Kant as the founding father of post-Kantian correlationism and test his alleged anti-realist tendencies.

However, needless to say, such a realist critique of modern philosophy is not unprecedented. Already Jacobi has raised similar charges against Kant. Later, the problem of realism was also perceived as central by the absolute idealists (Hölderlin, Schelling, Hegel), who, at least according to some accounts, tried to overcome Kant's and Fichte's subjectivisms. All these thinkers share an effort to reintroduce traits of realist ontology into the postKantian critical philosophy while at the same time avoiding the fallback into the pre-Kantian dogmatism. Put differently, the absolute idealists do not share the standard post-Kantian anti-metaphysical stance. For this reason, the 
absolute idealism proposes an important alternative to the traditional hermeneutical-phenomenological development of post-Kantian philosophy. I take Hegel's absolute idealism to be the most developed and consistent position in the absolute idealist camp and therefore choose him to represent absolute idealism in this thesis. It is important to note that this is alternative is usually omitted in contemporary realist thought, where Hegel is usually treated as just another correlationist (with a notable exception of Grant). Following such thinkers as Johnston, Grant and Gabriel I will attempt to propose a reading of Hegel's philosophy that is not correlationist.

Of course, the three paradigms (the post-Kantian paradigm, new and speculative realisms, absolute idealism) I analyze in this thesis do not exhaust the entirety of continental philosophy. Deleuze and new materialisms is another notable exception in the history of the post-Kantian philosophy. At least according to some interpretations (the most notable example being DeLanda (2013)), Deleuze openly revolted against the fundamental thesis of Kant's transcendentalism. Deleuze also perceives Kant's subjectivism and the limitation of knowledge to the sphere of experience as problematic. Deleuzian critique of Kant could greatly enrich contemporary realist critiques of Kant and post-Kantian philosophy. However, given the great complexity of Deleuze's philosophy and the limits of time and volume of this thesis, I will not be able to investigate it in this work and will be forced to leave it to the future research.

If the new and speculative realist reading of modern philosophy is right and modern philosophy is essentially anti-realist and correlationist, how can one escape the correlationist circle? Is it possible to move towards a realist position that would not be a return to pre-Kantian dogmatic metaphysics? Many answers have been proposed; many ontologies have been constructed. Actually, the sheer number of realist ontologies today raises suspicion to some of the critics: Consider Zupančic's remark that "'Realist ontologies' are emerging faster than one can keep track of them" (Zupančic, 2017: 73).

To represent the new realist paradigm in this thesis, I will analyze the philosophy of Maurizio Ferraris, the founder of the Italian version of contemporary continental realism. I chose him for the following three reasons: 1) Ferraris developed several versions of his realism: His position has undergone major revisions. Even at the same period of time, he is trying to work out a realist position using different arguments, authors and concepts. In this sense, Ferraris' later work follows a similar strategy to Heidegger's "wood paths". As my thesis will show, the analysis of the three stages of Ferraris' realism uncovers the trajectory of thought which makes evident the problems and the possibilities typical for the entire field of contemporary 
realist thought. 2) Ferraris' interpretation of modern philosophy can enrich the standard speculative realist critique of post-Kantian philosophy because it is similar but different from Meillassoux's critique. 3) Ferraris is still lesser known in the Anglophone world than his realist colleagues like Meillassoux, Harman, Grant or Morton, or even Gabriel.

All aforementioned conceptual conundrums could be grouped under the umbrella of the problem of realism. However, on the one hand, what is realism and what is its conceptual opposite remains unclear and varies in various proposals on how to solve the problem. On the other hand, in modern and contemporary debates the problem of realism is obscured by the fundamental overlapping between ontology and epistemology. Note that realism could be understood as an ontological stance when one claims that something exists truly and independently from the human mind or language. But there is also an epistemological realism: a claim about knowledge of this independent reality. At least in principle, one can be one without being another. For example, Harman is an ontological realist, but at the same time, he criticizes the claim that we can directly know reality that is independent from us through some privileged epistemic approach (a position he calls "epistemism" (2019)). The distinction between ontology and epistemology is not always clearly drawn in the post-Kantian philosophy. Rather the opposite, one could contend that the collapse of the clear distinction between ontology and epistemology is an essential feature of the post-Kantian thought. For this reason, the question of realism, which up until now I treated as lucid and clear, needs a more rigid formulation. In this thesis, the analyses of Ferraris, Kant and Hegel will allow me to propose to treat the question of realism as the following question (which is more ontological than epistemological): what is the source of determination in the world? If this question truly grasps the essence of the problem of realism, and the question of realism is the question about the determination then there is a need to retrace the main distinctions and arguments in the realism debate in the light of the problem of determination. This will be done in the second part of the analyses of Kant (who represents the paradigm of post-Kantian thought) and two alternatives to it, namely, Hegel (who represents the absolute idealist paradigm) and Ferraris (who represents new realist paradigm).

The problem: Given the fundamental role of the question of determination in contemporary realism debates, what is treated as the source of determination in the three main paradigms of Continental philosophy? 
The objectives of the thesis:

Treating Kant as the model for the subsequent post-Kantian paradigm, to investigate what according to Kant is the source of determination. To investigate how the answer to the former question relates to the way Kant thinks about Idealism and Realism and his position on things-in-themselves. To establish the validity of the critiques of Kant done by Hegel and Ferraris.

Treating Hegel as the model of the absolute idealist paradigm, to investigate his criticism of Kant's position and Hegel's alternative account of the source of determination. To investigate his arguments for overcoming Kantian distinction between idealism and realism. To show that absolute idealism is not correlationist and a valid alternative to both post-Kantian paradigm and new realism.

Treating Ferraris as the model of the new realist paradigm, to investigate his criticism of Kant's position and his alternative account of the source of determination. To unfold three different stages of Ferraris thought and analyze the relation of each stage to Kant's transcendental and Hegel's absolute idealism's. To uncover further possibilities for the development of Ferraris' realism.

To facilitate a fruitful debate between new realisms and post-Kantian philosophy by the analysis of the main terms of the debate (realism, idealism, constructivism, correlationism and etc.). This will be achieved through the analysis of the systematic context in which the notion of realism and arguments for it/against it appears in the works of all three philosophers.

Main defended statements:

The problem of realism is the problem of the source of determination. Although the aim of Kant was to establish the conditions of the possibility between subject and object, I claim that Ferraris and Hegel are right when they claim that Kant's philosophy is anti-realist and built on indefensible ontological presuppositions. I claim that there is a strong tendency to associate holistic theories of the source of determination with anti-realism in both Kant and early Ferraris, and that the working out of holistic theory of the source of determination that would not lead to anti-realist position is crucial to both Hegel and later Ferraris. 
The methodology and structure of the thesis. The goals of the thesis will be achieved through revealing a common core understanding of the problem of determination found in all three thinkers. My aim is to demonstrate that philosophies of Kant, Hegel and Ferraris are not three incommensurable planes, but rather parts of the same story. Successful uncovering of this common plane is central to facilitating a fruitful debate between three paradigms. In this way I hope to avoid taking the methodological commitment common to the post-Kantian paradigm, according to which it is possible to write a philosophical text only from a certain perspective. In my case that would amount to writing, for example, about Hegel and Ferraris "through the eyes of Kant", or the other way around. I find two weaknesses in such methodological approach when applied to task my thesis has to achieve. First, one could always ask further question: even if I interpret Hegel and Ferraris from the Kantian standpoint, from what standpoint do I interpret Kantian standpoint itself? In principle, such questioning could go ad infinitum. However, much more serious objection would be the following: isn't the idea that one can only interpret given authors from some kind of standpoint is exactly what contemporary realism argues about? This would mean that the thesis commits itself to the idea that only one of the paradigms holds true.

To achieve my goals, I will start from the analysis of Kant's transcendental deduction of the categories (§1.1-1.6), where the question of the source of determination is raised. Then I will present Kant's double bind between the experience and meaning $(\S 1.7)$ that follows from the transcendental deduction. This uncover tendency in Kant's thinking to associate ontological individualism with realism and holistic theories of the source of determination with anti-realism. All this will help me to demonstrate that for Kant the source of determination is transcendental subjectivity and not a concrete human subject (§1.8). Given these conclusions, I will further analyze Kant’s notion of determination. This will be done through the analysis of the anticipations of perception chapter ( $(1.8-1.11)$. The analysis will uncover Kant's dynamical notion of determination. I will end Kant part of the thesis with the analysis, enabled by the conclusions reached before, of what Kant claims idealism, and its conceptual opposite, namely, realism, to be (\$1.12).

Hegel introduces the question of the source of determination in the Introduction to the Phenomenology of Spirit. I will analyze the Introduction and demonstrate that for Hegel the absolute is the source of determination and display how this notion is arranged to serve as the critique of Kant (\$2.1-2.5). But what is the absolute for Hegel? I will provide the crucial context of Absolute Idealism (\$2.7) and show how the absolute is at the center of all Hegel's works. What is more, the arguments absolute idealists made against 
Kant's alleged subjectivism are present in Hegel's mature works (§2.8-2.10). Later, I will further analyze the absolute as the source of determination in Hegel's works (§2.11-2.13). In chapters §2.14-2.19 I will analyze Hegel's notion of determination and will compare it with Kant's one. Finally, all these analyses will allow me to demonstrate that for Hegel the opposite of his absolute idealism is not realism, but positivism. In this way, Hegel challenges the Kantian tendency to associate ontological individualism with realism and holistic theories of the source of determination with anti-realism.

I will start Ferraris part of the thesis with his assessment of Kant's philosophy (\$3.1-3.3). Later I will compare it with the standard speculative realist account of Kant (\$3.4-3.5). This will help me to demonstrate that for Ferraris the true opposite of realism is not correlationism, but constructivism (§3.6-3.9). Finally, I will conclude that for him the source of determination is reality itself (\$3.10). I will follow three developments of this idea in Ferraris' works and compare these developments with Kant's and Hegel's stance on the source of determination (\$3.12-3.13, §3,14-3.16 and §3.17-3.19).

In the last part of the thesis I will use the conclusions reached by the previous analyses to investigate the relation between holistic theories of the source of determination and anti-realism.

Previous research on the topic. Although contemporary realists suggest their own categories, the contemporary scholarship is not quick to accept and adopt them. Probably the most common framework scholars use to investigate the new realisms ${ }^{1}$ is the opposition between realism and anti-realism. The already classical example of such approach is Lee Braver's $A$ thing of this world (2007). In this work, Braver presents the history of the post-Kantian continental philosophy as a history of the ever-increasing anti-realism. The interesting feature of his work is that he attempts to work out the definition of realism. Nonetheless, the weakness of such approach lies in the term 'antirealism' itself. Braver's primary aim in the book is to facilitate the discussion between analytic and continental philosophy by demonstrating the anti-realist trends in both traditions. Yet, the notion of antirealism itself clearly comes from the analytical philosophy. What is more, Braver thinks that the antirealist must deny the six realist commitments Braver delineates. In other words, he presupposes that if realist claims something, anti-realist must claim the opposite. However, the post-Kantian philosophy often proposes a completely new perspective on the problem, or put differently, instead of

${ }^{1}$ Following Šerpytyte I use the term 'New realisms' to designate both new and speculative realism and other philosophies of contemporary continental realism. 
saying the opposite it says something completely different. The post-Kantian anti-realist would neither agree, nor reject six realist commitments that Braver proposes. For him, most of them would not make sense at all. Richard Sebold in his Continental anti-realism: Critique (2014) also uses the matrix of realism-antirealism. However, his ultimate goal, contra Braver, is to show that it is possible to work out a realist position inside the continental position.

Another option is to follow Meillassoux's own diagnosis of the postKantian philosophy as correlationism and oppose realism to it. And although practically all new realists accept this framework, there is no example of notable scholarly work that addresses both contemporary realism and history of post-Kantian philosophy using realist-correlationist framework.

Ian Hamilton Grant, one of the founding figures of the speculative realist movement, develops the question of realism using the original categories of German Idealism. Together with Dunham and Watson, he argues that idealism and realism are not mutually exclusive (2014). What is more, according to them, historically idealism has always been compatible with naturalism. This is demonstrated through an original interpretation of Schelling's and Hegel's philosophies and Schellingian interpretation of Plato. I sympathize greatly with the spirit of such reading of German Idealism.

In the Italian context, the question of new realism was, first of all, raised as a question about truth and interpretation. Early works of Ferraris suggested this way of raising the question (for example, see Non ci sono $i$ gatti, solo interpretazioni (1998)). Another substantial influence in the field at the time was Umberto Eco's negative realism and Eco's insistence on the limits of the interpretation (2012 and 2015). Finally, Gianni Vattimo's most fully developed answer to the challenge of new realism, Of reality (2016), also discussed the question of realism as the question about the truth and interpretation.

Rita Šerpytyte's perspective is based on the recognition of the fact that the word 'reality' is on itself not a clear term. In some languages, there are two words that both would be translated as 'reality' into English, or, for that matter, into Italian. For example, in the Lithuanian one can say either realybe, which is clearly derived from Latin realitas, or tikrove. Therefore, Šerpytyte wonders: "At once terminological question arises: about what reality (tikrovę) or in what sense it is about reality (tikrovę) what we are speaking about?' (Šerpytytè, 2012a: 8). She notes that Lithuanian distinction between realybe and tikrove resembles German pair Realität/Wirklichkeit. This connection allows her to trace the philosophical lineage of this distinction, which she traces back to Kant (Šerpytytė, 2012a: 9). If Realität has something to do with the thinghood of the thing, Wirklichkeit refers to a different 
understanding/profile of the real. Šerpytytė summarizes her analysis of Wirklichkeit in the following way:

"Kantian Wirklichkeit/Tikrove will not orient us towards the sphere of things, but rather towards the sphere of causes and effects. Not towards reality as the totality of objects, but towards a certain clash of forces. The notion of reality as Wirklichkeit will become a correlate to a new notion of truth: this notion of truth and Wirklichkeit which implies it will become a starting point of both hermeneutics and contemporary sciences of nature" (Šerpytytė, 2012a, 10).

The distinction between Wirklichkeit and Realität forces us to ask which reality contemporary realist and their critics have in mind. In my opinion, it is equally important to note that although the emphasis may differ greatly, any fully-fledged philosophical position must account for both Wirklichkeit and Realität, or at least reduce one to the other.

In her later works, Šerpytyte investigates transformations of reality as Wirklichkeit in contemporary philosophy, especially in the works of Agamben and Malabou (2019) (2021). She also traces a history of notions that are forerunners of Wirklichkeit back to Aristotle's energeia.

This research project is even more expanded in the introduction to the volume On reality (2021) written by Sabolius. For Sabolius the question of the relation between Realität and Wirklichkeit and imagination as a certain power of creating possibilities/thinking the virtual is essential.

The Lithuanian scholarship on the subject matter. Publications on new realisms and realism, in general, are still relatively few in Lithuanian scholarship. Šerpytyte is the main scholar in the field. In her 2012 paper, she presents her reading of the contemporary realist debate through the distinction between Wirklichkeit and Realität and wonders if Brassier's Nihil Unbound (2007) is a banalization of nihilism (2012a). In the same year, she published a paper in which she criticized the early version of Ferraris' realism and his famous use of the phrase "there are no cats, only interpretations" (2012b).

In the context of aesthetics and imagination studies, Sabolius deals with Meillassoux's ontology and works out two different possible relations such ontology can have with artistic practices (2014). Sabolius is also an editor of the biggest volume on the topic in Lithuanian scholarship so far, On the Real (2021). The book consists of various perspectives, starting with the founders of the new realist movement Harman and Ferraris, continuing with internationally acclaimed authors who have mixed relationships with the movement like Malabou, Danowski and Viveiros de Castro, and ending with scholars involved in a critical dialogue with the movement, such as Sabolius, 
Šerpytytė, Montani, Habdankaite, Dagys, Cecchi, Šatkauskas and the author of this thesis.

The problem of realism is also fundamental to the philosophy of Arvydas Šliogeris. However, he himself does not employ such term and contrary to some strands of new realisms he mostly uses the resources of post-Kantian philosophy itself. Probably his most relevant work regarding the subject matter is his doctoral-thesis-based Human world and the existential thinking (1985). In this work, he tries to trace different configurations of "immanent transcendent" in existential philosophy while working out his critique of it as anti-realist (the term which, again, he himself does not use) tendencies.

My own prior research of the subject matter is limited to a few articles. In 2019, I published a paper Why Kant is a weak conceptualist, which was an attempt to lay the groundwork for the interpretation of Kant for this thesis. I published a paper on the problem of virtuality and agency in Object-Oriented ontology (2020) in which I employed the hypothesis defended in this thesis that the question of realism is the question of the source of determination to explain the divergence and the debate between two versions of OOO, namely, Harman's OOO and the position developed by Levi Bryant in his Democracy of Objects (2011). Finally, I published a paper in the aforementioned volume On the Real edited by Sabolius, in which I argued for the validity of absolute idealist position as an alternative to both new realism and the post-Kantian correlationism.

Relevance and novelty of the research. The so-called return of the reality made the debate on realism one of the central questions in contemporary continental philosophy. This thesis tries to critically analyze the main positions in the debate and provide the common ground for fruitful debate, also giving the fair representation of the absolute idealist position in the debate.

Further research plans. At the end of the thesis the problem of the relation between an object as the source of determination and its appearance emerged. Given that an object appears differently to different observers and objects, what is the relation between it as the source of determination and appearance of an object? And how can an appearance affect an object? Could these interactions be thought in causal terms? Or is an object as the source of determination non-ground of appearance? Should we think about these interactions in terms of translation, as is done by Levi Bryant? Or following Deleuze, we should accept that an object as the source of determination must in no way resemble its appearance? I think that answer to this question is vital to all realist thought. Given research opportunities, I hope to inquire into these questions in the future. 


\section{THE KANTIAN REVOLUTION AND THE PROBLEM OF DETERMINATION}

In a more than two hundred years since the publication of the Critique of Pure Reason, there have been countless interpretations of Kant's philosophy. However, all this work scarcely brought any consensus on the interpretation of the Kant's main themes, arguments, and concepts. In a rather pessimistic passage, Dieter Heinrich sums up the history of Kant scholarship in the following way: "A quarter of a millennium after his birth, almost two hundred years after the publication of the Critique of Pure Reason, and despite the never-interrupted continuity of labor on his opus - our ability to interpret basic texts of Kant's critical philosophy remains far below all legitimate expectations" (Heinrich, 1994: 126). The poverty of Kant scholarship is further exposed by the contemporary critiques of Kant delivered by new and speculative realists. If scholars cannot agree even on the interpretation of the most basic themes and arguments Kant puts forward, how are we to evaluate critiques against Kant?

To alleviate this problem, I must stress two points. First, the object of this thesis is not the history of Kant scholarship. Rather, I focus on the renewed realism debates in the last couple of decades and the place Kant and Hegel occupy in them. That is not to say I will, or somehow could, ignore the scholarly work done on Kant in all those years. However, my interest in the debates between Kant scholars will be limited only to questions I consider important for the scope of the thesis. I do not lay claim for any comprehensive and final answers to the scholarly disputes on Kant. As all Kant's interpreters, "I have to concede that there are some passages that count against my interpretation; but insist that these do not represent the spirit, intention, or ultimate direction behind Kant's thought" (Beiser, 2002: 19).

Second, I hope to bring Kant's philosophy into a fruitful dialogue with Hegel and contemporary new realism. The philosophers in contemporary realism debate often employ the central terms of the debate (realism, correlationism, idealism, anti-realism, constructivism) differently, and most of these terms (if they had been used at all) had been used in a very different way in classical German philosophy. For this reason, I will focus not only on Kant's own categories of realism and idealism but also on how the terms Hegel and Ferraris use to conceptualize realism debates fare in relation to Kant. In this way, the hermeneutical procedure of putting the main arguments and concepts of Kant, Hegel, and Ferraris against each other and then 
returning to each philosopher separately will provide the general orientation for the interpretation of each of them.

To uncover Kant's notion of the source of determination, I will first need to demonstrate the broader context in which it is situated. As I will show, Kant's notion of experience is crucial for this task. The fact is noteworthy because it shows that Kant's notion of determination is inseparable from his notion of the subject, who is the locus where the experience happens. To show that this is the case, I will first turn to the heart of the first Critique - the transcendental deduction of the categories. Kant there presents the most important theoretical decision - the decision concerning the source of the possibility of determination - from which Critique of Pure Reason springs.

\section{The Fundamental Alternative}

Kant starts "Transition to the transcendental deduction of the categories" - which should bring the argument of the first part of the Critique of Pure Reason to the conclusion - with a fundamental alternative:

"There are only two possible cases in which synthetic representation and its objects can come together, necessarily relate to each other, and, as is were, meet each other: Either if the object alone makes the representation possible, or if the representation alone makes the object possible" (Kant 1998: 224).

What is at stake here is nothing other than a fundamental shift between the critical and the precritical philosophy concerning the question of determination. For Kant, the shift has to do with the issue of coming together (Zusammentreffen), relating (Beziehen), or meeting (Begegnen) of an object and a representation. The fact that he considers the possibility that something which is supposed to mirror (re-presentation), and therefore by definition be secondary, could be as a source, signals something unusual about Kant's notion of representation. Indeed, for Kant representation (Vorstellung) is not only something that represents an outside object but, first and foremost, a state of a subject. Keeping this in mind, the precise meaning of rather nontheoretical expressions ('meeting' and 'coming together') is revealed by the framing of the alternative: Either a possibility of representation is "made" by an object or a possibility of an object is "made" by a representation. But what are a representation and an object in general? From the point of view of cognition, they both are nothing other than the wholes of determinations. The 
object or the representation is given to me as this concrete object with these concrete determinations (properties). Therefore, the shift between the critical and the precritical philosophy concerns the source of the possibility of determination: Kant claims that the possibility of the determination arises either out of objects or from the representation. The question is absolutely fundamental because it concerns not only the possibility of (synthetic a priori) judgment but also the possibility of the determination as such, or to put it otherwise, the possibility of the existence of anything at all.

Fichte follows exactly the same line of thought when he presents the difference between dogmatism (the pre-critical philosophy) and idealism (the Kantian philosophy). He notes that the thing and the intelligence can in principle be distinguished in the experience. If that is true, a philosopher will confront a decision,

„If he leaves out the former, he retains an intelligence in itself, that is, abstracted from its relation to experience, as a basis for explaining experience; if he leaves out the latter, he retains a thing-in-itself, that is, abstracted from the fact that it occurs in experience, as a similar basis of explanation. The first method procedure is called idealism, the second dogmatism" (Fichte 1982:8-9).

This does not mean that either Kant or Fichte believe that it is possible to clearly distinguish what in the experience comes from an object and what comes from us (intelligence or representation). Pippin puts this point beautifully when he states that for Kant the intuition is "distinct, but inseparable" from the intellect (Pippin 2018: 22). Therefore, this is rather a question of the standpoint and the order of explanation.

At least two objections could be raised against this kind of picture. First, one could claim that there are other alternatives omitted in Kant's account. For example, the Platonic way of solving the problem of the source of possibility of determination appeals neither to object itself nor to the representation. Second, one could also ask if this alternative marks the passage from pre-critical to critical philosophy, what is the place of clearly pre-critical rationalism of the inborn ideas? These two questions will help me to elucidate Kant's position with a greater precision. 


\section{Other possibilities?}

According to Kant, "there are only two possible cases" of how the determination is possible. However, one could come up with other ways how to explain it. One of the most obvious examples of such "another way" is the Platonic theory of ideas: According to this view, the source of determination is not an object, but the ideas subsiding in the otherworldly hyperuranios. Although Kant is traditionally depicted as an a-historical philosopher, the argument he presents against Plato's position appeals directly to the history of philosophy. This is the reason Kant never mentions this possibility in the Transition chapter. Instead, he starts the first Critique with the rejection of it. According to the beginning of the first Critique, the metaphysical explanation of determination leads to "obscurity" and "contradictions" and produces "the battlefield of endless controversies" (Kant 1998: 99). Its "reign" is "dogmatic" (Ibid). In other words, because of the "endless controversies", metaphysics is unable to achieve any measurable progress. However, Kant's most important argument is the following: There is no way to conclusively prove which metaphysical theory is the true one, therefore "endless controversies" without conclusive solutions finally lead to the indifference to the entire field. As Kant puts it, "now after all paths (as we persuade ourselves) have been tried in vain, what rules is tedium and complete indifferentism" (ibid). Therefore, the problem is neither that we cannot know which metaphysical theory is right (if any), nor that they are all wrong or meaningless (as Kant will later try to prove) but that nobody cares about them anymore. All these arguments and historical reflections lead to one claim: if thinking is to be scientific, the source of determination cannot be some metaphysical entity or principle.

Another possibility Kant never mentions in his object/representation dichotomy is a "middle path." Kant deals with this possibility later, when he claims that "if someone still wanted to propose a middle way between the two $\langle\ldots\rangle$ that is that the categories $\langle\ldots\rangle$ were rather subjective predispositions for thinking, implanted in us along with our existence $\langle\ldots\rangle$ then this would be decisive against supposed middle way: that in such a case the categories would lack the necessity that is essential to their concept" (Kant 1998: 265). Obviously, Kant has the theory of inborn ideas, which was a typical view to be held in early modern philosophy, in mind. In fact, the argument against it may sound surprising at first. How come if the categories are planted in our minds by God, could they lack necessity? Kant further explains that even if the categories were actually implanted in our minds, "I would not be able to say that the effect is combined with the cause in the object (e.g. necessarily), 
but only that I am so constituted that I cannot think of this representation otherwise than as so connected; which is precisely what skeptic wishes most" (ibid). I believe that here Kant suggests that the inborn ideas cannot reach the object itself, or to put it differently, they cannot connect to indifferent things. In the end, the ideas remain, ontologically and explanatory wise, completely different from things and are only applied to them from the outside. If that would be the case, an object and inborn ideas would not come together (Zusammentreffen) and neither would they meet (Begegnen). Furthermore, then we would only have knowledge of ideas and not of objects. The gap between an object and an idea would remain persistent. In contrast to this, Kant's critical philosophy will claim that the manifold of intuition and categories meet, and the first one is transformed into objects by this meeting.

\section{Transcendental argumentation}

But why this obsession with the possible sources of determination and possibilities in general? Would it not be better to argue for one position and provide arguments only against the strongest alternatives? I will now try to show, that for Kant it is absolutely essential that there would only be one possible set of conditions through which experience could be realized. The entire idea of transcendental argumentation is built on this. Formally, the argument could be summarized in five steps: 1) Something undoubtedly exists; 2) If it exists, it is possible; 3) If something exists, conditions of its possibility are actual. 4) Therefore, if you are able to demonstrate that "an undoubtedly existing thing" has only one set of possibilities that allow its existence, 5) You have proven that these conditions of the possibility of an undoubtedly existing thing are actual. Indeed, such a formal structure of the argument was missed by so many Kant's contemporary readers that he added the entire chapter titled "Synthetic a priori judgments are contained as principles in all theoretical sciences of reason" to the introduction of the second edition of Critique of Pure Reason to shine more light on the issue. Mathematics and Physics play a pivotal role there, as according to Kant, they show that the synthetic a priori judgments undoubtedly exist. He explains that "about these sciences, since they are actually given, it can appropriately be asked how they are possible; for that they must be possible is proved through their actuality" (Kant: 1998, 147). That's why from "the two possible cases" of the source of determination one must be shown to be false. 
The fact that Kant has to eliminate all possible sets of conditions except one for a transcendental argumentation to work is attested by the length he goes to show that space and time cannot be metaphysically real. In "Metaphysical expositions" he provides four arguments why both space and time cannot be determinations found in objects but are a priori intuitions. In this way, he tries to leave only one option open: that it is the transcendental subjectivity that is the source of them. At first glance, Critique of Pure Reason lacks similar arguments on why the source of other determinations could not be objects themselves. The dealing with the issue in "Transition to the Transcendental Deduction of the Categories" is brief and decisive.

\section{The alternative of the object}

"There are only two possible cases in which synthetic representation and its objects can come together, necessarily relate to each other, and, as is were, meet each other: Either if the object alone makes the representation possible, or if the representation alone makes the object possible. If it is the first, then this relation is only empirical, and the representation is never possible a priori." (Kant, 1998: 224).

From this quote it seems clear that the object as the source of determination is rejected on the grounds of its empirical character. What does Kant mean by this? And why does he think that one sentence is enough to deliver one of the most important arguments of the first Critique? First of all, one has to note that the premise of the argument is already established in the introductions to the A and B editions of the Critique. As established by Kant's famous classification of judgments: Only a priori judgments are necessary, while all empirical judgments are contingent (Kant, 1998: 130-133). Therefore, if the source of determination turned out to be "empirical", all our knowledge would lack necessity. Again, Kant thinks that the (synthetic) a priori representations are necessary for mathematics, physics, and metaphysics - sciences that produce necessary true claims - to exist. As I already noted, Kant thinks that at least the first two actually do exist (Kant: 1998, 147). From this Kant concludes that the source of determination cannot be the object itself because then the aforementioned sciences would be impossible. Another reason why Kant does not go at great lengths with his argument here is historical: In his opinion, Hume's critique of induction already established this point beyond any reasonable doubt. 
It is noteworthy that Kant's transcendental argumentation allows him to make an ontological claim (objects are not the sources of determination) based on (broadly speaking) epistemological claim (the necessary character of the scientific statements). Such a procedure will be heavily criticized by Ferraris', who worries that it constitutes the reversal of the primacy of ontology over epistemology.

Kant thinks that now the metaphysical, the rationalist and the empiricist explanations of the source of determination have been rejected. If this holds, the project of the Critique of Pure Reason has a green light because the source of the determination is the representation itself. But if that is the case, what sort of notion of representation Kant operates with? To answer these questions properly I will further explore Kant's notions of representation and experience.

\section{The second possibility}

I have traced Kant's argument for the claim that the source of the possibility of determination is the representation. What does such notion imply? Does representation produce its object? Are we then the pure mental beings who somehow introduce things into existence by the sheer power of will? Kant is quick to delimit himself from such a Berkeley-type idealism. To answer such worries, he claims that "representation in itself (for we are not here talking about its causality by means of the will) does not produce its object as far as its existence [Dasein - R.B.] is concerned" (ibid). From the standpoint of empirical consciousness, the existence of an object is, obviously, a determination. However, contrary to all other determinations Kant investigates (space, time and categories), the possibility of existence does not come from the representation. We cannot simply introduce things into existence by the power of will. This suggests that Kant presupposes a certain duality: the subject and its representations on the one hand and non-subjective source of existence of representations on the other. One can argue that this is that Kant points to when he introduces the distinction between the matter and the form of appearance in the opening pages of transcendental aesthetics: "I call that in the appearance which corresponds to sensation its matter, but that which allows the manifold of appearance to be intuited or ordered in certain relations I call the form of appearance" (Kant, 1998: 155-156). From this quote, it seems that the source of the existence of the matter of experience cannot be the experience itself. This distinction is similar to another founding 
distinction of Kant's critical philosophy, i.e. the one between spontaneity and receptivity. It is equally crucial to note here that what Kant calls the form allows appearance to be intuited or ordered (synonymy), not intuited and ordered (a sequence of time). From the standpoint of Transcendental I, to intuit and to order is the same. The acts of intuition and synthesis are not separated or done one after another. Paradoxically, as we will see, it could be argued that for Kant ordering is always prior to intuiting. Whichever is the case, according to Kant, our receptivity and spontaneity are closely intertwined (distinct, but inseparable in concrete experience). In addition, now we see that already in the first pages of "Transcendental Aesthetics" Kant starts to lay the ground for what he will try to prove in the "Transition to The Transcendental Deduction of the Categories".

\section{Kant's dubious language}

However, Kant is much less decisive in the transcendental deduction. Although the argument here has to establish universal validity of the categories as the explanation of the possibility of determination, the question about the scope and reach of this validity remains. In a few paragraphs, Kant relates the categories with the processes of "cognition", "intuition", "thought" and "experience". For example, Kant claims that "the representation is still determinant of the object a priori if it is possible through it alone to cognize something as an object" (Kant, 1998: 224). Such formulation allows some readings that only treat cognition as structured according to the categories while keeping intuition nonconceptual. This is an extremely important point for the study of Kant's notion of determination, because if such reading is right, Kant may have at least two notions of determination (one categorical and another nonconceptual).

I think that the most decisive passage by far in the first Critique regarding the scope of the universality of the categories is the following:

"The question now is whether a priori concepts do not also precede, as conditions under which alone something can be, if not intuited, nevertheless thought as object in general, for the all empirical cognition of objects is necessarily in accord with such concepts, since without their presupposition nothing is possible as object of experience. $\langle\ldots\rangle$ the objective validity of the categories, as a priori concepts, rests on the fact that through them alone is experience possible (as far as the form of thinking is concerned). For they then 
are related necessarily and a priori to objects of experience, since only by means of them can any object of experience be thought at all" (Kant 1998: 224).

Only one thing is certain: for Kant, no experience would be possible without the categories. It is equally clear that it is impossible to think the object of experience without categories. However, it is possible to think the thing-in-itself because it is not the object of experience. Most importantly, the relation between intuition and categories is put under the question mark, with a slight suggestion that it is also impossible to intuit something without categories ("if not intuited, nevertheless thought as object in general"). Therefore, if we know for certain that experience is impossible without the categories, but cannot clearly distinguish the relation of the categories have with regards to thinking and intuiting, the question of what precisely Kant means by experience is crucial.

Kant's answer to this question can seem to be disappointing. He insists that experience is nothing other but the "coming together" of categories and intuition under one consciousness: "Consequently the categories do not afford us cognition of things by means of intuition except through their possible application to empirical intuition, i.e. they serve only for the possibility of empirical cognition. This, however, is called experience" (Kant, 1998: 255). Therefore, for experience to be possible, the categories depend on "the given"; We cannot simply introduce the external things into the experience by our power of the will. Put differently, for Kant, only cognition in which the categories meet existence is experience. But the question remains: Can I as empirical consciousness reach the intuition which is not yet constituted by the schemas of the categories? Are there then two experiences? One experience in which categories and intuition "come together" and on which science and knowledge are built, and another one, experience in the casual sense of the word, simple nonconceptual awareness of the empirical? ${ }^{2}$

To answer this question one needs to focus on what Kant tries to prove in the first part of the first Critique. It is well known that Kant there reacts against Hume's skepticism towards induction. According to Hume, we can never

${ }^{2}$ This is suggested by some Kant scholars. See, for example, Grüne, S., 2011. Is there a Gap in Kant's B Deduction?, International Journal of Philosophical Studies 19 (3): 465-490 and Hanna, R., 2011. Kant's Non-Conceptualism, Rogue Objects, and The Gap in the B Deduction, International Journal of Philosophical Studies 19 (3): 399415. 
establish any causality with the strict necessity with regard to the perceived things, because we do not have any experience of necessary relation. Regularities in nature can be presupposed only because it is a pragmatically useful habit. Against such a stance, Kant tries to prove the universal validity of causation (along with all other categories). Keep in mind that Kant's model of causation is Newtonian: He believes that all natural events happen according to the strict laws. Therefore, it would not possible to explain the conditions of the possibility of such a model if there were gaps in experience and we could experience something to what causation would not apply. I take this to be a crucial point: If everything must fall into the causal order (causal closure) and causation is a transcendental category, then every intuition must be structured according to it, and ergo it is impossible to have any intuition not structured according to the categories in general. As Kant himself claims, "There is only one experience" (Kant, 1998: 234).

The critic now might object that Kant first claimed that the source of the possibility of determination is representation but then it turned out to be the categories. It could be replied that by representation Kant in fact meant the spontaneity of the subject and its powers in the first place. If this is the case, one could accuse Kant of some loose use of the concepts but not the real inconsistency.

\section{The double bind}

The determinations that come from the representation are omnipresent in the life of the subject. It is not possible to experience things that do not have the extension in time and space (the categories of quantity), have quality (the categories of quality), are caused or causes (the categories of relation) and are actual or necessary (the categories of modality). This Kantian idea is one of the pillars of post-Kantian philosophy: We cannot reach anything that is not structured by our own categories. In this context, Kant's famous dictum - "the I think must be able to accompany all my representations; for otherwise something would be represented in me that could not be thought at all, which is as much as to say that the representation would either be impossible or else at least be nothing for me" (Kant 1998: 246) - unfolds its precise meaning. According to Kant, any experience is composed both of appearance, constituted according to the categories, and the one who experiences, the thinking I. Therefore, the experience is always, on the one hand, an experience of something, of an object. On the other hand, it is my mental act or, using the language of phenomenology, intention. This also means that everything that 
could be experienced is composed of bits of possible knowledge and, therefore, is meaningful. This point can be well attested by our own ordinary lives: everything appears to us as something. Heidegger will later draw the attention to this fact in the famous paragraph 32 of Being and Time (Heidegger 2001: 189-195). By contrast, if we try to imagine that the manifold of intuition would look like prior to the work of imagination and intellect, we would be left with something completely unintelligible. As Kant claims, such manifold "would then belong to no experience, and would consequently be without an object, and would be nothing but a blind play of representations, i.e., less than a dream" (Kant 1998: 235). Prior to the work of the categories, our receptivity catches something "less than the dream." This suggests that from the point of view of the empirical consciousness, the manifold of intuition as such is not accessible. Consciousness enjoys its life never leaving the land of experience. Or, as Kant puts it less poetically, "Thus the manifold in a given intuition also necessarily stands under categories" (Kant 1998: 252). Now the meaning of the claim that representation is the condition of possibility of determination is clearer. Kant does not want to demonstrate that without the subject there would be no experience. This is trivial, as it is true. His claim is much more radical: Without the subject, some determinations that the subject finds in the object would not be there at all. This means that objects sensu stricto become objects what they are only in experience. To summarize: For Kant all experience is meaningful and some determinations we find in objects would not be there at all if there would be no activity of the subject.

While Kant limits experience to the field of meaning, he conversely limits the field of meaning to the field of possible experiences. Some schools of the post-Kantian philosophy followed Kant and the empiricist tradition in limiting the scope meaningfulness of the concepts to the scope of their possible extension. According to this tradition, to understand that the concept means is to know what objects this concept picks out in the "world." Note that Kant differentiates between the empirical concepts and the categories, which makes his position more nuanced. However, the limitation of experience to the sphere of the (possible) empirical intuition - the content of experience - is a commitment Kant undoubtedly shares. As his famous dictum declares: "Thoughts without the content are empty" (Kant 1998: 193). Thus dictum, also limits the sphere of knowledge to that of empirical. It is the thoughts that are empty if they retain no empirical content. To summarize: For Kant, all meaning is tied to the experience.

The second part of Kant's dictum might be even more significant to the contemporary debates on realism. Kant famously states that "intuitions without concepts are blind" (Kant 1998: 193-194). If the first part of the 
dictum delimits knowledge, the second delimits experience. It is only possible to experience what is constituted by the concepts. Fortunately, as we have hitherto seen, "the manifold in a given intuition also necessarily stands under categories" (Kant 1998: 252). Therefore, the empirical consciousness is never completely blind and never experiences something "less than a dream." This, however, means, that it is the transcendental subjectivity that makes consciousness open its eyes and see. It follows from this that every experience is structured according to the structure of possible knowledge. Therefore, for Kant, not only every experience is meaningful (as was established two paragraphs ago) but also every experience is knowledge. To summarize, when translated into positive terms Kant's second limitation actually means: For Kant, every experience is knowledge.

In this way, we arrive at the meaning of the "thoughts without the content are empty and intuitions without concepts are blind" (Kant 1998: 193-194). Kant's dictum constitutes a double bind: Knowledge is confined by the empirical in the experience and experience is confined by the possible knowledge. Or, to put it more simply: every experience is knowledge and every knowledge has one root in the experience. Even thinking itself is confined to the categories. When we think the thing-in-itself, God, freedom and other practical ideas we still apply the categories, albeit, strictly speaking, unjustifiably. We apply them beyond the limits of experience, with the justification of practical ends.

\section{The source of determination: subjectivity or the subject?}

"There are only two possible cases in which synthetic representation and its objects can come together, necessarily relate to each other, and, as is were, meet each other: Either if the object alone makes the representation possible, or if the representation alone makes the object possible" (Kant, 1998: 224).

Even after exploring the double bind to which Kant commits, the concrete way "representation alone makes the object possible" remains obscure. One has to keep in mind that establishing the exact mechanism of how this happens could be the task Kant does not commit himself to. For example, Dieter Heinrich convincingly argues that Kant believes that it is not possible to establish how conditions of possibility are actualized but only that they are (Henrich 1989: 32-37). Nonetheless, this does not mean that Kant is vague on what the claim "representation alone makes the object possible" entails. 
To respond to the question of how "representation alone makes the object possible", or to at least see the Kantian perspective on it, it is critical to understand the revolutionary move the first Critique made while solving this problem. Formally, transcendental argumentation is not something unique. Already Plato deduced (in the Kantian sense) the existence of various ideas by appealing to the fact that they are the only way of how to account for the knowledge of the phenomenal world. According to Plato, ideas have to exist, because they are the sole conditions of the possibility of knowledge, and knowledge is the fact of our everyday life. What distinguishes Kant's position is not the formal structure of the argument but where he puts "the conditions of the possibility of experience." For Plato, they are through and through in the objective. Kant, on the other hand, locates them in the "powers of the soul." On the abstract level, these powers are sensibility, imagination, and intellect. Kant makes this extremely clear at the end of the "Transition": "The possibility of an experience in general and cognition of its objects rest on three subjective sources of cognition: sense, imagination, and apperception" (Kant 1998: 236). Thus, "the representation alone makes the object possible" means that the subject alone makes the object possible. It is the powers of the subject that are the source of determinations in the experience. However, does this leave us with a full-blown subjectivism?

Kant is indeed a subjectivist, but of a very peculiar kind. Subjectivism is typically thought of as closely related to perspectivism, and even relativism. However, nothing can be further from Kant's position than the last two. This is the case because the concrete empirical subject is also only constituted in experience, as a correlate of an object. Therefore, one can further ask, how could the representation be the source of the possibility of experience if it is itself already dependent on the categories. To put it in even more crucial terms: How can a subject be the source of determination if he himself is determined by the very same objective categories? These questions indicate, that already in Kant the objective order of the categories could be said to be prior to both subject and object. Therefore, Kant's subjectivism has an objectivist dimension. That is not to say that a subject and an object do not exist prior to their relation in experience. Rather, Kant claims that it is only in experience where they acquire their concrete form, which, for that reason, should not be attributed to them in themselves. But, at the same time, the transcendental subjectivity is also dependent on the existence of rational subjects. If there would be no rational agents, there would be no categories. In this sense, the transcendental subjectivity is neither objective nor subjective in the usual sense of the terms. Rather, the subject splits into the transcendental-subjectas-ground in that the empirical subject partakes and the empirical- 
consciousness-as-grounded. To put it in a German Idealist jargon, the subjectivity posits itself. But this positing is enabled by the fact that the concrete subjectivity is never equal to itself as a finite empirical subject; there is always something objective in the subject. This is why Kant always warns us against reading his philosophy as a form of psychology. Therefore, I have to correct the judgment I made in the preceeding paragraph: It is not the subject who is the source of determination but the transcendental subjectivity. But in what sense transcendental subjectivity could be said to be prior to a concrete subject? It is well known that Kant remains silent on historical priority: for him, it does not make sense to inquire if the transcendental subjectivity is prior historically to the appearance of rational subjects. In this sense, he asks us to accept that neither is primary. However, it seems clear that with the disappearance of the rational subjects' the transcendental subjectivity as the source of determination would also disappear. Therefore, while being prior to both object and subject in the sense of their constitution, the transcendental subjectivity is still essentially tied to the human as a rational agent. In other words, for Kant, the source of determination is entangled with concrete human subjects.

This new space of the transcendental opened by Kant may be his greatest philosophical achievement and it is there where most philosophical "discoveries" took place after Kant. These discoveries/inventions in the transcendental topos are the historical a priori's of Hegel and Foucault, the passive syntheses of Husserl, the language of the linguistic turn, Derrida's quasi-transcendentals, and the entire plead of Heidegger's figures: the structures of Dasein, the clearing, the fourfold and all figures of an opening. This is one of the arguments that I propose to defend my treatment of Kant as the model of post-Kantian philosophy in this thesis.

Another evidence that we cannot strictly distinguish between the experiencing subject and the transcendental subjectivity is Kant's commitment to the existence of the things impossible to intuit. Note that he explicitly commits to the existence of things too small for us to intuit and these things also play a role in the constitution of determination. Lucy Allais' works out this point in her Manifest Reality: Kant's Idealism and his Realism:

"For Kant, very small things, very distant things, and entities posited by science can all be part of what is empirically real, despite the fact that we cannot actually perceive them. He talks about stars that exist even if no one will ever perceive them (A469/B524), and magnetic force, for Kant, is part of appearances, but it is not something we perceive - we lack the requisite sense apparatus to perceive it. He says, that "crudeness" of our senses "does not 
affect the form of possible experience in general" (A226/B237)" (Allais: 2015: 47).

From this, a certain broadening of experience follows, because otherwise determination would be constituted of something that critical philosophy would have no way of accessing. If Allais is right, we can infer that Kant allows knowledge to be built not only from experiences but also from possible experiences. At least in principle, with the help of technology this broadening transcends consciousness and includes everything physical into the scope of experience. Therefore, transcendental philosophy does not disqualify talk about atoms, waves, quarks and etc. The main point of Allais' book (with which I agree) is that this implies that Kant is not a phenomenalist. To stress this once more: Kant's commitment to the existence of things unperceivable yet structured according to the categories, in principle implies that the plane of (possible) experience is equal to that of the physical as such. The main point of this is the following: The broadening of experience implies that the transcendental subjectivity is the source of determination even of the things empirical consciousness is unable to perceive.

The theory of the source of determination comprises of two conceptual parts (the source and the determination). I established that, for Kant, the source of determination is the transcendental subjectivity. Now I will turn the second part, namely, Kant's notion of determination. To do that I will investigate Kant's theory of quality as it is developed in the Principle of the anticipations of perception. This principle is a priori result of the use of categories of quality on the manifold of intuition. The analysis of the principle will uncover two important features of Kant's notion of determination.

\section{The two formulations of the principle}

The first thing to note when analyzing the principle of anticipations of perception is two different formulations of the principle in two editions of the Critique. In the second edition, the principle is: "In all appearances, the real, which is an object of the sensation, has intensive magnitude, i.e., a degree" (Kant, 1998: 290). However, in the first edition of the Critique the Principle has a more confusing form: "In all appearances the sensation, and the real, which corresponds to it in the object (realitas phaenomenon), has an intensive magnitude, i.e., a degree" (Ibid). The debate on which formulation to follow has very high stakes. As Giovanelli notes: 
"Therefore, one can reasonably ask whether "sensation has a degree, as the first edition of the Critique of Pure Reason says," or "reality as the second says," or perhaps both. In the last case, one might ask whether reality has a degree because sensation has a degree or, vice versa, whether sensation can present diverse degrees because the real that corresponds to it in the object presents differences in degrees: from the citations the argument cannot be resolved." (Giovanelli, 2011: 18).

According to Giovanelli, the fundamental question is whether sensation has a degree, because "the real" has a degree or, vice versa, "the real" has a degree because sensation has one. In other words, the question is still the same: What is the source of determination in experience? I believe that the first option is clearly false if taken literally, because if there would be a degree only because "the real" would have a degree, then either the degree would not be a priori, or Kant's argument would draw a priori conclusions about something that is outside of experience. But if the second alternative is correct, another problem arises. Longuenesse explains it in this way:

"If we now have to admit that even the matter of appearances, that which "corresponds to sensation," depends on a synthesis of imagination, then not only does the distinction between receptivity and spontaneity seem altogether to disappear, but so too that between what is empirically given (the matter of appearances) and what is generated a priori by the constitution of the subject (the form of appearances)" (Longuenesse 1998: 299-300).

If she is correct, the second alternative also seems to be an unaffordable interpretation of Kant, because it contradicts the founding distinctions of the critical philosophy (first of all, the one between spontaneity and receptivity). We seem to be left without an option. In my opinion, this brings us back to the problem we already encountered. 1) If the transcendental subjectivity is the necessary condition of possibility of determination and 2) there is no other perspective then that of a finite subject, then there is no way to distinguish what in determination belongs to the "form", and what to bellongs the "matter", as these are always given together. Again, they are "distinct, but inseparable" (Pippin 2018: 22). However, one should not conclude that the distinction between "form" and "matter" collapses. We should not forget that Kant is not a phenomenologist and the distinction was never built on experience in the first place. Rather the distinction was built on the necessity of it as the condition of the possibility of experience. If this is the case, then 
there is no need to worry that anticipations of perception eliminate the distinctions between spontaneity and receptivity, or form and matter. The same could be said about a priori character of the principle, because "the real" has a degree a priori only in experience and nothing intelligent could be said about anything outside of experience. Put differently: for Kant, it is not the sensation that has a degree, but "that in the appearance which "corresponds" to sensation." However, the "corresponding" appearance is not something independent from the transcendental subjectivity,but rather constituted by it. One cannot unravel which is the first or more important (or which really has a degree).

\section{The anticipations and the broadening of experience}

I now turn to what the Principle states about experienced reality itself. The principle of anticipations of perception states: "In all appearances, the real, which is an object of the sensation, has intensive magnitude, i.e., a degree" (Kant 1998: 290). If "the real" as the plane of qualities is first of all the plane of determinations, then the idea that experienced reality is an intensive magnitude looks pretty straightforward. The qualities of the object, such as temperature, texture, color and so on, always have a degree or intensity. We can see that one redness is more intense than another, one surface is rougher than another and can measure the temperature of the chilly Winter air in Vilnius. All these qualities seem to be reducible to a numeric expression and be comparable. What is more, given that in this context Kant talks about magnetic phenomena, the principle seems not to be limited even to human sensitivity. This is the case, because Kant needs to account not only those we experience in our mundane everydayness but also for the qualities natural sciences speak about. Indeed, one can even argue that non-sensible reality is more important to Kant than the layer of sensible qualities. This point is beautifully argued by Hermann Cohen, one of the most attentive readers of this part of the first Critique, in his Kant's theory of experience written in 1871. According to Poma, Cohen sees Kant's efforts to conceptualize the nonsensible layer of reality as the continuation of Leibniz's philosophy (Poma, 1997: 41-44). While attempting to ground sciences ontologically, Descartes defined material things as res extensa. According to Poma, for Kant, the problem with such definition is that by doing so Descartes still defined matter through the reference to the senses, as an extension in space. The principle of intensive magnitudes has to solve precisely this error. Kant's argument can be 
summarized in the following way: 1) Heat, for example, is an intensity; 2) Every intensity can be reduced to degrees and be measured. It seems that Kant thought that even visually experienced phenomena are reducible to intensity and have a degree; Obviously, a degree could be expressed in numbers. Thus, 3 ) in the final analysis, every quality is reducible to a number ${ }^{3}$. Poma stresses that this is the reason Cohen calls this principle "the triumph of thought" when Cohen writes that "Thus reality is the category, which, in this role, fills the forms of space and time at the initial stage with the content that prepares the mathematical object for its future as a physical object. But this can be termed "the triumph of thought": that in its effort towards realization it overcomes sensible conditions" (in Poma, 1997: 42-43). In other words, the notion of determination as an intensive magnitude offers the notion of reality clean from the "illusions" our usual sensual experience implements on our theoretical notions. As I already argued, this implies the broadened scope of experience to which even the things human subjectivity cannot perceive belong.

\section{To the table of categories: the negation and the limit}

Kant claims that "between reality and negation there is a continuous nexus of possible realities, and of possible smaller perceptions" (ibid). First of all, note that the possible realities are placed by Kant between reality and negation. This shows the double use of the word reality by Kant: Reality sometimes denotes the category but also means a concrete reality as the quality of concrete appearance. However, there is a crucial philosophical point Kant makes here. If a possible reality (an intensive magnitude) is between pure reality and pure negation, what does Kant mean by negation? Is negation for him just an absence, the nonexistence of degree? Indeed, such conclusion could be derived from the text because Kant uses the equation "negation $=0$ " a few times. For example, he writes about "the real, which corresponds to sensations in general, in opposition to the negation $=0$ " (Kant, 1998: 295). Such notion of negation would explain why Kant says that reality is between pure reality (positive degree) and negation (no degree). But this would be an utterly trivial claim for Kant to make. Also, it is hard to imagine what in the

\footnotetext{
${ }^{3}$ One can see the development of this principle in the German Idealism. In it, the quality is always reducible to quantity. For example, see the table of contents of Hegel's Science of Logic. There is some inner connection between mathematics and idealism.
} 
manifold of intuition would correspond to this "no degree." Therefore, such interpretation seems to be too metaphysical for the present context and incompatible with the actual experience. Fortunately, there are other possible readings of Kant's category of negation.

In the context of this problem, many scholars point to Kant's precritical text An Attempt to Introduce the Concept of Negative Magnitude into Philosophy written in 1763, eighteen years prior to the publication of Critique of Pure Reason. The title of the text itself points to a different interpretation than "negation $=0$ " because 0 would not be a not a negative magnitude, but merely the absence of magnitude. In this text, Kant distinguishes between two types of negation. One is a simple lack, defectus, and the other is privation, privation. I have already explored the difficulties that arise if we were to take Kant's negation in the first Critique to mean defectus. Therefore, only privation could serve as a legitimate understanding of Kant's notion of negation. Longuenesse explains what this entails:

"the second (privation - R.B.) is the absence of a determination resulting from the conflict of opposed determinations. For instance, rest (absence of movement) may be the effect of two moving forces of opposed directions. $<\ldots>$ The second case (privatio) is the more interesting, however, for it relates both reality and negation to the third category of quality: limitation. Indeed, as we shall see, all reality and negation, determination of a thing (Sachheit, Realität) and absence of such a determination, is nothing but limitation: the determinations of each thing given in space and time are nothing but reciprocal limitations of determinations universally opposing each other (limiting each other) in space and time (Longuenesse 1998: 304)."

According to such notion of reality, the determination is never atomic, primary fact, but a result of the opposition of two forces. Determinations are nothing other than "reciprocal limitations." For example, the fact that I am now sitting still is the result of an equilibrium between the force of gravity and my muscle power. Kant's model in the Anticipations seems to be the sciences of magnetic and chemical phenomena of his day, where we find the notion of the equilibrium of negative and positive charges holding a given element together. This is why Kant stresses not to understand negative magnitudes as simple negations when he claims that "negative magnitudes are not negations of magnitudes, as similarity of the expressions has suggested" (Kant, 1992: 209). The magnitudes are negative only in concrete situations when they are in opposition to other magnitudes: "[negative magnitudes are - R.B.] something truly positive, albeit something opposed to the positive magnitude" 
(ibid). Therefore, one also has to keep negative magnitudes inside reality and at the same time explain how possible realities are constituted between pure negation and pure reality.

In my opinion, this is best done by Cohen. For him, similarly to Longuenesse ("Indeed $\langle\ldots\rangle$ all reality and negation, $\langle\ldots\rangle$ is nothing but limitation" (ibid)) the category of limitation is essential in Kant's notion of reality. However, Cohen reinterprets Kant's notion of the limit itself. As Poma notes, Cohen brings to attention the fact that Kant employs the concept of the limit taken from the differential calculus (Poma, 1997: 41-44). In calculus, the limits are used to calculate what happens to a function when an independent variable gets very close to a particular value. One can ask, for example, what is the value of $\mathrm{Y}$, when $\mathrm{X}$ approaches 2 in some given function. The concept of the limit is thus completely formal. It is a point, or, as it is usually denoted in the axis of coordinates, an empty point, in which one value approaches another value. In other words, it marks an infinitely small difference. What does all this have to do with Kant's notion of reality? Cohen reasons along these lines: "Possible realities" are constituted by the difference between the opposing degrees. The differential concept of the limit helps to conceptualize it: as reality approaches negation or vice versa (or, in concrete examples Kant gives, negative or positive degrees of color, warmth, a moment of gravity) there is an infinite variation of realities, as there is infinite values between $X$ that approaches 2 and 2. Therefore, for Kant, the reality is this process of the approaching to the equilibrium of opposing forces. Another important point thing is this: Quality has always to have a degree which is not 0 because otherwise such quality would be experienced as emptiness or blankness. But that never happens in experience. Therefore, the opposing forces can never achieve the full equilibrium and cancel each other. That is why zero is always a limit point, an infinite approximation to zero. There is no empty experience. For the argument of this thesis, it is crucial to stress that this means for Kant's notion of determination: determination is never primary but is always a result of the conflict of the opposing forces.

\section{Kant's Dynamic Notion of Determination}

If one keeps in mind that the problem of reality is essentially the problem of determination, then it is worth comparing these conclusions with Heidegger's remarks on Kant's notion of reality in The Basic Problems of Phenomenology. I think his remarks are both partly correct and partly 
misleading. Heidegger claims that Kant's has a different understanding of reality when compared to the contemporary one, when he claims that "Realities are the what-contents of possible things in general without regard to whether or not they are actual, or "real" in the modern sense" (Heidegger, 1982: 34). In this Heidegger is right, realities are determinations. However, one should note that realities are not only "what-contents" of the possible things but also of the actual things. The concept of possibility is not some higher-order category with which one could explain the concept of reality in Kant. To claim otherwise is to completely collapse the distinction between the categories of quality and the categories of relation.

Heidegger's reading goes astray when he claims that for Kant "The real is what pertains to the res" (ibid). I find this emphasis on the dependence of Kant's notion of reality and determination on the thinghood to be misleading. As I showed, determination for Kant is the result of the play of forces. Not only that: non-thinglike entities of physics and chemistry are the model of reality for Kant. In this regard, Kant's reality is much closer to the processional reality of physics than the substantial reality of classical philosophy.

\section{Transcendental idealism}

Henry Allison's book Kant's transcendental idealism (1983) played a huge role in assigning the label 'transcendental idealism' to Kant's position. Although debatable for Kant's project as a whole, this label fits perfectly for the first part of the first Critique that I've been working with. What features define Kant's idealism? The first thing to note is the opposition in which he thinks his idealism. In classical thought, the opposite of idealism was materialism. The debate between idealism and materialism was the debate about what ultimately the world is made of. As I already demonstrated, Kant tries to explain not what the world is made of, but, rather, what is the source of determination in the world. Therefore, to Kant and German idealists, transcendental idealism is the opposite of realism, not materialism. In this perspective, realism (or dogmatism) is the position that "the object alone makes the representation possible" and the object alone is the source of representation of which we are passive recipients. We already saw Kant's reasons for rejecting realism. Against it, transcendental idealism claims that "the representation alone makes the object possible" and that determinations we experience and know do not exist outside of experience. Historically, such 
use of the terms was further obscured by Marx who again opposed materialism to (Hegel's) idealism, thus returning to the classical opposition.

What does the 'transcendental' part of transcendental idealism signify? As I argued before, Kant's idealism is transcendental in the topos ("the powers of the soul"), which is the source of representation. However, Kant's transcendentalism is nonetheless restricted. It never becomes a subjective idealism. Although the transcendental subjectivity is the source of determination, its logical and transcendental condition of possibility, the subject does not produce determinations (objects) out of thin air. It does so in harmony with the manifold of intuition. In my opinion, many commentators of the Critique of Pure Reason get carried away sometimes while talking about the scope of the "Copernican revolution." It's not so much that "it is we who are giving orders" (Deleuze, 1984: 14). We - meaning the transcendental subjectivity - give lawfulness and order, but not concrete orders. It is impossible to deduce the laws of nature from the transcendental because the transcendental contains only the most basic forms of lawfulness. Therefore, Kant's empirical realism means not only that space, time and categories are objectively valid for the empirical consciousness, but also that there is a lot to learn from the empirical.

What about the 'idealism' part of Kant's transcendental idealism? His idealist position follows directly from the fact that Kant rejected all other possible sources of determination. It means that transcendental subjectivity not only imposes its forms on the manifold of intuition but also that these forms cannot mirror anything in the manifold itself. To put it differently, many determinations empirical consciousness experiences would not be in the world at all if there would be no transcendental subjectivity. This is that ideal means here for Kant: 'Ideal' simply means "dependent on the subject." From this Kant infers his famous conclusion that we can only know appearances, not the things in themselves. This can sound as if it contradicts the claims I made on Kant's labor of bringing the subject and the object into the contact ("meeting") and the role of the empirical in the constitution of the experience. However, Kant does not see the contradiction here. In the constitution of an object, the manifold of intuition plays a role and produces determinations, but only by filing the forms of space, time and categories. As Kant states, "Thoughts without the content are empty" (Kant, 1998: 193), however the contents as contents do not have a separate existence without the forms.

It seems to me that here Kant reaches a certain limit. The phenomena can only be separated into the form and matter by abstraction. We can never actually sort out what in some concrete experience comes from the receptivity and what from the intellect. That is the case because 1) Kant starts from the 
premise that it is the transcendental subjectivity that is the condition of the possibility of determination and 2) he never oversteps the perspective of the finite subject who always experiences a synthesis of form and matter. I think that these two to presuppositions lead to the situation where the subject experiences only "formed" matter, while never being able to reach the pure matter itself. This leaves the matter of experience what 'matter' always was in the history of philosophy: unintelligibility, which somehow still participates in the constitution of the intelligible phenomena. It does not seem to be the case that the problem could be dissolved by simply re-branding the Kantian distinction between matter and form, to those of act and content or noesis and noema. At the heart of phenomena, we uncover the problem of the thing-initself repeated. We are unable to reach the matter of experience in itself.

Kant never considers the possibility that the transcendental subjectivity does not so much form or constitute the object, but brings it out or uncovers the object that appears exactly as it is itself. The same idea is also essential for the transcendental argumentation to work: Kant has to prove that determinations we find in objects cannot be present in the objects themselves. As we will see later, the same link between "constitution", "construction", and "creativity" on the one hand, and "difference", "the creation of something new" or even "distortion" on the other, also governs the thought of Ferraris. I think that the rejection of this link is one of the insights Hegel will develop.

\section{The Copernican or Ptolemaic Revolution?}

My analysis of Kant's theory of the source of determination brought out the fact that, for Kant, the transcendental subjectivity constitutes determinations even well below the threshold of human sensibility. In this sense, Kant's theory of the source of the determination is not strictly speaking equal to the theory of the human experience of determinations. However, today Kant is attacked for alleged anthropocentrism on another ground.

Lately, the leading new realists charged Kant's transcendental idealism with being the opposite of, rather than, the Copernican revolution. According to Meillassoux, Kant actually starts the Ptolemaic counter-revolution: "Yet it has become abundantly clear that a more fitting comparison for the Kantian revolution in thought would be to a 'Ptolemaic counter-revolution', given that what the former asserts is not that the observer whom we thought was motionless is in fact orbiting around the observed sun, but on the contrary, that the subject is central to the process of knowledge" (Meillassoux 2008: 53). 
The same idea is echoed by Ferraris in his Manifesto of New Realism (Ferraris 2014b: 6), while Gabriel Catren claims that overcoming this aspect of Kant's philosophy is central to his philosophical project: "Philosophy will finally be modern only if it can sublate the critical moment, crush the Ptolemaic counterrevolution and deepen the narcissistic wounds inflicted by modern science" (Catren 2010: 335).

My analysis of Kant's theory of the source of determination confirms this critique. However, the argument against Kant must be more nuanced than the often presented versions of it. My point is that for Kant the source of determination is not a concrete subject, but the transcendental subjectivity. A concrete subject finds himself already constituted by the transcendental subjectivity. In other words, one should not equate the transcendental subjectivity with the human. However, as I argued, the transcendental subjectivity is still essentially tied to the concrete human subjects, because if these would disappear it would disappear also.

I think that Graham Harman puts this argument in the most powerful form. Kant argues that there is only one set of conditions of the possibility of the meeting of the subject and the objective. Given that he denies the possibility of transcending the perspective of the finite subject, all talk about other ways of the meeting becomes nonsensical. According to Harman, this means that we cannot say, for example, that a hammer hits a nail, or a dog pushes a bone, but only that a hammer hit the nail in our perspective and that a dog pushed a bone in our experience. This idea is expressed, for example, when through Garcia he asks: "“'And in fact," Garcia asks, "why should I think that the table and the paperweight enter into relation as objects only from the moment when I enter into relation with their relation?"' (Harman 2013: 157). In other words, all 'object'-'object' or 'non-human-subject'-'object' interactions can only be accounted for in a (possible) experience and are denied the subject independent existence. This line of thought is exemplified by Agamben's already mentioned fascination with Uexkülls theory of Umwelt. Once again, Agamben comments on the illusion of the common world:

"This illusion rests on the belief in a single world in which all living beings are situated. Uexküll shows that such a unitary world does not exist, just as a space and a time that are equal for all living things do not exist. The fly, the dragonfly, and the bee that we observe flying next to us on a sunny day do not move in the same world as the one in which we observe them, nor do they share with us - or with each other - the same time and the same space." (Agamben 2004: 40) 
In this way, the quality of the meeting Kant establishes starts to turn doubtful. If Harman is right in his criticism, and Agamben in his theory of the world, does the true meeting between the bee and dragonfly never happens? Is not this the triumph of Fichte, who claimed that we always only meet ourselves?

\section{Conclusions and further investigation}

I started with Kant's fundamental decision with regard to the source of determination in experience. Kant's thesis on determination is that it arises through interplay, "the meeting", between the activity of the transcendental subjectivity (spontaneity) and sense-data (receptivity). The first part of this 'Kant chapter' is devoted to the question of how exactly this 'meeting' is conceptualized by Kant. After the analysis of Kant's category of reality and the anticipations of perception, I have reached the following conclusions:

1. For Kant, the source of determination in experience is the transcendental subjectivity. This means, that the "meeting" conditions established by Kant only applies to those, who could be/have transcendental subjectivity. In Kant's system, this de facto leaves only humans as capable of the meeting. Therefore, the authors are right to point out that Kant's revolution is more Ptolemaic than Copernican. However, despite that Kant's theory of determination is not equal to the theory of human experience because the transcendental subjectivity constitutes qualities well below the threshold of human sensibility (as in the case of magnetic and electric phenomena).

2. For Kant, the source of determination is the transcendental subjectivity, not the concrete human subject. The concrete human subject finds himself in the space constituted by the transcendental subjectivity. However, with the disappearance of the rational subjects' transcendental subjectivity as the source of determination would also disappear. Therefore, while being prior to both object and subject in the sense of their constitution, the transcendental subjectivity is still essentially tied to the human as the rational agent.

3. Contrary to many accounts prevalent today, Kant sees his aim as one of establishing the conditions of the 'real' meeting between the subject and the objectivity in the experience. In other words, he does not seek to enclose us in our subjectivity, but to get us in touch with the objective.

4. Kant postulates the "double bind" between experience and knowledge. For Kant, all experience is constituted from fragments of (possible) 
knowledge, and all knowledge is constituted from fragments of (possible) experience.

5. Kant defends the notion of qualities as intensive magnitudes. Intensive magnitudes are constituted by the opposition between the opposing forces (Realität and Negation). This means that forces constitute determinations qua qualities. Determinations are not primal or atomic. Kant's notion of reality is dynamical and not based on the substance model.

6. Finally, Kant thinks the question of realism in the realism-idealism opposition. For Kant, idealism concerns the ontological status of determinations. Kant calls himself an idealist because he claims that determinations given to human subjects only exist in experience and not in the world apart from the human subjects. 
The analysis of Kant allowed me to reach the following conclusions: 1) the question of realism for Kant is the question about the source of determination; 2) For him, the source of determination is the transcendental subjectivity; 3) Determination itself is not primal but the result of the tension between opposing forces. These three claims led Kant to conclude that we can only ever access the human experience and therefore scientific metaphysics is possible only as the metaphysics of morals. It is well known that Hegel tried to overcome this conclusion. I will begin the investigation of Hegel's notion of the source of determination from the Introduction to the Phenomenology of Spirit. The question of the "meeting" between a subject and an object is raised there in a completely different manner than in Kant's philosophy. This leads to a rethinking of the status of determination in general. The key to understanding his attempt to overcome Kant's limitation of knowledge to the sphere of appearances is his notion of the absolute ${ }^{4}$. After the analysis of the absolute as the source of determination, I will turn to Hegel's analysis of the determination Realität in Science of Logic. Exactly like Kant, Hegel works out his theory of determination in a greater detail under the rubric of reality. Finally, I will end the investigation into Hegel's notion of the source of determination with the analysis of the relation between reality and common sense. This will help to uncover the concrete meaning of Hegel's idealism and its relation to realism.

\section{With what must we begin? The path of phenomenology}

Hegel starts the introduction to the Phenomenology of Spirit with a direct confrontation with Kant. He writes that "it is a natural supposition that in philosophy, before one gets down to dealing with what is at issue, namely, the actual cognition (wirkliche Erkennen) of what, in truth, is, it is first necessary to come to an understanding about cognition, which is regarded as the instrument by which one seizes hold of the absolute or as the means by which

\footnotetext{
${ }^{4}$ It is interesting that in After Finitude Meillassoux also returns to the absolute and claims, that his aim is to find "another relation to the absolute" (Meillassoux, 2006: 29). According to Ennis, Meillassoux has "the assumption that an abandonment of metaphysics is taken to entail a correlative abandonment of the absolute" (Ennis, 2011: 31).
} 
one catches sight of it" (Hegel 2018: 49). Hegel makes three crucial points in this opening sentence of the Introduction. First of all, Hegel affirms that the mission of philosophy, "what is at issue" in philosophy, is "the actual cognition of what, in truth, is." Hegel will adhere to this clearly Aristotelian definition of philosophy reinterpreted in a post-Kantian way in both Phenomenology and Science of Logic. Therefore, for Hegel, philosophy is ontology. Second, Hegel affirms that it is natural that before "dealing with what is at issue" philosopher turns to another kind of inquiry first. In other words, it seems natural that before attempting to know something one should investigate the way he knows and the limits of his way of knowing, to later return to the world with confidence and prevent errors. According to Hegel, philosophy has a natural leaning towards epistemology. Third, philosophy has to do with knowledge and cognition of the absolute.

As I showed, Hegel's second point concerns the "natural" epistemological turn in philosophy. Indeed, it seems natural to think that a warranted knowledge requires one to first know how the instrument of his knowing, namely cognition, works. This seems to be so natural that the epistemological turn presents itself as not having any ontological presuppositions at all. This allegedly presuppositionless nature of epistemology will be the principal target of the Introduction. Hegel further discerns the two main "paradigms" of Kant-style epistemology. The first one regards cognition as the instrument which seizes hold of the absolute, the second one "as the means by which one catches sight of it" (ibid). Against epistemology, he starts Phenomenology with the rejection of these two ways of understanding cognition. For Hegel, only the question of the absolute can solve the riddle of ontologyepistemology nexus. But before delving into that, I will present Hegel's arguments against epistemology because they constitute the first step in Hegel's rethinking of the relation between knowledge and experience.

\section{Cognition as seizing the hold of the absolute}

What happens if we treat cognition as an active instrument seizing hold of the cognized? According to Hegel, if this is presupposed "then it becomes immediately clear that the application of an instrument to a thing no longer leaves the thing as it is for itself, but rather goes about forming and changing it" (ibid). The thing cognition tried to seize hold of then eludes its grasp because cognition alters the thing, therefore, it ends up with a different thing. This seems to be the conclusion Kant reached in the first Critique. However, 
it could be argued that it is possible to distinguish what determinations in the cognized come from the cognized itself and what is constituted by the instrument. I have already demonstrated the reasons why Kant thinks this is impossible. Hegel agrees with Kant on this point and offers a much simpler argument: "However, this improvement would in fact only bring us back to where we were before. If we again subtract from a formed thing what the instrument has added to it, then the thing - here, the absolute - is again for us exactly as it was prior to this consequently superfluous effort" (ibid). But even this would be impossible, for it would require us to know the thing prior to the application of the instrument, which would beg the question of why the instrument was needed in the first place if we were able to know the thing without it.

What happens if we treat cognition as a passive medium through which cognized is to be seen? Hegel argues that the outcome is the same: "If cognition is not an instrument of our activity but is to a certain extent a passive medium through which the light of the truth reaches us, then here too we do not obtain it as it is in itself but only as it is through and in this medium" (ibid). I believe Hegel's target here is the precritical rationalist and empiricist theories of the passive cognition that see cognition as a passive medium, a wax tablet, on which ideas are imprinted. It is intriguing that while being completely false, the example of the passive medium is also one of the most commonly used when explaining Kant's philosophy. For example, Kleist's famous elucidation of Kant's philosophy to his fiancée Wilhelmine von Zenge also appeals to a passive medium: "If all men had green glasses instead of eyes, then they would have to judge that the objects they see through them are green and they would never be able to distinguish whether their eye shows them the things as they are or whether it does not add something to the which belongs not to them but to the eye" (Kleist, 1977: vi). Now, Kleist's example shows that the model of cognition as a passive medium falls prey to the same objection: it is unable to reach the thing "as it is for itself." Moreover, Hegel argues that we cannot discern that comes from the medium and that comes from the thing because if we would remove the properties of the medium from the thing itself all we would be left with would be "pure direction or empty space" (Hegel 2018: 50). I think that all these considerations finally lead to the conclusion that it is impossible to differentiate between the passive medium and the active instrument insofar as a medium has to produce some minimal activity to not turn into a simple void. I think this is indicated by Hegel then he qualifies that a passive medium is passive "to a certain extent" ("If cognition is not an instrument of our activity but is to a certain extent a passive medium through which the light of the truth reaches us, then here too 
we do not obtain it as it is in itself but only as it is through and in this medium" (Hegel 2018: 49) - my emphasis).

Therefore, Hegel's conclusion is simple: If we start doing philosophy by giving ourselves into the natural tendency to start with the epistemology as Kant did, we do not get closer to the objective but only further from it. Or in his own words: "In both cases, we make use of a means which immediately brings about the opposite of its goal" (Hegel 2018: 49). Epistemology is unable to establish the promised conditions of meeting between an object and a subject and always leaves us in the position of a subjective pole. On this, Hegel and Ferraris (or any other new realist) would agree. Moreover, for Hegel, this means that epistemology necessary leads to skepticism or at least Kant-style quietism: "This concern is even bound to be transformed into the conviction that the entire project of acquiring for consciousness through cognition what is in-itself is absurd in its very concept and that between cognition and the absolute there lies a limit which completely separates the two" (ibid). It is absolutely essential to note that Hegel sees the reason for the skepticism in the separation of the cognition and the absolute. It is immediately clear that in Hegel's eyes this equally applies to Kant. He began with the question of the condition of the possibility of meeting between the subject and the objective, but according to Hegel, entire Kant's thinking is built on the presupposition of the separation of the subject from the objective or, to employ the language of classical philosophy, the separation of thought and being. Therefore, it seems that Kant's critical philosophy in its entirety stands on the fundamental premise that is not argued for. Hegel will further investigate this premise. The conclusions he will reach will lead him to rethink the problem of determination in a new way.

\section{The error, the fear of error and the possibility of science}

If the turn to epistemology only gets us further from the real, what is to be done? Hegel's answer may seem disappointingly simple. He claims that "meanwhile, if the concern about falling into error sets up a mistrust of science, which itself, untroubled by such scruples, simply sets itself to work and actually cognizes, it is still difficult to see why on the contrary a mistrust of this mistrust should not be set up and why one should not be concerned that this fear of erring is already the error itself" (Hegel 2018: 50). But what is this "mistrust of the mistrust" built on? Does it simply signify Hegel's preference towards ontology, as if one is free to choose according to his own liking? 
Obviously, no. However, Hegel's strategy is not to argue against the fear of error. Rather, as I argued, he attempts to show the hidden presuppositions that determine such fear. He points out three presuppositions of this kind in the Introduction to Phenomenology. The first two are 1) the "representations of cognizing as an instrument and as a medium" and 2) the presupposed "difference between our own selves and this cognition." The third is the most crucial for him and is related to the absolute. Hegel writes:

"Above all it presupposes that the absolute stands on one side and that cognition stands on the other for itself, and separated from the absolute, though cognition is nevertheless something real; that is, it presupposes that cognition, which, by being outside of the absolute, is indeed also outside of the truth, is nevertheless truthful; an assumption through which that which calls itself the fear of error gives itself away to be known rather as the fear of truth" (ibid).

It is easy to infer that the true target here is Kant. Already in Faith and Knowledge Hegel identified the aforementioned antithesis as the core of Kant's philosophy, when he claimed that "the fundamental principle common to the philosophies of Kant, Jacobi and Fichte is, then, the absoluteness of finitude and, resulting from it, the absolute antithesis of finitude and infinity, reality and ideality, the sensuous and the supersensuous, and the beyondness of what is truly real and absolute" (Hegel, 1977a: 62). According to Hegel, it is on these presuppositions that Kant's denial of knowledge of the thing-initself rests. The fear of error forces Kant to equate the field of justified use of concepts to that of the empirical (the double bind) so "endless metaphysical controversies" could be avoided. And, it is also the fear of error that forces Kant to make the conclusion that the transcendental subjectivity is the source of determination but yet only our way of constituting experience and thus $a$ subjective way.

But even if this is true, how can one overcome this mistrust? Are these presuppositions simply to be replaced by other presuppositions? In the following chapter, I will demonstrate that for Hegel's project of restitution of ontology the problem of the absolute is essential. 


\section{The absolute which is always with us}

The clue why the mistrust is to be mistrusted is given in a peculiar image of the Introduction. According to Hegel, one should not try to catch the absolute through some clever epistemological procedure, either with an instrument or through a medium. Hegel ridicules such attempts, claiming that a philosopher who does this tries to catch the absolute like "a bird caught through a lime twig" (ibid). What is a lime twig? It is a hunting technique in which hunter covers a branch of a tree with glue, so the bird would stick to the branch when he lands on it. Hegel suggests that it is exactly what the effort of the philosopher to overcome the separation between the subject and the objective and secure a meeting with the absolute amounts to.

According to Hegel, all these countless strategies and tools philosophers use would not amount to anything if we would not already be in contact with the absolute. He writes that "the absolute would surely ridicule such a ruse if it were not in and for itself already with us and did not already want to be with us" (Hegel 2018: 50). Hegel declares this idea of an enormous significance in passing: the absolute is always in and for itself already with us. However, the translation of this passage is extremely difficult. The German text goes as follows: "so würde es wohl, wenn es nicht an und für sich schon bei uns wäre und sein wollte, dieser List spotten". Miller's translation is a little bit different than the one I originally used: "it would surely laugh our little ruse to scorn, if it were not with us, in and for itself, all along" (Hegel 1979: 47). Baillie uses "beside us" instead of "with us" in his translation: "if it were not in its very nature, and did it not wish to be, beside us from the start" (Hegel, 2008: 28). Whatever translation one prefers, the general direction is clear: One should not search for the way to approach the absolute, because it is always with us already, besides us from the start. Therefore, one does not need to establish the conditions of the "meeting" as Kant did.

But what does it all mean? Does it mean that one can altogether ignore the modern fascination with epistemology and turn back to metaphysics? Can one simply presuppose that there is no separation between us and the absolute? Are the countless critics right then, when they attack Hegel with the claim that he places himself in God's place? Does the claim that the absolute is always with us amounts to the claim that Hegel thought to have a direct line of communication with the absolute? Are we dealing here with the worst sort of ontotheology? Or, on the contrary, as Frank Ruda claims, for Hegel the fact that the absolute is "beside us from the start", means that we can only have a 
perspective of it from a certain side? ${ }^{5}$ To answer these questions, I will now turn to Hegel's concept of the absolute because the concrete character of Hegel's notion of the source of determination depends on it.

\section{What is the absolute? The First clues}

The question of what the absolute is for Hegel is not an easy one to answer. Markus Gabriel notes that "if we ask the question, "what corresponds to the absolute in Hegel's mature system?" we will barely get a clear-cut answer" (Gabriel 2011: 106). Therefore, it seems a good idea to first look at the sources that deal with the usage of the terms in Hegel's philosophy - dictionaries.

In his A Hegel Dictionary, Michael Inwood gives a very traditional explanation of what the absolute is. First, he notes that the word 'absolute' "derives from the Latin absolutus ('loosened, detached, complete'), the past participle of absolvere ('to loosen, detach, complete'), and thus means: 'not dependent on, conditional on, relative to or restricted by anything else; selfcontained, perfect, complete"" (Inwood 2017: 27). He adds that "German philosophers after Kant regularly use das Absolute to refer to the ultimate, unconditioned reality" (ibid). It is important to note that Inwood uses the word 'reality' in a completely different sense than it is used in this dissertation. Here reality means something like "the ultimate being" or "the ultimate ground." But what is more important, Inwood's remarks raise more questions than they answer. What is the "ultimate, unconditioned reality" for Hegel? And what is it loosened, detached, independent from?

Burbidge's dictionary is much more helpful when it reminds the crucial thing: "In the Critique of Pure Reason (B380-382) Kant defines the adjective "absolute" as (1) what is true of a thing in itself apart from its context, "the least that can be said of an object," and as (2) what is valid in all respects, without limitation, "the most that can be said of the possibility of a thing"" (Burbidge 2008: 21). For Kant, what is true of a thing apart from its context and in all contexts is absolute. Now, if we turn this adjective into a noun 'absolute' simply means 'what is true in itself and in all respects'. However, Kant's strategy is not as simple as it seems. The Kantian definition of the absolute is not about the search of the ultimate, unconditioned, detached and

5 These remarks are taken from Ruda's talk "Where is «auprès de nous»?" given on the 1 of October, 2018, at the conference on Badiou's "The immanence of truths" (see https://www.youtube.com/watch?v=DqBfraFk4bo,minutes from 9 to 12). 
complete reality, or object. If we would try to get in touch with the absolute understood in this way, the very action would contradict the detachment of the absolute. Therefore, for Kant, the only absolute "things" are the ideas of reason, which are valid independently in all possible contexts (for example, freedom or the categorical imperative). Now, Hegel follows and completely agrees with Kant up to a point. Where he does not agree is the limitation of the use of the term only to the products of our free and spontaneous reason. Nevertheless, Kant gives a direction for the interpretation of Hegel's notion of the absolute.

The analysis of these few entries clearly points to ontological rather than theological usage of the term 'absolute'. However, to understand how Hegel uses the notion one needs to track its development in the works of German Idealists who reacted against Kant and Fichte, who were seen as subjectivists. The dissatisfaction these thinkers had with Kant is remarkably similar to those raised today by the New and speculative realists. I will now turn to Beiser, who traces the history of the concept of the absolute in his wonderful German Idealism: Struggle Against Subjectivism (2002).

\section{The absolute in the absolute idealism}

While criticizing the subjectivist interpretation of German Idealism, Beiser notes that "it ignores the underlying logic behind one central concept of post-Kantian idealism: the concept of the absolute" (Beiser, 2002: 5). However, this logic is not easy to uncover, because "in the context of German idealism the term 'absolute' is rarely explicitly defined or explained" (Beiser, 2002: 351). Also, note that according to Beiser this "underlying logic" is common to all "absolute idealists" he analyses in the book (namely, Hölderlin, Novalis, Schlegel, Schelling and Hegel). What is this underlying logic? According to Beiser,

"The post-Kantian idealists understood the absolute in transcendental terms as the fundamental condition of the possibility of experience; as such, they refused to define it as either subjective or objective; rather, they argued that both subjectivity and objectivity fall within experience, so that these concepts cannot be applied to the absolute except on pain of circularity" (Beiser, 2002: 6). 
Beiser makes two important claims. First, the absolute is not something grasped from the perspective of the subject as in Kant's philosophy, but rather subject and object themselves are found only in the absolute. The subject is no longer the ground on which everything is explained but itself only appears in the bigger whole. Therefore, at least formally, the absolute is undoubtedly the source of determination. The formal definition of the absolute is a whole in which subject and object emerge. The insistence on a priority of such whole makes 1) every subjectivism indefensible as far as it cannot account for the appearance of the subject itself, and 2) the absolute the condition of the possibility of experience. The distinction between subjective idealism of Kant and Fichte and the absolute idealism was founded on this ground. The absolute is the condition of the possibility of experience. However, this does not mean that the subject is now completely dissolved in this bigger whole. As Beiser notes, "to be sure, the realm of spirit, the subjective, could be the highest manifestation, expression, or embodiment of the absolute; even so, however, it had to remain only one of its appearances" (Beiser, 2002: ibid). Second, the absolute is not argued for speculatively, but in a transcendental manner, as a condition of the possibility of experience, because only in it a subject and an object emerge. In this sense, absolute idealists saw themselves as faithful developers of Kant's project.

According to Beiser, Spinoza's influence provided another crucial layer to the absolute idealist notion of the absolute. It is well known that Spinoza understood substance as an independent and self-sufficient being that has no outside. According to Beiser, this implies that Spinoza's substance is "equivalent to the universe as a whole, because anything less than the whole of all things must depend on something else outside itself" (Beiser, 2002: 351). $\mathrm{He}$ adds that it is exactly that term meant in the context of absolute idealism after Fichte: "Though it has religious and mystical associations, the term usually meant nothing more than the universe as a whole. Hence its cognates were sometimes 'the universe' (das Universum), 'the one and all' (Hen kai pan) or, more simply, 'being' (Seyn)” (Beiser, 2002: 352). Again, note that as early as Hölderlin's Urtheil und Seyn such ontological notion of the absolute is not derived by some speculative procedure, but as a condition of the possibility of experience, and thus, as the condition of possibility of determination. Therefore, at least in the eyes of absolute idealists, their efforts were completely in line with those of Kant.

In conclusion, Beiser's work demonstrates three important features of the post-Fichtean notion of the absolute: 1) idealists understood the absolute to be equivalent of the being as a whole or "the universe itself." 2) Such whole incorporates both the pole of a subject and the pole of an object and is 
ontologically prior to both of them. Therefore, the absolute is the source of determination. However, the subject is usually seen as the pinnacle of absolute's development. 3) These philosophers see such notion of the absolute as both critique and development of Kant's critical philosophy.

\section{The absolute in early Hegel}

All arguments Beiser presents to draw the distinction between subjective and absolute idealisms are expressed already in Hegel's The Difference Between Fichte's and Schelling's Systems of Philosophy. He launches the essay by posing Kant's problem of a meeting between subject and object. However, Hegel's name for such meeting is absolute identity. According to Hegel, two different idealisms try to tackle this problem. Hegel calls Fichte's idealism a subjective Subject-Object identity. According to Hegel, "Fichte posited only one of the opposites in the Absolute, or in other words, as the Absolute. For him, the right and the necessity reside in self-consciousness; for only self-consciousness is a self-positing, a Subject-Object" (Hegel, 1977b: 157). In other words, according to the subjective Subject-Object idealism, all determination comes from the pole of the subject and the meeting, in the end, is the meeting of the subject with himself. Crucially, note that according to Hegel, the other idealism (absolute idealism) does not simply return to dogmatism, as a simple objective subject-object identity would imply. Rather, Schelling's idealism is different because "in the philosophy of nature Schelling sets the objective Subject-Object beside the subjective SubjectObject and presents both as united in something higher than the subject" (Hegel, 1977b: 81). Put differently, the alternative to subjective SubjectObject idealism is not the objective idealism, but absolute idealism. The argument Hegel gives for the need for such "higher than the subject" unity is a perfect example of the "absolute idealist" reasoning Beiser presented:

"For absolute identity to be the principle of an entire system it is necessary that both subject and object be posited as Subject-Object. In Fichte's system identity constitutes itself only as subjective Subject-Object. [But] this

subjective Subject-Object needs an objective Subject-Object to complete it, so that the Absolute presents itself in each of the two Subject-Objects, and finds itself perfected only in both together as the highest synthesis that nullifies both insofar as they are opposed. As their point of absolute indifference, the 
Absolute encloses both, gives birth to both and is born of both (Hegel, 1977b: 156).

In other words, the subjective Subject-Object idealism is incomplete and "needs" a correction to explain the possibility of the meeting (the absolute identity) because the subject itself is only an instance of what it supposedly constitutes. Therefore, the higher standpoint of the absolute is necessary for such meeting, or identity, to be actual. However, this does not mean that the subject is now dissolved in the higher unity as it is still the highest expression of the absolute. The absolute not only "gives birth to both" but also "is born of both." Finally, this is what Hegel means when he says that the absolute identity is "identity of identity and non-identity."

The standard absolute idealist critique of Kant, to which Hegel subscribes, betrays a twofold relation to Kant. In Kant part of the thesis, I claimed that for Kant the source of determination is transcendental subjectivity which cannot be equated with a concrete human subject. In this sense, already the Kantian subject finds itself constituted by something objective which is prior to himself. If that is the case, the absolute idealist argument for the absolute as the source of determination must be seen not only as an argument against Kant but also as the continuation of the tendency already present in Kant's first Critique. However, Hegel's insistence on the subjective character of Kant's transcendental shows that for Hegel Kant's "objectivist tendency" is not insufficient. In the end, the analysis shows that according to Kant there is no transcendental without the concrete human subjects. Therefore, there is a relation of codependency between them. Of course, the relation between the absolute as the source of determination and the concrete human subject is also one of codependency, however, this is a codependency of a different kind. In that follows I will explore how this codependency unfolds in the different works of Hegel.

\section{The True and The Absolute in preface of Phenomenology}

Hegel makes the absolute the central topic of the introduction to Phenomenology. The preface is also full of the talk about the absolute. Therefore, it could be surprising that the most famous line of the Preface, which announces the idea on which everything "hangs", does not mention the absolute. Hegel writes that "in my view, which must be justified by the exposition of the system itself, everything hangs on grasping and expressing 
the true not just as substance but just as much as subject" (Hegel, 2018: 12). But is the absolute truly absent from the famous Hegelian formula? I claim that this is not the case. If Hegel follows the absolute idealist definition of the absolute, then the expressions 'the absolute' and 'the true' would have to be seen as synonyms. Therefore, we can read the famous remark as "everything hangs on grasping and expressing the absolute not just as substance but just as much as subject.'

What does Hegel's formula "not just a substance but as much as subject" say about the absolute? It is probably more natural to understand the absolute as a substance, self-standing independent being, devoid of any changes and imperfections. One can simply point to Spinoza's system to illustrate such understanding of the absolute. However, according to Hegel, we must also grasp the absolute as the subject. There are many ways to understand what Hegel means by the subject here. If we think that the subject is simply a human subject, then we turn Phenomenology into anthropology. But if we think the absolute as some sort of super subject, Phenomenology becomes theology. One could argue that this is implied in Hegel's remark, that "that the true is only actual as a system, or, that substance is essentially subject, is expressed in the representation that expresses the absolute as spirit - the most sublime concept and the one which belongs to modernity and its religion" (Hegel, 2018: 16). However, these two interpretations would equate Phenomenology with some disguised special discipline taking the place of ontology. This cannot be the case, because Phenomenology tries to incorporate all disciplines and practices (forms of consciousness), and, therefore, has to be in some sense prior, or metadiscourse, in relation to them. This fact is indicated by Hegel's hard labors to start his main works without presuppositions taken from any special disciplines. Therefore, one should try to interpret "the subject" in more primordial and ontologically neutral terms. I propose to simply read 'subject' as 'activity.' Then, Hegel's phrase turns into: 'the absolute must be grasped and expressed not only as substance but just as much as an activity."

If that is the case and the absolute is also an activity, a process, this activity must have a history. Therefore, only the absolute and its history fully constitute the absolute itself. In this way, "The true is the whole" (Hegel, 2018: 13). Phenomenology as "science of experience of consciousness" traces this history as it appears to consciousness. And this science is only possible because we ourselves are the actors in this history (because the absolute is always already with us). Now it is clear that from the beginning of his philosophical labors (Differenschrift) and throughout Phenomenology the absolute is Hegel's central concern. But what is the relation of Science of Logic and the absolute? 


\section{Logic as the science of Absolute}

Science of Logic, in which Hegel deals with the determination reality ${ }^{6}$, is also a science of the absolute. Hegel remarks on the determination Being that

"This concept could be regarded as the first, purest, that is, most abstract, definition of the absolute - as it would indeed be if the issue were just the form of definitions and the name of the absolute. In this sense, just as such an abstract concept would be the first definition of the absolute, so all further determinations and developments would be only more determinate and richer definitions of it." (Hegel, 2010: 51-52).

If being is "the first definition of the absolute" and "all further determinations and developments would be only more determinate and richer definitions of it", then the object of the Science of Logic as a whole is the absolute. However, if Phenomenology deals with various epistemic, existential, ethical, religious and ideological shapes of consciousness that grasp the absolute in history, Logic deals with the absolute as it appears to pure thought. Hegel comments that "the task is indeed to demonstrate what the absolute is. But this demonstration cannot be either a determining or an external reflection by virtue of which determinations of the absolute would result but is rather the exposition of the absolute, more precisely the absolute's own exposition, and only a displaying of what it is (Hegel, 2010: 466). Logic is "absolute's own exposition." This means that Logic does not demonstrate how the absolute presents itself to us but the self-determination of the absolute itself. Naturally, this self-determination of the absolute depends on the selfdetermination of the subject, but not because the subject constitutes the absolute from the outside as just another object of experience, but because a subject is a part of the absolute itself. Such conclusion seems to be an astonishing claim which confirms all the worst charges Hegel critics laid

${ }^{6}$ I will argue that Science of Logic presents the self-determination of the absolute in various determinations. If that is the case, all determinations in Logic are the determinations of the absolute. This forces me to use linguistically strange expression "determination Reality", instead of more usual the determination of reality. That is the case, because "the determination of reality" makes an impression that there is a reality and then a determination of it. However, that is not the case. As I will later show, if we want to get Hegel right, we have to understand that reality is this determination and nothing other. 
against him. If Hegel's book is absolute's exposition of itself, does this mean that Hegel manages to elevate himself to the perspective of the absolute?

To dispel these worries one has to take into account two critical moments. The first point to stress is the fact that Logic is an exposition. As Hegel stresses, this exposition is not some external theory philosopher develops and then applies to the absolute as an object,but rather an exposition from the inside. In this sense, Logic is also a certain kind of phenomenology. I think that what troubles the contemporary reader the most is the fact that the object of this phenomenology is the determinations of the absolute. To put it crudely, it is easy to imagine the exposition of the history of (semi)historical shapes of consciousness, or the history of a certain concept, as it appears in time. For example, one can imagine a study of the history of the concept of being, of its different meanings and uses in various historical periods and works of philosophers. However, how the exposition of the concept itself would look like? What does Hegel ask us to think through here?

Šerpytyte is helpful here when she appeals to a "categorical experience" (Šerpytyte, 2015: 120). What is a categorical experience? I think most of us have the experience of independence and certain lawfulness of the conceptual realm. Some concepts just stick with other concepts while others do not. Some inferences just follow from conceptual content while others do not. And I am not talking about analytical or tautological relations between the concepts. We are dealing with philosophical connections. In Logic Hegel displays these connections between pure determinations. For example, the reader quickly notes that it is not analytically that the truth of being and nothing is becoming but philosophically. In this sense, Hegel's Logic has much more to do with Greek logos than the modern mathematical logic. Moreover, this also means that Logic opens the space for a new type of judgment: As far as the exposition of the conceptual happens on its own in the pure thought, it is a priori, however, as long as it is not driven by analytical relations, it is synthetic. Crucially, as long as these judgments depend on the actual development of the self-determination of the absolute they become synthetic a priori only $a$ posteriori.

Now the central place of the absolute in Hegel's thought is clear. However, his notion of the absolute still needs greater clarification. Two important questions that can be tackled together remain. While I follow Beiser's definition of the absolute as "the universe as a whole", the question of what Hegel considers to exist in the universe remains. Note that answer "everything" is not helpful here, because one may still ask if ideas, history, matter, or nature, to mention only the most intriguing examples, are part of everything, or are they in some sense unreal? Another important question 
addresses the relation humans have with the absolute. Note that the fact that the absolute does not depend on anything else does not mean that everything else does not depend on the absolute. In this sense, the absolute may still have relations. I will first address the second question stressing the influence Schelling's philosophy of nature had on Hegel's concept of the absolute and will later turn to Hegel's notion of immanence. The latter will help to answer the first question. Only then I will be able to draw conclusions about Hegel's notion of the source of determination.

\section{Absolute, We, Nature}

Interpreters of Hegel have conceptualized the relation between the absolute, which is always with us, and us in many ways. Hyppolite captures this relation on the most abstract level when he claims that "being is to itself its own light, its own reflection" (Hyppolite, 1997: 87). According to Hyppolite, being (or the absolute) is in a knowledge relation with itself. However, Hyppolite's statement is not very helpful because on the most abstract level the 'We' disappear and only the being (or the absolute), which is in relation to itself, remains. Therefore, while not being false, Hyppolite's statement must be made more concrete.

Nancy sees Hegel's absolute as a much more concrete (non)entity. This helps Nancy to desubstantialize Hegel's absolute. For example, in his powerful Hegel: The Restlessness of the Negative Nancy treats the absolute as Hegel's name for a community. According to him, all shapes of consciousness (Phenomenology) and determinations of the absolute (Logic) ultimately reveal nothing other but the great labor of humanity: "Rather, all of these figures expose us, through their determinateness, to the unbinding or dislocation of every "Self", of all self-certainty. It is we who are exposed, and it is therefore to us that we are exposed. Each with the others, each near the others: the near of the absolute is nothing other than our near each other" (Nancy, 1998: 7879). ${ }^{7}$ This quote signals that in Nancy's picture, the absolute is the We as

7 Nancy's reading of Hegel is heavily influenced by the discussions on communitarianism. In the 1970s-1990s one witnessed the reaction of continental philosophers against what they considered to be the metaphysical notion of community of in works of Charles Taylor and his followers. Along with Nancy's The Inoperative community (1986), Agamben's The coming community (1990) and Esposito's Communitas: The Origin and Destiny of Community (1988) are the best examples of this discussion. 
(post)humanity. In this way, Hegel's idea that the absolute is in the relation of self-knowledge is completely demystified. Absolute's self-knowledge turns out to be the collective knowledge of humanity as a whole. Although I agree with Nancy that by the absolute Hegel does not mean God or some abstract metaphysical reality, I have trouble with Nancy's 'We." Does not such insistence on a community of interpreters, who are "near each other", make Hegel to hermeneutical? Would not such a hermeneutical notion of the absolute be vulnerable to a standard absolute idealist charge that it is possible only as a part of the bigger whole? And as such, vulnerable to a challenge of realism?

I claim that for Hegel the absolute is indeed We, but that he has a broader understanding of the We than Nancy's book seems to imply. Hegel's own depiction of the development of German Idealism shows him as heir not only of the subjective idealism of Fichte and Kant but also the objective idealism of Spinoza. It is also a fact that Hegel himself defended Schelling's Naturphilosophie for some time. Therefore, there are good reasons to think that, for Hegel, not only human subjectivity but also the natural world is included in this we, which is the absolute. I agree with Sebold, that Schelling's influence should not be overlooked on this issue. As Sebold notes, "for Hegel, as for Schelling, nature's organization into mind, i.e., nature becoming selfconscious, is its highest purpose" (Sebold, 2014: 91). This structure of the emergence of human subjectivity from nature and nature's later selfknowledge through human subjectivity is upheld in most of Hegel's works. For example, in Logic the determination life is reached through the sublation of determinations of mechanism and chemism, in Encyclopedia human subjectivity also appears derived from natural causes, rather than being originary. As Malabou notes, "the course of the Anthropology as a whole explicates the process whereby originary substance, leaving behind the natural world, progressively differentiates itself until it becomes an individual subject" (Malabou, 2005: 28). In both cases, the subject is the pinnacle and final realization of the self-determination of the absolute but this does not imply any ontological gap between the subject and everything else. In this sense, Hegel's absolute which knows itself through us closely resembles Schelling's Nature, which opens her eyes in human beings to know herself.

These conclusions put Hegel as far from Kant as possible. For Kant, subjectivity is originary and nonderivable. We are thrown into subjectivity, which is contingent and cannot be explained. It is just how it is, "brute facticity" (Braver, 2007: 499). Hegel, on the contrary, tries to show how subjectivity enters the world. But this implies that subjectivity cannot be the sole source of determination. This also implies that Hegel has no problems 
writing about the processes that happened long before the appearance of human subjectivity and this would in principle also include archi-fossils. In Kant part of the thesis I argued that for Kant the meeting between the subject and the object is established only from the perspective of the human subject. Therefore, Kant's position is more Ptolemaic than Copernican. The arguments I made so far allow me to claim that the same could not be said of Hegel's position. In addition to the exposition of his notion of the absolute, I could refer to many instances of Science of Logic and especially Encyclopedia where non-anthropocentric meetings between the animal subjects and the objective occur and are accounted for.

\section{From the absolute to immanence}

The relation between the absolute and us is now clarified from the side of the absolute: The absolute knows itself through beings. Hegel calls the other side of the relation - our relation with the absolute - immanence. The view that Hegel's philosophy is the ontology of immanence is so prevalent today what one can forget to clarify in relation to that everything is immanent to. Hegel's constant reference while discussing this question is Kant. According to him, Kant's philosophy is the philosophy of transcendence, because the truth (the thing-in-itself) always transcends consciousness. To Hegel, this justifies the description of Kant's position as the philosophy of antithesis (Hegel, 1997a: 60-63). By this Hegel means that the quality of determination (its what-isness) is partly determined (limited) by something that falls outside of the scope of accessible, while the accessible and the inaccessible stands in stark opposition. In opposition to that, Hegel's philosophy claims that the plane of determination is completely determined from the inside and there is no external perspective, gaps or discontinuities in being. Naturally, there are still inner perspectives, inner gaps, and inner discontinuities, but these do not constitute insurmountable ontological gaps. However, even such way of describing Hegelian immanence does not demonstrate what concretely every determination is immanent to.

Probably the worst way to solve the issue is to claim that for Hegel everything is immanent to some all-including consciousness. This may help to highlight the continuity between Hegel and Kant, but, at the same time, would equate Hegel's position to a certain reading of Fichte and completely sideline developments of notions of subject and subjectivity in the postKantian philosophy. Another way is to talk about Hegel's immanence 
negatively. Then immanence is taken to be Hegel's term for the situation in which there is no outside and any outside perspective is impossible. Without further specification, this would still remain a Kantian reading where immanence would become a limit concept, rather than an ontological one.

I think that Hegel's notion of Absolute-as-substance-and-also-a-subjectand-the-True can help to see his notion of immanence differently and explain why Hegel thinks that Kant's critique of metaphysics is limited. I claim that if the absolute is "in and for itself already with us", Hegel's immanence should be understood as immanence to the absolute. This, however, does not mean that Hegel drops back to monist metaphysics like those of Plotinus or Spinoza. One has to keep in mind that the absolute, or the True, already is selftranscendent and involves a difference in itself. But what is more important, I suggest that we should read the claim "we are always immanent in absolute" similarly to young Schelling's claim that we are a part of nature. Hegel immanence is not some exalted metaphysical claim that we are part of God, but rather the opposite: It is a modest position that although there are differences in being, there are no unbridgeable ontological gaps, ruptures or abysses between any beings and between any being and the absolute (the True). Therefore, Hegel holds the thesis of the continuity of being. From such perspective, Kant's idea that specific forms of intuition and the categories while connecting us with being also makes it inaccessible in itself, begins to raise suspicion. Where does the rapture come from? Note that it is not the case that the Hegelian immanence is the negation of Kantian transcendence of the thing-in-itself. Rather the opposite, Hegel's move is to show that Kant's transcendence is the negation of immanence which turns it into "mere appearances." What is more, Hegel aims to show that the appearance of the rupture between transcendence and immanence is simply presupposed. Actually, I find nothing strange in the idea of the continuity of being. On the other hand, the idea that consciousness is something completely different than "non-consciousness" and there is an a priori ontological gap between it and other beings seems to have its roots in some sort of creationism. Therefore, "Kantian humility" turns out to be Kantian exceptionalism.

However, if we are always in touch with the absolute, does this mean that doing ontology is like taking a walk in the park? And more importantly, does this mean that Hegel simply returns to pre-Kantian metaphysics? These questions are of extreme significance if we want to properly understand Hegel's notion of determination, because his notion of the absolute as the source of determination allows him to overcome Kant's limitation of knowledge to experience. 


\section{The two senses of ontology}

If everything I have claimed so far is correct, then the greatest difficulty in approaching Hegel is that for him two different senses of the word ontology collapse into one. Although it may be surprising, the word 'ontology' came into frequent use in philosophy only in the $19^{\text {th }}$ century, after being popularized by Christian Wolff. For him, ontology is the study of "being in general", being qua being. Not surprisingly, even the title of Wolff's work, Philosophia Prima sive Ontologia (First Philosophy as Ontology) (1736) betrays a close relationship of Wollf's denoted discipline with Aristotle's "first philosophy", or metaphysics. Both Wollfian and Aristotelian ontologies are usually seen as realist ontologies while the term realist is understood to "roughly suggest that one can gain a complete understanding of how the world functions in purely third person, objectivistic language" (Sebold, 2014: 263). In this classical sense ontology is the science of mind-independent being-quabeing.

The word ontology shifts its meaning to a more Kantian terrain in the work of Heidegger. In Heidegger's philosophy, we should "reserve the term "ontology" for that theoretical inquiry which is explicitly devoted to the meaning of entities" (Heidegger, 2001: 32). From this perspective, ontology deals not with mind-independent reality, but rather with the "meaning of entities." Put differently, ontology investigates how entities are given to us. Therefore, Heidegger's famously claims that "only as phenomenology, is ontology possible" (Heidegger, 2001: 60). In other words, while classical ontology completely erases mind and experience from the investigation of being-qua-being, Heideggerian ontology limits ontology with the experience of being. Today, Heidegger's understanding of ontology is no less dominant in continental philosophy than a classical one.

The difficulty with Hegel's absolute idealism is that it is simultaneously ontology in both classical and Heideggerian senses and is not identical to neither taken separately. As I argued, Hegel's ontology is the ontology of being qua being and is not limited to experience. However, it does not erase experience and mind from the picture and does not relapse to the "thirdperson" descriptions from God's point of view. In this sense, Hegel is both an idealist and a realist. For Hegel, the problem is not that we cannot know mindindependent reality but that reality itself would be different without minds. Therefore, we cannot simply subtract minds from the world, because this would get us further from the True and not closer to it. We are both the sources of determination and determined by other sources inside the plane of 
immanence that the absolute is. Put differently, for Hegel, knowing the appearance is also knowing the thing in itself. Contra some tendencies in New realism, Hegel maintains that without the appearances the things-inthemselves would lack a fundamental layer of their existence. Contra Kant, he argues that things-in-themselves are determining appearances to the point that it is impossible to limit our knowledge to the sphere of appearances. Such an attempt would result not only in destroying our knowledge of things in themselves but also of appearances.

I argued that Kant's notion of determination is the notion of experienced determination. Now it is clear that the same could not be said about Hegel's position. Hegel agrees with Kant that determinations we experience arise in the meeting of an object and the subject. However, he disagrees that this meeting can be conceptualized from the perspective of the subject. That is the case because the subject itself is only constituted in such meeting. Therefore, the possibility of determination can only be explained from the standpoint of the absolute that determines both a subject and an object. In this sense, the absolute is the source of determination. Therefore, one cannot maintain that Hegel's notion of determination is the notion of experienced determination because reality also uncovers the reality in itself, as an independent source of determination. Now, when the analysis of Hegel's notion of the source of determination is done, I will proceed to the analysis of his notion of determination, as it is developed in the Science of Logic.

\section{Reality, existence and the rise of determination}

As I have argued, the Science of Logic is the self-exposition of the concept of the absolute. This means that every determination we find in Logic is the determination of the absolute. Put differently, Logic explores what happens when the absolute (or the True) constitutes itself as a specific determination. For example, the beginning of Logic shows what happens when the absolute constitutes itself as the determination being. The ontological side of Logic is evident when we explore such determinations as being or becoming but becomes much less obvious when considering the absolute as judgment or chemism. All this means that the determination reality is also a determination that the absolute becomes.

In Logic, the determination reality opens up the chapter on existence (Dasein). Now, existence is a result of sublation of becoming, the unity of being and nothing. This happens because in pure becoming being and nothing 
have been shown to vanish into each other. If the moments of becoming are shown to be identical, becoming itself halts. McTaggart sums up the part prior to existence chapter beautifully:

"Being and Nothing only exist in Becoming as disappearing moments. But Becoming only exists in so far as they are separate, for, if they are not separate, how can they pass into one another? As they vanish, therefore, Becoming ceases to be Becoming, and collapses in to a state of rest, which Hegel calls Being determinate" (McTaggart, 1910: 17).

Following McTaggart, Houlgate calls existence as determinate being "a settled unity of being and nothing." As the name of the determination ('determinate being') itself suggests, the determination as such now arises in the Logic for the first time. Existence overcomes the pure abstractedness of Being, Nothing and Becoming: "Existence corresponds to being in the preceding sphere. But being is the indeterminate; there are no determinations that therefore transpire in it. But existence is determinate being, something concrete; consequently, several determinations, several distinct relations of its moments, immediately emerge in it" (Hegel, 2010: 84). This leads Winfield to consider this part of Logic as the beginning of Hegel's "theory of determinacy" (Winfield, 2012: 68). Although determination as such arises from the inner necessity of development of the first category, one can also see here the development of the ideas Hegel himself held. For example, he maintained that the absolute has to be something, not a purely abstract lumpentity devoid of any identity. To use Hegel's famous metaphor, the absolute cannot be the "night in which all cows are black." Be it as it may, it is important to note that reality enters Logic together with determination as such. In this sense, the question of reality is the question of the status and the genesis of determination exactly like in Kant's thinking.

\section{Reality and quality}

Hegel provides a nice summary of the further development of determinate being:

"In existence (a) as such, its determinateness is first (b) to be distinguished as quality. The latter, however, is to be taken in both the two determinations of existence as reality and negation. In these determinacies, however, existence 
is equally reflected into itself, and, as so reflected, it is posited as (c) something, an existent" (Hegel, 2010: 96).

I will now focus only on the first step of the development. Quality for Hegel seems to have all the same moments determinate being had and therefore to be a redundant determination. As my aim is to uncover Hegel's notion of reality and not the validity and truth of Logic itself I will not get into the scholarly debate regarding this question. I will note only two things. First, I agree with Winfield when he claims that "the term "quality" will be used to distinguish determinacy as such from the other determinacies, such as quantity, existence and so forth" (Winfield, 2012: 72). I think it is important for Hegel to distinguish between the form determination gets in this early part of Logic from determinations taken more broadly, because every "category" of Logic is a determination. Second, the richer explication of what 'quality' entails will only unfold in the chapters on reality and negation. For now, it will be enough to note three points on quality. First, for Hegel, the quality is "a settled unity" of being and nothing. As Houlgate puts it, "quality, for Hegel, is thus nothing but definiteness and settledness that enjoys being" (Houlgate, 2005: 304). Second, this makes the architectonic surrounding reality and negation exactly the same we found in Kant's table of categories. Third, however, all these determinations are taken to be the determinations of the absolute and not the a priori concepts of a transcendental subject.

\section{Reality and negation}

"Quality", writes Hegel "is to be taken in both determinations of existence as reality and negation" (ibid). What does Hegel mean by reality and negation? And what are the relations between these two and quality? Hegel claims that "quality, in the distinct value of existent, is reality; when affected by a negating, it is negation in general, still a quality but one that counts as a lack and is further determined as a limit, restriction" (Hegel, 2010: 95). First of all, much like in Kant, reality is a positive or existent quality/determination. However, while Kant interpreted negation as a negative magnitude, for Hegel, negation is a limit. Is this the difference only in terminology or marks a philosophical disagreement? I think that there are two important points to make here. For Kant, the question of reality arises in the situation where there are two: a consciousness and an object. Thus, the quality is constituted in the existence of an object and its relation to the subject. To put it otherwise, reality 
of an object is constituted in the isolation from other objects. Relations of objects are the matter of the dynamical categories. But this is not the situation we find ourselves in Logic. Reality here enters the scene when the abstract absolute starts to differentiate into somethings. Thus reality already implies relationality which Hegel conceptualizes in terms of limit. For Hegel, reality and realization mean precisely this: The shattering of uniformity of the absolute into the concrete individual moments. Much later in Logic Hegel affirms this when he presents how the judgment is the realization of the concept: "Judgment can therefore be called the first realization of the concept, for reality denotes in general the entry into existence as determinate being. More precisely, the nature of this realization has presented itself in such a way that the moments of the concept are totalities" (Hegel, 2010: 550). This shows that for Hegel, reality itself does not already imply the multiplicity of realities as determinate beings, however it starts the process of the formation of the multiplicity. Therefore, quality as reality and negation is not only the minimum model of determination but also the beginning of the formation of the multiplicity. It is also important to note that in Hegel's Logic determinations reality and negation are much more minimal than those Kant worked out in the anticipations of perception. For Hegel, reality and negation "only signifies the being of determinacy, which can be just as logical or mental as opposed to material" (Winfield, 2012: 72), while Kant's notion of reality concerns, first and foremost, the material.

\section{Logic as the logic of impurity - something}

With the appearances of reality and negation the real difference appears. In other words, determination introduces difference. Reality is positive determination, and negation is a negative determination, but most importantly, they both are determined and, therefore, they differ from each other. As Houlgate notes, "determinacy thus turns out to involve either being settled and real or being differentiated and negative" (Houlgate, 2005: 309). However, Houlgates great insight is that Logic quickly unveils that not be the case. Reality and negation only appear to be clearly separated. Houlgate argues that "on the one hand, reality is determinate not only by virtue of being what it is but also by virtue of differing from - and so not being - mere negation. It is therefore intrinsically negative in itself. On the other hand, negation is

determinate not just because it differs from - and so is not - reality but also because it is the quality it is, namely, negation. It is therefore irreducibly real" 
(ibid). Put differently, on the one hand, for reality to be positive it has to differ from negation and thus be negative. And negation, on the other hand, has to be minimally positive be differentiated. The determinations thus get „,contaminated" (Houlgate, 2005: 291) by each other. Therefore, it turns out that the difference between them is not a pure difference, but also contains a partial identity.

The inner difference quality maintains and impurity of this difference will further lead the development of Logic to something: the determination which will internalize this impure difference between reality and negation. Therefore, Hegel will claim that "something is $\langle\ldots\rangle$ the mediation of itself with itself" (Hegel, 2010: 95).

\section{What gets lost in reality? The beginning of the individuation}

Although Hegel himself does not use the term 'individuation', the further development of Logic through the sequence of existence, reality/negation, something, and finitude betrays the ever-increasing progression of individuation enabled by the dialectics of reality and negation. Reality should be treated as the beginning of this process because 1) it is the minimal level of determination and 2) the multiplicity of being is implicit in it through its differential structure. This is already implied in a determinate being. As Houlgate comments, "determinate being does not mean just being settled or being this, but also being this rather than that - specifically, being real rather than negative, or negative rather than real" (Houlgate, 2005: 308). The structure "being this and being this rather than that" explicates both the individuation of the absolute and its tendency to become more than one. According to Hegel, this process of individuation is "of the highest importance if we do not wish to halt at existence, life, thought, and so forth, as generalities - also not at Godhood (instead of God)" (Hegel, 2010: 89). Therefore, without this process of individuation the absolute would remain the pre-individualized ontological lump. From this, I infer that Hegel takes a pre-individualized ontological lump to be less than reality. This would apply to Spinoza's substance, Schopenhauer's will, but also to many Deleuzian and postDeleuzian positions.

However, reality is not only the beginning of individuation, it also betrays the fatal deficiencies of ontological individualism. This is already evident in something, which is "the first negation of negation, as simple existent selfreference" (Hegel, 2010: 89). In something, the relationality gets negated and 
relation to itself becomes a constitutive moment. In Hegel's words, something is "mediation of itself with itself" (ibid). However, even if all relationality with other entities is negated in something, it is still established through the self-relation. Therefore, even the determination supposed to be pure individual form withdrawn from all relations is relational.

More generally, the determination which enables individuation comes from two poles. Hegel calls one pole in-itself (Hegel, 2010: 90-95). The initself is the inner determination of an object, corresponding to reality. Hegel calls the second source of determination being-for-other (ibid). The Beingfor-other is a relation, corresponding to negation. The problem is that in reality the relational side (being-for-other) of determination is hidden:

"Both are an existence, but in reality, as quality with the accent on being an existent, that it is determinateness and hence also negation is concealed; reality only has, therefore, the value of something positive from which negating, restriction, lack, are excluded. Negation, for its part, taken as mere lack, would be that nothing is; but it is an existence, a quality, only determined with a nonbeing" (Hegel, 2010: 85).

Therefore, reality appears to be composed of self-sufficient substantial beings. In other words, reality seems to be completely independent of any otherness, or as Hegel loves to say, it seems to be "indifferent externality." This concealment of relationality is also a constitutive moment of something. In something, all relations with others are negated. Therefore, "Something is the first negation of negation, as simple existent self-reference" (Hegel, 2010: 89). The beginning of the individuation of the absolute goes hand in hand with the concealment of relationality.

From such perspective, Hegel's Science of Logic could be seen not only through the opposition of form and content and their later identity (as is traditionally done) but also through the dialectics of individuality and relationality. On the one side of this continuum, we find individuals allegedly independent from any relations, like something or pure reality, on the other, pure relations without objects or subjects, the logic which the logic of shine seems to develop. Therefore, the main question implicit in Hegel's notion of reality is how to keep both poles of determination (reality and relation) in a live tension without reducing either one to another. The fact that, in Logic, individuation appears to be dialectically bound to relationality signals that for Hegel to become an individual entity is to enter relations. Paradoxically, to determine itself through itself, an entity has to be determined by its relation with other entities. This allows me to make two conclusions about Hegel's 
notion of determination: With Kant, Hegel holds that determination is not atomic and primary, but the result of tension between reality and negation, however, Hegel also shows how the way determination articulates itself tends to conceal its relational character.

\section{Finite as the truth of reality}

I think that analysis done so far helps to understand Hegel's famous remark about idealism. One more step is needed to confront the remark. As I already mentioned, after reality and negation, the logical development goes through 'something' to 'finite.' The finite is a determination worked out from the determinations of reality and negation I analyzed. In finite, negation and relational side of the absolute is dominant, "non-being constitutes this being" (Hegel, 2010: 101). Therefore, one can say that finitude is nothing other but the admission of the fact that "reality itself contains negation." I quote Hegel: "When we say of things that they are finite, we understand by this that $\langle\ldots\rangle$ non-being constitutes their nature, their being" (ibid). With this in mind, consider the second remark on the chapter "Existence", where Hegel writes: "The claim that the finite is an idealization defines idealism. The idealism of philosophy consists in nothing else than in the recognition that the finite is not truly an existent" (Hegel, 2010: 124). Remember that the finitude of finite is constituted by the fact, that "reality itself contains negation" (Hegel, 2010: 88). Therefore, I think, one possible paraphrase of Hegel's famous sentence is: The claim that the reality is an idealization defines idealism. If I am right on this, we can formulate that idealism means for Hegel in a negative and a positive way. Negatively, idealism is the denial that reality is "truly an existent." By this Hegel simply means that realities are not self-dependent beings, substances, which exist independently of any relations. But this is exactly what is meant by 'reality' in our everyday language: A totality of indifferent self-subsistent things. What replaces the denied determination? The claim that reality is an idealization. Again, by this Hegel simply means that reality is also defined by negation, the limit, and relations that are "hidden in reality."

At first it may seem that Hegel's definition of idealism is very different from that of Kant. For Kant, idealism concerns the status of determination. In what follows, I will show that Hegel's definition concerns exactly the same question. However, I first have to show the relation between Hegel's remark on idealism and his notion of experience. 


\section{What is idealism? Hegel's answer}

Hegel ends the chapter "Existence", which contains determinations 'Reality' and 'Finitude', with the famous 'Remark' on the idealism. The remark consists of two paragraphs. The first one concerns the meaning of the term and the second the critical exposition of the modern version of idealism. The remark shows that Logic still argues for the same fundamental insights reached in the Differenschrift: There are two types of idealism and subjective idealism is a fundamentally flawed position.

Hegel starts the remark with an outright statement: "The claim that the finite is an idealization defines idealism. The idealism of philosophy consists in nothing else than in the recognition that the finite is not truly an existent" (Hegel, 2010: 124). If finite is the truth of reality, one could state by extension that "The claim that the reality is an idealization defines idealism." However, everything here hangs on what "truly" in "not truly an existent" means. The analysis of determination reality showed how reality is not a substantial being. This, however, does not mean that reality is in some way illusionary. For Hegel, reality is not truly an existent in the sense Greeks understood "true existence": it is not a self-sufficient independent being but one also constituted by negation. To highlight this Hegel appeals to the "ancients": "The principles of ancient as well as more recent philosophies - whether "water," "matter," or "atoms" - are universals, idealizations, not things a given immediately, that is, in sensuous singularity" (Ibid). However, the most telling example is Hegel's remark on Thales. According to Hegel, "not even the "water" of Thales is that, for, although also empirical water, it is besides that the in-itself or essence of all other things, and these things do not stand on their own, selfgrounded, but are posited on the basis of an other, of "water," that is, they are idealized" (Ibid). Here Hegel gives the beautiful formula of what "not being a truly existant" means: It is to not stand on one's own, self-grounded, but to be posited on the basis of another. Hegel adds that to be posited on the basis of another is to be idealized. Now, the question philosophy asks is what is this "another basis" on which everything else is posited. The ancients found this another in some substantial being. In Kantian idealism, this another is the transcendental consciousness. As Kantian view was dominant in Hegel's time, he remarks that "by an idealization is normally meant the form of representation" (ibid). Therefore, from Hegel's perspective, the distinction between the ancients and the moderns cannot be established on the realistidealist dichotomy. Both traditions are idealist because they explain something as posited on the basis of another. Or, as Hegel states, "the 
opposition between idealistic and realistic philosophy is therefore without meaning" (ibid). Also, note that in this sense every philosophy which has ontological ambitions is idealism because it explains the existence of some entities by the existence of other ones.

For Hegel, idealism is the position according to which reality is not truly an existant. This means that reality is constituted both by its positive and negative moments. The negative moment, the relationality of reality, puts reality in the network of relations. Hegel uses the concept 'whole' to designate such a network. The first paragraph of the remark on the idealism ends with the explication of these two moments: "an idealization is on the one hand something concrete, a true existent, but, on the other hand, $\langle\ldots\rangle$ its moments are no less idealizations, sublated in it; in fact, however, there is only one concrete whole from which the moments are inseparable" (Ibid). In this sense, the true opposition of idealism for Hegel is not realism as for Kant, but ontological positivism that believes in the existence of atomic facts.

\section{The night of reflection and the noonday of realism}

The proper understanding of "the claim that the reality is an idealization defines idealism" and its relation to common sense could be seen if we turn our attention to the chapter "Relation of speculation to common sense" in Hegel's Differenschrift. ${ }^{8}$ Hopefully, this will help to elucidate a realist reading of the famous remark on the idealism that I am after. However, I delimit myself from the analysis of central topics of the essay (speculation, reflection and common sense) because that would simply take too much space and open too many questions that fall outside the scope of this thesis. I will rather focus on the ontological layer of the chapter expressed by the metaphors of light and darkness (that stand for reality and negativity, in terms of Hegel's Logic). As I demonstrated, in Logic reality is the determination of the absolute,

${ }^{8}$ It could be objected, that this early essay cannot serve as a key to understand later Hegel, because in this essay Hegel is still very close to Schelling, whom he will later fiercely criticize. I do not think this argument holds water on this concrete issue. Paul Giladi recently challenged tradition view of the relation between Hegelianism and common sense drawing mostly on Hegel's mature works (Giladi (2018)). What Giladi construct's as Hegel's "nuanced philosophical vindication of common sense" is very similar to the conclusion Hegel arrives at in the Differenzschrift. This suggests, that Hegel's view on the subject matter remains pretty much the same through his entire life. 
constituted by reality and negation. It is the first individualization of absolute, which also points to the limits of individualization and its dependence on relationality. In Differenzschrift Hegel paints a similar picture: "what the socalled common sense takes to be the rational, consists similarly of single items drawn out of the Absolute into consciousness. They are points of light that rise out of the night of totality and aid men to get through life in an intelligent way" (Hegel, 1997b: 99). In both reality and common sense "single items" are manifest, while the whole these items owe their determination remains hidden. Note how the description of common sense and its reality echoes the description of reality in which negation is hidden: "Although common sense expresses itself for reflection, its dicta do not contain the consciousness of their connection with the absolute totality. The totality remains inward and unexpressed" (Ibid). In Differenzschrift, common sense sees reality as flashes of light but is blind to the background, just as in Logic the negation is hidden in reality. Notably, common sense sees something true. However, it cannot see the whole picture, only speculation can. Thus, "speculation understands sound intellect well enough, but the sound intellect cannot understand what speculation is doing" (ibid). What is the relation of speculation to common sense and its reality then? According to Hegel, common sense believes that idealization of reality is always a turning of reality into a representation constituted by the transcendental subjectivity. But it is not what speculation is doing. In a beautiful passage, Hegel writes:

"The only aspect of speculation visible to common sense is its nullifying activity; and even this nullification is not visible in its entire scope. If common sense could grasp this scope, it would not believe speculation to be its enemy. For in its highest synthesis of the conscious and the non-conscious, speculation also demands the nullification of consciousness itself. Reason thus drowns itself and its knowledge and its reflection of the absolute identity in its own abyss: and in this night of mere reflection and of the calculating intellect, in this night which is the noonday of life, common sense and speculation can meet one another" (Hegel, 1997b: 101-102).

At night of reflection and calculating intellect, the noonday of Science of Logic brakes. At this noonday, Logic achieves the true knowledge of the reality common sense experiences and believes in. On the one hand, this knowledge is one of the realist type: reality itself does not exist, it exists only in the networks of negativity. For Hegel, this is true about reality itself, not only about our interpretation of it. On the other hand, that reality itself does not exist is a speculative claim. Reality does not exist as a totality of self- 
subsistent things as common sense takes it to be. But from yet another perspective, reality is not a "realm of shadows", some illusion, it exists in the bigger whole, that is Science of Logic itself. I again arrive at the conclusion that the antithesis of idealism for Hegel is not realism but ontological positivism, i.e. the position that the source of determination is not the entangled whole, but atomic individuals. That is why common sense and speculation can meet one another. Therefore, we arrive at another layer of the famous dictum of Hegel: "The opposition between idealistic and realistic philosophy is therefore without meaning" (Hegel, 2010: 124).

\section{Conclusions}

Kant raised the question of the possibility of the meeting between a subject and an object. This question led him to investigate the origin of determination as such. Hegel follows Kant in thinking the problems of determination and reality together, however, he formulates an absolute idealist alternative to the Kantian paradigm.

1. Hegel's notion of the absolute helps him to rethink these questions and overcome Kant's limitation of knowledge to experience ("double bind"). Hegel follows the standard absolute idealist critique of Kant and maintains that the possibility of the meeting between a subject and an object can be explained only from the standpoint of the absolute (the bigger whole). When it comes to determination, neither subject nor object could be taken to be the source of determination (ontologically or explanatory wise), because they only emerge in opposition in experience. Therefore, the absolute is the condition of the possibility of experience and the source of determination.

2. Hegel argues that the entire Kantian enterprise is built on the premise that there is a separation between a subject and the absolute which remains forever unreachable. Hegel rejects such presupposition in favor of the thesis of ontological continuity and immanence. Therefore, for Hegel, the meeting always already happened, the absolute "is in and for itself already with us". We are immanent to the absolute.

3. 1 and 2 explain why Hegel thinks that he can overcome Kant's limitation of knowledge to experience while remaining faithful to the Critical project, i.e. investigating the conditions of the possibility of experience. This means that Hegel's notion of determination in Science of Logic is not merely the notion of experienced determination like Kant's is. 
4. Science of Logic, in which the determination reality is dealt with, is the logic of the determination of the absolute. Here we find reality at the beginning of the doctrine of being, the rubric of quality. Reality is linked with the determination negation.

5. Reality is a positive determination while negation - negative. In this part of Logic Hegel understands negation as the limit. Therefore, reality is composed of reality and the limit. However, as Houlgate shows, further development of Logic shows that there is no clearcut distinction between reality and the limit because their constitution is codependent.

6. In Logic, Hegel's analysis of determination reality establishes the threefold notion of reality. First, reality is first and the most basic determination and as such it is the beginning of Hegel's theory of determination. Hegel's notion of reality accounts for the determination of logical, mental, ideal and not only, or first of all, material. Second, reality, which is composed of the mixture of it and negation, introduces a real difference into the absolute. This means that Hegel agrees with Kant that determination is not atomic and primary, but a result of the dynamic tension between the opposing forces. Determination is the beginning of the multitude in Logic. Reality is the beginning of both the individuation and relationality in the development of the absolute. Third, in reality the negation, and with it the relational side of reality, is hidden.

7. Hegel's notions of the absolute and reality show that for him the opposition of idealism is ontological positivism, not realism. Therefore, for Hegel, being an idealist is fully compatible with being a realist. Hegel's notion of determination transcends the Kantian opposition between idealism and realism. 


\section{FERRARIS' NEW REALISM AND THE QUESTION OF THE SOURCE OF DETERMINATION}

In the first part of this thesis I presented Kant's position on the question of the source of determination. I argued that Kant's position was followed by most of the authors of continental philosophy and therefore could be called dominant paradigm. In the second part I presented the first reaction to Kant that tried to overcome Kant's subjectivism and anti-realism: absolute idealism. I chose Hegel to represent absolute idealist stance on the question of the source of determination. I will now turn to another alternative to the Kantian paradigm: new realism.

I chose Ferraris' to represent this movement, because I think that various developments of realism we find in his work uncover tensions, problems and possibilities of the entire new and speculative realist field. From the standpoint of the question of the source of determination, I propose to recognize three stages of Ferraris' realism: 1) notion of reality as unamendability, 2) theory of three kinds of objects and 3) positive realism. I think that what gives unity to Ferraris works is not answers and the main concepts he employs, but the problems he tries to solve. The goal of Ferraris thinking is to develop positive realism and bridge the gap between our thinking and theories and reality.

However, I will not start by directly tackling this question. Rather I will analyze Ferraris relation to the Kantian paradigm first and situate him in the broader contemporary realist movement by analyzing the similarities and differences between Ferraris' critique of Kant and Meillassoux's critique of correlationism.

\section{Ferraris and Kant's ontological theses}

Ferraris develops an entire book to sort out his relationships with Kant. However, as the title of the book indicates, his Adieu, Kant! What still stands of the Critique of Pure Reason? is written as a general 'claim-after-claim' reevaluation of Kant's first Critique. For this reason, the book sometimes has a character of a general introduction. Another notable thing is that Ferraris focuses on the first two parts of the Critique of Pure Reason, Transcendental Aesthetics and Logic, leaving Transcendental Dialectics aside and the Doctrine of Method barely mentioned at all. My aim is to reconstruct Ferraris' vision of Kant because the diagnosis of what went wrong with Kant determines Ferraris' view of what went wrong with the post-Kantian 
philosophy in general. This, in turn, shapes his realist program, his alternative to the post-Kantian paradigm.

Ferraris' ambitious project is to "sum up" the first Critique in seven theses (Ferraris, 2013a: 20). The first five are ontological, the last two epistemological. I will start with ontological ones and sort them out into three groups.

The first two theses Ferraris attributes to Kant are the theses about space and time. Ferraris quotes Kant and explains: “"By means of outer sense, a property of our mind, we represent to ourselves objects as outside us, and all without exception as in space." In other words, there is a container, space, with three dimensions, that contains all the extended things, from atoms and molecules upward, and that precedes them" (Ibid). These comments seem strange. Not only it is debatable if the Kantian space is really a container, but Ferraris also does not bother to stress that space, in the quote he himself provides, is defined as "outer sense, a property of our mind." However, these descriptions will be somewhat enriched with the latter theses. The thesis about time is practically identical, the only difference being the fact that time also contains "more fleeting objects (such as memories and expectations), existing in time but not in space and possessing duration but not extension" (ibid).

The next pair of theses have to do with processes in the physical world. These are the thesis about substance and the thesis on cause. I think that Ferraris presents them as the core of the first Critique because substance and cause seem to explain identity and change. In this way, the first four theses Ferraris attributes to Kant would account for space, time, identity and change of physical objects. That is to say, almost the entirety of all physical processes. Returning to the theses on substance and cause, Ferraris stresses their a priori character (which was not stressed when he spoke about space and time) and specific relation with experience: "We do not learn of this unvarying substance from habit, but we are endowed with a concept that precedes experience and that helps us understand, for instance, that water, ice, and steam are three states of a single substance" (Ibid). Accordingly, the causal structure of the world is also in us "prior to any experience" (ibid).

To illustrate the last thesis Ferraris quotes Kant: "Thesis about the Self. "It must be possible for the "I think" to accompany all my representations"" (Ibid). He proceeds to explain: "Every time I have a sensation or a thought, the self registers it and refers it to itself (I am hot; I see red; I am thinking of Pegasus or Napoleon). If it did not do so, the experiences and thoughts would attach to nothing, as is the case when we perform some action, such as shutting the door, without thinking about it, and then we can't remember doing it" (ibid). Put differently, consciousness ensures its continuity by establishing an 
essential link between experience and experiencing subject. The analysis of Kant that I have done in previous parts of the thesis indicates that the example of "shutting the doors, without thinking about it" is not appropriate to illustrate the workings of transcendental subjectivity. At this point, it looks like Ferraris thinks that for Kant the source of determination is a concrete human subject (who shuts the door and does countless other mundane activities). However, I have shown that not to be the case. For Kant, the source of determination is transcendental subjectivity that is prior to the human subject and his cogitations and struggles in the world. In other words, it seems that Ferraris psychologizes Kant.

Another problem with the five ontological theses Ferraris presents is that they barely differentiate Kant from the rationalist theories of inborn ideas. The first four theses (space, time, substance and cause) are explained by appealing that they are "prior to any experience" and that without these concepts being in us, we "would not arrive" at them through experience alone. This is a severe shortcoming of Ferraris' presentation. However, it is corrected by the presentation of two epistemological theses to that I presently turn.

\section{Ferraris and Kant's epistemological theses}

According to Ferraris, "the ontological theses rest upon two epistemological theses" (Ferraris, 2013a, 21). These are the theses of conceptual schemes and phenomena. According to Ferraris, "Kant was the first philosopher to maintain that, in order to have experiences, it is necessary to have conceptual schemes (transcendental idealism); and he was probably the first - at least among philosophers - to maintain that only what is in space and time exists (empirical realism)" (Ibid). At this point Ferraris' presentation allows explaining how the thesis of conceptual schemes is different from that of inborn ideas. The thesis of inborn ideas, first of all, applies to thinking and presupposes the identity of objects themselves (thus, one can talk about the harmony of ideas and things). Nothing about the status of the objects themselves is presupposed in the thesis of conceptual schemes. Remember that according to Kant, the manifold of intuition before the synthesis is "something less than a dream." Therefore, the difference between inborn ideas and conceptual schemes is that later structure not only thinking, but also experience qua empirical intuition: "it is not enough to be able to see to have eyes: we need spectacles to turn unfocused and disorderly perception into clear and coherent experiences" (Ibid). According to Ferraris, the thesis about 
conceptual schemes, "sums up and makes possible the five ontological theses" (ibid). In other words, the ontological theses turn out to be theses about the experience and not the world outside of it. If ontological questions now depend on experience, then the concept of ontology has fundamentally changed its meaning. And this development brings us to the last thesis Ferraris attributes to Kant.

If the thesis on conceptual schemes is correct, then "we do not have direct traffic with things in themselves, but only with objects that appear to us through the mediation of space and time (the pure forms of the intuition and the perceptual apparatus that carries them), of the self and of the conceptual schemes or categories" (ibid). We encounter only the things as they appear to us and not as they are in themselves. At this point, it is essential to note that the first five theses are "summed up and made possible" by the thesis of conceptual schemes and the last one follows from it. Therefore, one could claim that in Ferraris' account this thesis is central to Kant's philosophy.

After presenting how Ferraris sees the main argument of Kant's Critique of Pure Reason, it is time to ask what he perceives to be flawed in it. Actually, Ferraris rejects most of it. However, the critical flaw to which Ferraris returns, again and again, is the so-called "transcendental fallacy."

\section{The transcendental fallacy}

According to Ferraris, the entire history of interpretations of Kant missed his "grossest fallacy", because it was "too obvious" (Ferraris, 2013a: 39). Ferraris names this fallacy transcendental and the presentation of it appears through out many of his works. ${ }^{9}$ This fact suggests the central significance of this diagnosis for Ferraris' thinking. What is this fallacy Kant allegedly makes? According to Ferraris, the fallacy consists in maintaining "the underlying continuity between Kant and the dominant tradition in philosophy to regard science and experience as two extremes that are wholly interchangeable: science is experience made that bit more refined and systematic, and experience is science that lets itself go and is available to everyone" (Ferraris, 2013a: 41). There is a lot to unpack here. First of all, one should keep in mind a rather textbook fact that Kant established the necessity

\footnotetext{
${ }^{9}$ We find the presentation of "Transcendental fallacy" in Manifesto of New Realism, Realism as Emergentism, New Realism as Positive Realism, Goodbye, Kant!, The Short Story of New Realism, Ding an Sich, and etc.
} 
of synthetic a priori judgments based on the existence of Physics and Mathematics. Ferraris does not question whether Physics and Mathematics could be used as the firm foundation of one's philosophical doctrine. Rather, he questions the way the concrete principles of Physics and Mathematics (and not their simple existence or synthetic a priori character of judgments) influences the content of a priori for Kant. Ferraris asks why Kant "did not wonder whether his synthetic a priori of the "I," substance, cause, time, and space might not be just an abstraction of some physical principles? And the answer must be that he was utterly convinced of the identity between physics and experience, and between physics and logic" (Ferraris, 2013a: 38). Put differently, Kant believed that the laws that govern the contents of experience are fundamentally the same as the ones that govern the physical world which Physics studies. What is problematic with that? Contemporary physics makes this claim extremely doubtful. The world we perceive seems to be entirely different both according to its phenotype and the laws that govern it when compared to the quantum world. However, in an even deeper sense, the transcendental fallacy consists of not taking into account the possibility that the manifest structure of the world might be different from the actual structure of the world. This is rather baffling because one could consider this to be one of the founding distinctions of philosophy. I can only agree with Ferraris that the identity of science and experience constitutes a very problematic presupposition of Kant thinking.

Ferraris thinks that "four things" follow from this fallacy in further philosophical developments. 1) First, "The fallacy makes a thing depend on the way that it is known. Here, "knowing" means having an experience that is more or less science" (Ferraris, 2013a: 40). In other words, the transcendental fallacy consists of two steps: First, by taking experience to be a prototype of physics it establishes the essential truthfulness and a-historicity of experience; second, by inscribing physics into the a priori structures of experience it naturalizes physics. Now the structure of the world is in principle equal to the structure of our experience. I think that the conclusion of the analysis of Kant done in this thesis shows that Kant does not seem to hold such a strong thesis, as he believes that concrete laws of physics do not depend on the transcendental subject for their concrete parameters but only for their lawfulness. For example, the concrete gravitational force of Earth does not depend on the transcendental subject for Kant, only its causal character does. Notwithstanding these objections, the general direction of Ferraris' argument appears to be true. 2) Second, the fallacy introduces fundamental ambiguity into what "we know" means. Does "know" still mean what we know something true about the world, or is knowledge only knowledge about our 
own constructions? And this means, 3) third, that "we end up with a reduction of objects to the subjects that know them. And this reduction can be read in differing ways according to how we conceive the role of subjectivity in it" (Ibid). If we take into account the significance of Transcendental fallacy in other works of Ferraris then there is a strong claim to make that he regards the entire history of philosophy after Kant as the history of "differing ways according to how we conceive the role of subjectivity" in "reduction of objects to the subjects that know them." I want to stress that "reduction of objects to the subjects that know them" is only one of the possible interpretations of Kant's thesis that transcendental subjectivity is the source of determination. 4) Finally, fourth, as already indicated, the identity of physics and experience leads Kant to treat questions that are in principle answerable to be a priori unanswerable. Ferraris gives an example taken from the Transcendental Dialectic: "for instance, whether the world had a beginning in time or not could not be decided. But in the twentieth century just this sort of question would be the subject of scientific discussion; thus, contrary to what Kant thought, the unknowability in question is not absolute but subject to history" (ibid). The reduction of objects to subjects that know them is basically a relocation of the source of determination. In this Ferraris and Hegel agree: Kant's alleged subjectivism is wrong. However, they find different underlying causes of why Kant's philosophy became subjectivism. For Ferraris, Kant's main fallacy is his notion of experience based on the identity of science and experience, while Hegel believes that Kant's subjectivism is grounded in the ontological presupposition of the separation between the absolute and the finite. I will return to this difference later. However, before proceeding to Ferraris' account of the source of determination, it is useful to compare his account of Kant's shortcomings with Meillassoux's depiction of the entire post-Kantian tradition as correlationist. As Meillassoux's account could now be called the standard speculative realist critique of Kantianism, this will help me to situate Ferraris in the broader contemporary realist field and bring more precision in my analysis of Ferraris by showing his differences from Meillassoux's account. 


\section{Meillassoux notion of correlationism}

Meillassoux develops his notion of correlationism ${ }^{10}$ in the first chapter of After Finitude (2006). Thematically speaking, the chapter consists of three topics: the distinction between primary and secondary qualities, the exposition of correlationist thesis and the description of the loss of "the great outside." All three topics uncover what Meillassoux means by correlationism. I will start with a presentation of Meillassoux's text and later formulate some conclusions about what his notion of correlationism consists of. Then I will compare the correlationist diagnosis with Ferraris' critique of the PostKantian philosophy. This will highlight how Ferraris fits into the broader realist context and the distinct features that set his realism apart.

After Finitude starts from the recollection of the distinction between primary and secondary qualities. The distinction clearly comes from the early modern philosophy, and Meillassoux is pretty orthodox in his presentation of it. According to him, secondary qualities are actually only relations between a subject and an object: "Whether it be affective or perceptual, the sensible only exists as a relation: a relation between the world and the living creature I am" (Meillassoux, 2006: 8). The idea could be explained by appealing to the paradigmatic example of colors. According to many thinkers of that period, colors cannot be the qualities of the thing-itself because they appear only when a certain visual system is in place. Many animals do not experience colors, including some humans. From this, the conclusion is made that some qualities appear only in our experience and not in the world "without us." However, these are not determinations that subject creates out of thin air; the interaction with an object is always necessary. According to Meillassoux, "in actuality, the sensible is neither simply 'in me' in the manner of a dream, nor simply 'in the thing' in the manner of an intrinsic property: it is the very relation between the thing and I" (Meillassoux, 2006: 8). By contrast, the primary qualities are

${ }^{10}$ In her contribution to aforementioned volume On Reality (2021) Habdankaitè emphasizes the importance of the distinction between weak and strong correlationism. According to her, Meillassoux rejects only strong correlationism, while in some sense remaining inside of weak correlationism. Therefore, one could object that in this thesis I present correlationism as a single notion, thus misrepresenting Meillassoux project. I will restrain myself to two remarks here: 1) I think such reading of Meillassoux is too much in line with general scheme of destruction (or deconstruction) of metaphysics (which is criticism from inside without ever being able to escape metaphysics completely). 2) I think that the aim of Meillassoux project, to think the absolute, is incompatible with any version of correlationism. 
qualities which are intrinsic to an object itself and exist even if an object does not enter any relations: "They are properties of the thing as it is without me, as much as it is with me - properties of the in-itself" (Meillassoux, 2006: 910). Meillassoux tries to show, that while post-Kantian philosophy accepts the idea of secondary qualities it rejects the idea of the primary qualities. In short, according to Meillassoux, after Kant, all qualities are thought of as secondary qualities ${ }^{11}$.

The second topic of the first chapter of After Finitude basically attests to the same idea, although it does not employ the terminology of secondary and primary qualities anymore. The 'correlation' is the main term now. According to Meillassoux, "by 'correlation' we mean the idea according to which we only ever have access to the correlation between thinking and being, and never to either term considered apart from the other" (Meillassoux, 2006: 13). In other words, the correlationist agrees that all qualities of an object are relations (secondary qualities), however, he adds that the same is also the case for all qualities of a subject. In this way, he seems to depart from the standard reading of modern philosophy as the philosophy of the subject. Meillassoux seems to imply that correlationism by definition must abandon the idea of the subject as an a-historical ideal instance against which everything else is determined. ${ }^{12}$ Therefore, "the 'co-' (of co-givenness, of co-relation, of the co-originary, of co-presence, etc.) is the grammatical particle that dominates modern philosophy, its veritable "chemical formula"' (Meillassoux, 2006: 14). It is essential to note that at this point Meillassoux's descriptions are purely technical: He did not start to criticize correlationism yet.

Negative implications start to appear only with the introduction of the last great topic of the first chapter. If correlationist is right, the subject cannot think the object as such, separated from his own thinking. However, the subject still explores objectivity, but only in correlation. According to Meillassoux, this creates "a strange feeling of imprisonment or enclosure within this very exteriority" (Meillassoux, 2006: 16). This will be his main objection to correlationism on which everything else hangs. The questions of truth and

${ }^{11}$ Kant famously makes the analogy between his appearances and the secondary qualities in Prolegomena (Kant, 2004: 40-41). The good summary of the scholarly debates on this topic is provided in the "The secondary qualities analogy" chapter of Allais Manifest reality: Kant's idealism and his realism (2015).

12 In this sense, Meillassoux disagrees with Heidegger's diagnosis of modern philosophy as the philosophy of the subject as hypokeimenon. Rather, he inscribes Heidegger himself into his description of modern philosophy as "a strong correlationist" (Meillassoux, 2006: 70). 
objectivity are introduced (Meillassoux 2006: 12-13) to prepare us for the idea of imprisonment, while the fossil argument is meant to illustrate that we are actually not as imprisoned as correlationist claims. All this is to demonstrate that

"It could be that contemporary philosophers have lost the great outdoors, the absolute outside of pre-critical thinkers: that outside which was not relative to us, and which was given as indifferent to its own givenness to be what it is, existing in itself regardless of whether we are thinking of it or not; that outside which thought could explore with the legitimate feeling of being on foreign territory - of being entirely elsewhere" (Meillassoux, 2006: 17).

The three topics with which Meillassoux opens After Finitude allows us to summarize his notion of correlationism in two points. First, correlationist claims that it is impossible to think either a subject or an object in separation, these two can only be given together. Second, such primacy of correlation creates the feeling of imprisonment on the subjects' side, the feeling of the loss of "the great outside."

\section{Ferraris and Meillassoux on what went wrong with modern philosophy}

According to Meillassoux, the nexus of the post-Kantian philosophy is the treatment of the correlation between a subject and an object as primary and inescapable. Such state of affairs causes a feeling of loss on the side of the subject. Ferraris' reading of Kant stresses the pole of the subject much more. As I hitherto showed, the transcendental fallacy consists in maintaining the identity between the structure of experience and the structure of science and knowledge, but not the other way around. According to Ferraris, in practice, this almost always means the reduction of the world known to the knowing subject. Another significant difference between their treatments of modern philosophy is that the question of experience is much more important to Ferraris than to Meillassoux. For the later, the theoretical-mathematical reason is the key to leaving the correlationist circle. To summarize, Ferraris focuses on the problems of experience, knowledge and the active role of the subject. Of course, the identity between experience and science, regarded as the identity between epistemology (experience) and ontology (science), could be interpreted as the rebranding of correlationist diagnosis because the identity 
seems to be prior to both poles. However, Ferraris' insistence on the empirical intuition and activity of a subject drives him to a different direction than Meillassoux. What is more, Ferraris' preference for the terms 'ontology', 'science', 'epistemology' and 'experience' allows him to focus on the question of truth to a greater extent. These differences are more apparent if one asks the question what is the primary opposition of realism in philosophies of Ferraris' and Meillassoux's and other new realisms.

\section{What is the opposite of realism?}

The problem of realism is inscribed in many theoretical frameworks. In his seminal After finitude Meillassoux proposes to think realism in opposition to correlationism, which he believes is the position that almost all thinkers after Kant held. According to Ferraris, who supports Meillassoux's criticism, correlationism forces one to accept the thesis that "there is no world without a spectator" (Ferraris: 2015: 120-121). Acting on such a diagnosis, Meillassoux presents his 'fossils argument' and tries to "breakout of the correlationist circle."

However, even if the critique of correlationism is the (only) common core of all new realisms, different thinkers stress different traits of the post-Kantian thought. According to them, it is these traits that determine the anti-realist character of the post-Kantian thought. Thus, Graham Harman constructs his realism in opposition to procedures of overmining and undermining (and the privileged human place in the cosmos) (2011 and 2019), while Ian Hamilton Grant thinks that the main anti-realist trait of modernity is the disappearance of nature (2006). Needless to say, these primary distinctions have a great influence on the characters of the aforementioned realisms. Therefore, the question naturally arises: what does Ferraris oppose his realism to? The answer to this question is misleadingly simple. For Ferraris, the essential opposite of the new realism is constructivism. For example, this is evident in his claim that "this is the mainstream of modern philosophy: not nihilism or solipsism (which butts against common sense too forcefully), but rather constructivism, i.e., the idea that reality exists but is itself amorphous, like cookie dough - an undifferentiated chora that is modeled by subjects, who become constructors of phenomena" (Ferraris, 2015: 120). In addition, consider this remark from Positive Realism: "There are those who object - we will discuss this later - that this philosophy never negated the existence of the world "outside", and often that is the case. It done worse. It imagined the world 
without form, quality, property, a modeling clay for subjects" (Ferraris, 2013b: 11). From these quotes, we can infer what a realist-as-opposed-toconstructivist must claim: reality is not "amorphous" and "undifferentiated" but has the structure prior to any interactions. While this is not self-evident, this is exactly what Ferraris "the slipper experiment" tries to convince us.

Before proceeding to "the slipper experiment", I have to highlight that the theoretical oppositions that Kant and two alternatives paradigms, namely, Hegel's absolute idealism and Ferraris' new realism, use to define realism are now clear. All three thinkers treat the problem of realism as the problem of determination. Kant calls (transcendental) idealism a position according to which the source of determination is the transcendental subjectivity and opposes such position to realism, according to which the source of determination is the objects themselves. For Ferraris, the theoretical opposition of realism is constructivism, i.e. the claim that reality in-itself is structure-less and subjects impose the structure onto this undifferentiated "cookie dough." The main shortcoming of such depiction of the post-Kantian philosophy is that it does not respect the difference between the human concrete subject as the source of determination and the transcendental subjectivity as the source of determination. Finally, for Hegel the opposition of his absolute idealism is positivism, i.e. the claim that the source of determination is atomic individuals as opposed to the claim that the source of determination is the absolute as the whole in which all determinations entangle and arise. From the analysis of Ferraris' arguments against Kant it is not yet possible to tell where he fells with regards to Hegel's idealism-positivism distinction.

\section{Slippers and others who encounter}

"The slipper experiment" is at the center of many works of Ferraris. ${ }^{13}$ However, for the reader used to a high level of complexity and suspicion (in the guise of the critique, genealogy or deconstruction) the experiment may seem naive, if not altogether silly. However, let's not fall prey to our habits and reject it out of hand. To uncover what is at issue in "the slipper experiment" I will first present "the slipper experiment" and then compare its conclusion with how similar themes shape out in the work of Agamben. This

${ }^{13}$ We find presentation of Slipper Experiment in Manifesto of New Realism, Il Mondo Esterno, New Realism as Positive Realism, Ding an Sich, and etc. 
will allow me to show that behind Ferraris' common sense argument lies the question of determination.

The crux of the experiment is pretty simple. Ferraris asks us to imagine the slipper lying on the carpet. The presentation of the experiment typically starts with something like the following: "Take a man looking at a carpet with a slipper on it" (Ferraris, 2014a: 28). Then Ferraris adds four other agents who have very different "conceptual schemes" when compared to our ones, if any. These usually include dogs, worms, ivy and the slipper itself. As is immediately evident, the list is designed so that the epistemic capacities of agents on the list are gradually getting more and more different from ours. Ferraris' aim is to show that all these agents have a completely different relation to the world ("conceptual schemes") but nonetheless "encounter" the same slipper. Consider this description of ivy's interaction with the slipper: "we cannot say to it, "Bring me the slipper." However, crawling on the carpet, if it meets the slipper, it can choose between two strategies: either to turn around it or to climb over it. In both cases, it encounters the slipper, although not quite like I encounter it" (Ferraris, 2014a: 29). According to Ferraris, this can only be explained if we reject constructivism altogether or restrict it only to certain domains. Or to put it otherwise, according to Ferraris the experiment is supposed to demonstrate the necessity of the shared common world before any interpretative interaction. As he puts in other place, "In fact, in this world we are able to interact with beings endowed with conceptual schemes and perceptive apparatuses that are profoundly different from our own, a circumstance that cannot be explained but through the sharing of a world 'out there' that is immune to our perceptive apparatuses and conceptual schemes that is, through the sharing of a great number of things in and of themselves" (Ferraris, 2015: 119-120). In another place, he restates the same idea in a different manner than he claims that "This interaction cannot be explained if not by the fact that we tackle things in themselves; otherwise, there would be miraculous harmony among different appearances (for example, a steak seen by a cat, by a wasp and by a man who wishes to eat it in holy peace)" (Ferraris, 2014c: 17). I will now try to disperse the simplicity of Ferraris' argument with a few possible objections.

\section{Possible critiques: slippers, atoms and anthropocentrism}

There are at least a few ways to rebuke this argument. To begin with, one could claim that Ferraris' argument works only insofar as the agents in 
question are agents we encounter in our everyday world. Atoms, for example, do not encounter slipper as they freely move through it. However, this seems to be the case not because atoms construct a "different reality" than dogs, but because of their sheer size and the fact that physical objects mostly consist of the void at the atomic level. An atom would still encounter the atoms the slipper is made of and it would interact with other entities of the similar size.

The second objection would claim that Ferraris' argument is too naive and anthropocentric. Actually, the "encounter" of a man and a slipper, and the "encounter" of ivy and slipper are completely different in kind. Therefore, using the same word to characterize these two relations is a mistake. This second argument is much more popular in continental philosophy and helps to bring out that is at stake in Ferraris' experiment. Therefore, I will now turn to Agamben, who presents a similar argument in his The Open: Man and Animal (2004).

\section{Agamben, encounters, determinations}

Agamben is equally interested in the "encounters" between different beings. Following Heidegger, he primarily focuses on the interaction between humans and animals. His line of thought is exemplified by his fascination with Uexkülls theory of Umwelt. Agamben writes:

"This illusion rests on the belief in a single world in which all living beings are situated. Uexküll shows that such a unitary world does not exist, just as a space and a time that are equal for all living things do not exist. The fly, the dragonfly, and the bee that we observe flying next to us on a sunny day do not move in the same world as the one in which we observe them, nor do they share with us - or with each other-the same time and the same space" (Agamben 2004: 40).

If we agree with Agamben the quality of encounter Ferraris talks about starts to turn doubtful. According to Agamben, we do not share the same world with the other agents we encounter precisely because the world itself is the creation of the conceptual schemes we find ourselves thrown into. So, instead of accepting the premise of the shared world that Ferraris presses, Agamben rejects that the actual encounter between different agents happens. 
Picking sides is not my primary concern here. ${ }^{14}$ What matters is that this polemic helps to uncover an important thing. Notice that for both philosophers the brute fact of existence (of the slipper) is not enough to establish their argument. For example, Agamben would not deny that the fly and the human in some sense encounter the same presences. Rather, he would question if there is any meaningful sense of this sameness, given that different conceptual schemes create different worlds the fly and the human live in. The same is the case for Ferraris, for whom it is essential that the interaction would be similar, at least spatially: "The ivy will either bypass the slipper, or it will climb over it, not too unlike the way a man would do in front of an obstacle of larger size, but with neither eyes nor conceptual schemes" (Ferraris, 2014a: 29-30). For Ferraris, it is necessary that the ivy would act "not too unlike the way a man would do." Therefore, I claim that the essence of the slipper experiment is not that we all encounter some brute presence, but that the determinations we encounter must arise from the objects we encounter, so even agents with different conceptual schemes (if any) would encounter them similarly. This shows that the question of the meeting (in Kant's words) between the subject and the object is also tied to the question of determination exactly like in Kant and Hegel. Therefore, this seems to be the argument for the hypothesis that the key issue in the contemporary debate on realism is the question what is the source of determination in the world and our experience. If we admit that the question of determination (which Ferraris rarely explicitly discuss) is at the center of Ferraris engagement with the post-Kantian tradition when his notions of reality become clearer.

\section{Ferraris notions of reality}

Kant claims that the source of determination is the transcendental subjectivity. Contra Kant, Hegel argues that it is the absolute. It is now established that for Ferraris realism is the claim that reality is the source of determination as opposed to the claim that the source of determination is the subject who constructs his experience. However, it is clear that such answer

14 Although I certainly agree with Ferraris that these encounters actually happen, whatever 'actually' means in this case. 
is not sufficient. The analyses of Kant and Hegel showed that reality as a term was always used to designate some notion of determination. Therefore, if one says that reality is the source of determination, he is indulging in a tautology. Therefore, I will need to analyze concrete notions of reality Ferraris operates with. I claim that there are three developments of the notion of reality as the source of determination in Ferraris' works. Matters are even more complicated by the fact that not all of these developments are explicit. Finally, I doubt that all these developments and notions are compatible with each other. I will therefore now explore three main developments of the notion of reality in Ferraris. First, I will present his notion of reality as unamendability, then turn to his notion of three types of objects, and finally, to his notions of affordances, invitation and positive realism ${ }^{15}$.

\section{Reality as unamendability}

Unamendability (inemendabilità) is the main characteristic of reality in the works that follow Estetica razionale (1997) and up to Documentalità (2014b) and Realismo positivo (2013b). The philosopheme is still present in his later works, but there it is only one of the ways reality is thought. It is worthy of notice that unamendability as a term is absent in his most substantial work of the early period, Rational Aesthetics, but the primacy of aesthetics and sensual experience announced in this period could be seen as a forerunner for unamendability. Ferraris himself refers to Analogon rationis (1994) (Ferraris, 2014a: 94) as the text he first introduced the term, but I will analyze Manifesto of New Realism where reflections on unamendability take complete shape found in the later writings.

Unamendability is an essentially negative way of describing reality. In Manifesto Ferraris presents a clear definition of what the term has to denote: "I propose we define this fundamental character of reality's "unamendability": the fact that what we face cannot be corrected or changed by the mere use of conceptual schemes" (Ferraris, 2014a: 34). First of all, note that the metaphors of the meeting (always tied to the question of reality, as we now see) are

${ }^{15}$ Ferraris lately worked out a version of his realism using histeresis as a central term. This was done after I worked out most of the analysis of Ferraris' realism found in this thesis. I chose the affordances to represent the last stage of the development of Ferraris realism, because I believe that philosophical proposal developed in the Metaphysics of the Web (2021) still falls under the broader rubric of the positive realism. 
unavoidable and immediately suggest themselves to Ferraris (be it meeting with a slipper or reality as "what we face"). More to the point, at this layer, reality as unamendability unfolds as something that resists our interpretations, that lies beyond them and our epistemic activities. To illustrate this point Ferraris provides many vivid examples: ““'Unamendability” is precisely this: looking at the fire, I can think that it is a phenomenon of oxidation or the action of phlogiston and caloric, but (unless I am provided with asbestos gloves) I cannot but burn myself if I put my hand in the fire" (Ferraris, 2014a: 36). Note that reality is not unamendable per se, but only through our epistemic capacities. One can still put the fire out by pouring the water on it, but one cannot turn it into something that does not burn the hand through the change of the conceptual system one has (although one can modify one's beliefs about why fire burns, what does it mean and so on). Or, as Umberto Eco puts it, "my objection is that this table cannot be interpreted as a vehicle which can be used to travel from Athens to Thessaloniki. The problem is that such severe limitation tells us that the table can be interpreted (and known) in many ways (including those that its producer was not thinking of), but not in whichever way" (Eco, 2015: 389). As Ferraris stresses, this shows the difference between ontology and epistemology, ontology being the study of unamendable reality and epistemology the study of our ways of knowing it. I do not see any reasons to disagree on this with Ferraris.

However, Ferraris can say a little positive about reality at this stage of the development of his realism. Thus, unamendability looks more like an argument against constructivism than the way of thinking about reality that is valuable in itself. For Ferraris reality now is the source of determination, especially in perception, but because the only way to speak about reality is negative, many problems arise. He likes to present his theory in a catalog fashion and because of this the relations between different parts of the theory sometimes look underdeveloped. For example, one can ask, if the perception is still thought to give us direct contact with reality (as in Rational Aesthetics), why then not to talk about reality positively? And how and why the perception gets distorted in our thinking and why our conceptual schemes become so detached from reality? I think it is to avoid all these questions that Ferraris uses unamendability as the central concept at this stage of his thought. Reality does not verify our concepts and theories and for this reason, the gap between us and the world persists. However, reality is not infinitely plastic and it does falsify our theories about it by resisting and being unamendable. Unamendability is more of an obstacle than an independent agent. The fire that burns us has the minimal determination independent from us, but this determination does not impress itself on our theories. It only resists when we 
act on it. Therefore, unamendability barely gets us anything new that the slipper argument has not yet established. It seems that now reality is the source of determination in the world, but it is not clear what is the source of determination in our heads. Moreover, unamendability seems to be unamendability of individual objects as opposed to the holistic character of our interpretations. In this sense, at this point of the development of his thought, Ferraris seems to implicitly maintain the tendency we found in Kant to associate holism with anti-realism and ontological positivism with realism. Therefore, Ferraris negative realism seems to opposed not only to the Kantian paradigm, but also Hegel's absolute idealism.

\section{Eco's negative realism}

At this stage, Ferraris' realism is remarkably similar to Umberto Eco's negative realism. ${ }^{16}$ In his Some Remarks on New Realism (2015) Eco describes the debate he had with Rorty. According to Eco, Rorty "denied that the use made of a screwdriver to tighten screws is imposed by the object itself, since we can also use it to open a package. Thus the "nature" of the screwdriver is imposed by our subjectivity" (Eco, 2015: 388). Put differently, Rorty defended a typical constructive position, according to which reality is an amorphous plane on which subject imposes determination. Contra Rorty, Eco remarked that although screwdriver could be used in many ways, these ways are not unlimited. As he remarks on another example, "my objection is that this table cannot be interpreted as a vehicle which can be used to travel from Athens to Thessaloniki. The problem is that such severe limitation tells us that the table can be interpreted (and known) in many ways (including those that its producer was not thinking of), but not in whichever way" (Eco, 2015: 389). Some interpretations are disproved or forbidden by the object itself. Eco calls this feature of reality the "lines of resistance." I think it is evident how similar lines of resistance are to Ferraris' unamendability. Finally, for Eco, this negative side of reality forces one to commit to a realist position: "screwdriver answers positively (so to speak) to many of my possible interpretations, bat in

${ }^{16}$ Di Martino (2012) suggests that there are important ethical differences between Eco's and Ferraris' position. According to her, Ferraris' invites us to drop the postmodern ethical project, while Eco's remains faithfull to some modified version of it 
certain cases says NO. This sort of refusal opposed by the objects of our world is the basis of my prudent idea of a Negative Realism" (Eco, 2015: 392).

There are two further remarks to be made on Eco's "modestissimo realismo negativo." First, Eco is commited to the thesis that reality (in his case mostly works of art) has to have some kind of structure before any interpretation. $\mathrm{He}$ claims: "I do not think that even the most fundamentalist among deconstructionists really thinks that there are no facts at all, since to carry out an interpretation one must have something to interpret, and if the series of interpretations has no final terminus ad quem it must have at least a terminus a quo - a starting point that, however matters stand, we can call a fact (Eco, 2015: 388). I think that Ferraris' would agree on this point. However, Ferraris will try to overcome Eco's second point in his positive realism. According to Eco, negative realism is a form of fallibilism that does not force one to commit some sort of positive notion of reality. In fact, I think that Eco sees certain agnosticism as a very attractive feature of negative realism. Therefore, for him, "to state that there are lines of resistance does not yet mean, as Peirce would have said, that there are universal laws at work in nature. The hypothesis of universal laws (or the hypothesis of a specific law) is only one of the ways in which we react to the onset of a resistance" (Eco, 2015: 394). This also explains why for him facts "scarcely tell me if I am right" (Eco, 2015: 392). I think that for Eco such theory provides enough realism and at the same time does not restrict freedom of interpretation that his other works celebrate. I think that one could argue that Eco's position amounts to realism coupled with a quietism on the question of the source of determination.

\section{The three types of objects}

If one would have asked the reader of Ferraris what notion of reality Ferraris holds at the time I started my research project, the most probable answer one would get would be that he does not have one notion of reality, but rather maintains that there are three types of objects. The idea of the three types of objects and the concepts related to it comes to the center of Ferraris thinking in Documentality. To analyze this idea, I will 1) briefly present the theoretical context in which the idea appears; 2) present the three types of objects themselves; 3 ) provide the possible critique for the notion and finally; 4) consider the relation between reality as unamendability and the idea of three types of objects. 
Documentality presents a general ontology in the shape of the catalog of the world. In other words, Ferraris tries to present the typology that will accommodate all possible objects and subjects. It is equally significant to note that in many ways the book is more manifesto-like than the Manifesto of New Realism. In the first 13 pages, Ferraris declares the instruction of how to produce the catalog and then follows it wholeheartedly. The last three rules of the instruction (Exemplify, not simplify; Describe, not prescribe, Experience, not science) determine that most of the book consists of descriptions (except the part that deals with social objects), rather than proofs of the states of affairs. To put it differently, the book is somewhat declarative. Another important thing is that although Documentality is a general ontology as the catalog of the world, the book mostly deals with social objects. Thematically, three-quarters of the book deal with the issues surrounding them. Leaving social ontology aside, Documentality, first of all, is an attempt to return to a more Aristotelian way of doing philosophy, with the Derridian social ontology incorporated into it.

As already mentioned, Documentality suggests that there are three types of objects (Ferraris, 2014b, 32). The first type is "the natural objects that occupy place in space and time and do not depend on the subjects" (Ibid). The second type of objects are ideal objects "that do not occupy place in space and time and do not depend on the subjects" (Ibid). Even before proceeding to the third type of objects, the certain poverty of such descriptions is evident. Basically, Ferraris sorts objects according to two criteria: dependence on the subject and appearance in space and time. The dependence on the subject here is clearly understood as the dependence with regards to existence. According to him, natural and ideal objects would exist even if humanity would have never existed. And while it is true, such notion seems to be extremely thin and not informative. To put it otherwise, yet again, while the introduction of these objects into the catalog of the world may be a fruitful strategy while arguing against constructivism, this does not inform us much about reality itself.

The third type of objects will be at the center of Documentality and Ferraris social ontology. These are "Last but not least - the social objects, that occupy place in the space and time and depend on subjects but are not subjective" (ibid). There is much to say about his notion of social objects and it is probably the most original part of Documentality and of the subsequent works. However, I will limit myself to two remarks that are directly related to his notion of reality. First, social objects depend on subjects for their existence. The whole problem of Documentality is to provide an answer to how concretely this dependence is constituted in the world. To answer this problem Ferraris proposes deconstructionism limited to the social sphere (or weak 
textualism, as he himself calls it (Ferraris, 2014c, 183)). In other words, social objects are dependent on technologies such as writing, inscription and so on: and these would not exist without the subject. However, there are two important points to note. First, for Ferraris social objects depend on the subjects both for their existence and essence, but they are not subjective. On the contrary, the technical character of social objects helps to explain why it really does not matter if a concrete person believes in traffic rules, train schedules and etc. You would be still punished for a crime, even if you would deny the existence of the law as such. It is precisely the technological character of social objects that allows to explain their autonomy. Second, it is clear that social objects are created upon other objects. Although some social objects are pure inscriptions (such as financial capital), most of them are made from natural objects or materials. This allows Ferraris to reaffirm his realist stance when he claims that not all natural objects can become social objects. Or to put it more precisely, it is not the case that because social objects are created by humans any natural object can become any social object. Evidently, it would be impossible to treat huge stones as money because of the logistic problems, and the money made from meat would rot very quickly. There is much more to say about Ferraris' notion of social objects, but it would sidetrack me from the main topic of this thesis.

To summarize, three types of objects are natural, ideal and social objects. The first two notions are taken from classical realist thought, while the last one is a modified version of one of the most sophisticated anti-realisms. At this point one could say that different types of objects may have different sources of determination. I would really like to point out that general ontology proposed in Documentality marks a serious step forward compared to unamendability, if not in substance than at least in style. Although unamendability announces the break with constructivism, in many ways it is close to the tradition it criticizes. While showing the limits of constructivism, it still respects the limitations the post-Kantian paradigm imposes and accepts a certain style of doing philosophy that it presupposes. Documentality just proposes a general ontology without any irony, quotation marks or metatextual reliance. Ferraris still seems to be unable to provide a detailed account of the source of determination. However, at this point Ferraris was primarily interested in social ontology and therefore he didn't develop the ideas of natural and ideal objects further. I will now turn to two possible objections to Ferraris' account. 


\section{Anthropocene and natural objects}

The first objection comes from Šerpytyte.. According to her, the entire web of problems surrounding the topic of Anthropocene, that Ferraris deals with in his latter works, leaves no way to clearly distinguish between natural and social objects ${ }^{17}$. If we consider the social behavior of humans as the geological force of nature, then it becomes hard to find something purely natural. Consider dying coral riffs: are they still natural objects if their contemporary condition is defined by the effects of the social on the natural? The same holds for basically all plants and animals whose evolution and behavior is essentially marked by the social objects humans produce (fertilizers, cities, farms and so on). The simplest way out for Ferraris is to point to his definition of natural objects: natural objects do not depend on subjects for their existence. In other words, Ferraris may answer that the coral riffs would still exist even if humans would not, despite the fact that the actual state of these riffs would be completely different. However, that is not the case for all natural objects: would a given hurricane exist if there were no humans affecting the climate? Would there be any pigeons left if there were no cities? These questions seem to be impossible to answer. What is more important, even if the formal definition of a natural object may hold, the problem is that "an object without us" would be a completely different object (while, maybe, formally remaining the same object).

\section{The three types of objects and unamendability}

While being one of the main topics in the previous works, unamendability gets brief treatment in one section of Documentality. What is the relation between the notion of three types of object and unamendability? And does the former achieve the breakthrough in thinking reality itself positively and elaborating a concrete notion of the source of determination? To answer the second question, the formal definition of types of objects does not seem to have much more content in them then the negative notion of reality as unamendability. The expression "independent of a subject" seems to be synonymous with unamendability. This means that the answer to the second

${ }^{17}$ Personal communication. 
question is no. Only the notion of social object is worked out in a more positive way, and it's done with the help of antirealist philosopheme.

The notion of the three types of objects contains three very different notions of the source of determination. The idea of catalog presupposes the primacy of individuals. This point is also supported by the fact that Ferraris does not seem to ontologize the kinds as separate entities. In this sense, the notions of natural and ideal objects could be read along broadly Aristotelian lines coupled with nominalism about kinds. If such reading is correct, then individual objects are primary sources of determination in the world. However, this reading is contradicted by the fact that at the beginning of Documentality Ferraris refers to individual objects as examplars (Ferraris, 2014b: 14-25). This seems to imply that kinds are in some sense primary to the individual objects. If that is the case, then the sources of determination in the world are kinds themselves. Now, Ferraris does not try to unite these different kinds in some short of arkhe kind or common ground. So, instead of individuals themselves, the source of determination seems to be limited to a certain number of individual kinds. However, the notion of social object introduces an even more holistic approach to determination. In the constitution of a social object, the writing as a web of differential inscriptions is essential. Therefore, not a single social object would be what it is outside of the system of all inscriptions qua social objects. This means that the source of determinations is the differential system itself, rather than individual social objects or even individual kinds. If such interpretation is accurate, Documentality leaves more questions than answers when it comes to the question of the source of determination.

However, the investigation of Ferraris notion of reality uncovered two important points. First, the first two notions of reality Ferraris presents are unable to overcome essentially negative manner of thinking about reality itself. Moreover, it still subscribes to the Kantian tendency to associate the ontological individualism with realism and holism with anti-realism. Second, Ferraris efforts start to pull his project in different directions. We find three different notions of the source of determination (individuals, kinds, writing as a system) ranging from ontological positivism to ontological holism. Positive realism will try to address these problems. 


\section{Positive realism and affordances}

The main concept of the third period of Ferraris realism is the concept of affordance. Note that on many occasions he introduces this stage as a "third step" that has to address the questions I posed at the end of my discussion of unamendability. Namely, if reality is the source of determination, what is the relation between it defined in the negative terms as resistance and our theories of reality usually formulated in the positive terms? Affordance as the positive concept of reality must solve the issue: "The theory that I am defending through the affordance argument is that it is favorable to begin with objects (an area which includes subjects as well), in order to reduce the variance between our theories and our experience of the world" (Ferraris, 2014b: 5455). But what are these affordances and how do they work? Before answering these questions, I will turn to Gibson's theory of affordances to which Ferraris refers.

\section{Gibson's theory of affordances and a lack of ontological considerations}

Gibson formulated his theory of affordances in 1979's work The Ecological Approach to Visual Perception. ${ }^{18}$ In this work, Gibson sets out to reject the representational paradigm of perception (that is basically neoKantian) in the favor of direct perceptual realism. This where Ferraris interest lies: Account of direct perception could help him to escape the correlationist circle and the post-Kantian constructivism. Two primary agents in Gibson's account are not the stimulus and the brain, but a perceiving animal and his environment. In such context Gibson proposes his hypothesis of affordances: "Perhaps the composition and layout of surfaces constitute what they afford. If so, to perceive them is to perceive what they afford. This is a radical hypothesis, for it implies that the "values" and "meanings" of things in the environment can be directly perceived. Moreover, it would explain the sense in which values and meanings are external to the perceiver" (Gibson, 2015: 119). This sounds just what Ferraris is after. However, even a simple reflection demonstrates that Gibson's direct realism is not that direct. Consider the big

${ }^{18}$ Eco also mentions Gibson's theory of affordances both in Remarks (Eco, 2015: 389) and Di un realismo negativo (Eco, 2012: 98). 
old tree, with its lower branches really close to the ground. For human beings this tree affords climbing. Is 'being-climbable' a property of the tree-in-itself, directly perceived by us? I think that this cannot be the case. For example, for birds 'being-climbable' as a property does not make sense at all. But if the 'being-climbable' would be a property of 'tree-in-itself', would it not be perceivable to all animals? Gibson is perfectly aware of this. In the first pages of the chapter on affordances, he emphasizes that affordances are affordances relative to the animal (Gibson, 2015: 119-121). Therefore, the theory "implies the complementarity of the animal and the environment" (Gibson, 2015: 119). Is not complementarity just another name for correlation? Gibson strengthens such impression when he claims that "actually, an affordance is neither an objective property nor a subjective property; or it is both if you like" (Gibson, 2015: 121).

There are a few ways Gibson tries to escape from what we today call correlationism. First, he emphasizes that physical nature, or environment, exists prior to the existence of the animal who lives in it. In this sense, the qualities of nature that constitute affordances fall out of the correlationist circle. Put differently, at least one agent in complementarity of animal and environment exists fully before their relation. Another interesting remark Gibson makes is the following: "The physical, chemical, meteorological, and geological conditions of the surface of the earth and the pre-existence of plant life are what make animal life possible. They had to be invariant for animals to evolve" (Gibson, 2015: 120-121). Consider this remark in the context of the question of the source of determination. Gibson suggests that for the emergence of the agents able to interpret the world it is necessary that the world around them would be "invariant." In other words, it is the stability of the determination, rather than the infinite malleability of it that is necessary for life to be able to maintain itself.

To summarize: Affordances are the ways things in the environment "offer themselves" to the perceiver. According to Gibson, they are not deduced by some clever operation but perceived directly. However, as a psychologist, he does not inquire into the ontological conditions under which affordances are possible. The fact that different animals perceive different affordances suggests that they do not work according to the causal model. The thing does not cause its affordances to be perceived. Gibson stresses that in the entanglement of the perceiver and his environment "the object offers what it does because it is what it is" (Gibson, 2015: 130). However, given the fact that object could offer itself differently, Gibson owes us the theory of the relation between the object-in-itself and affordances it offers. I think that without this explanation the direct realism is still vulnerable. 


\section{Affordances in Ferraris' realism}

With the first sentence of Realismo Positivo (2013b) Ferraris announces the overcoming of negative realism: "The first essential principle of positive realism is the fact that the world does not limit itself by saying "no", by resisting, but constitutes a reservoir of positivity" (Ferraris, 2013b: 21). The reservoir of positivity consists precisely of the affordances objects offer. According to Ferraris, affordances are possibilities and determinations that objects offer in their environments: "Under these terms, what is real does not only manifest itself as resistance and as negativity. In every negation there is a determination and a possibility. The world employs an affordance through objects and the environment, which qualifies as a positive realism" (Ferraris, 2014b: 54). Let's consider every term separately. We already know that reality is the source of determination. Ferraris also adds that every reality contains possibilities. This merely means that any individual we encounter affords a huge, but limited, scope of possible interactions we can have with him. For example, a table may possess that seems to be countless affordances of use. One can eat or write on it, but also use it as an elevation to reach another object. However, two things are certain: 1) some affordances are more natural to the table and 2) affordances are limited. One cannot use the table as a football to play with his peers. Recall the already mentioned passage of Umberto Eco, "my objection is that this table cannot be interpreted as a vehicle which can be used to travel from Athens to Thessaloniki. The problem is that such severe limitation tells us that the table can be interpreted (and known) in many ways (including those that its producer was not thinking of), but not in whichever way" (Eco, 2015, 398). So far Ferraris' positive realism is really close to Gibson's theory of affordances.

According to Ferraris, affordances are enacted through objects and the environment. The following notion is not easy to integrate into Ferraris' realism. Remember that there is a compelling case for a claim that for him only individuals exist. Therefore, we either have to accept that the environment is an individual or that it does not exist. In the second case, one would be forced to admit that the concept of the environment designates "all objects in relation with individual x" (Nominalism). However, it seems that here Ferraris accepts the holistic view of the source of determination. If that is the case, his view gets close to Hegel's. Then the environment in Ferraris' theory plays a similar role to Hegel's absolute. The fact is that affordances do not emerge in a vacuum. Interactions with other objects (for example, our 
interpretations) can modify the character of affordances. ${ }^{19}$ However, one could worry that Ferraris here reaches the same limit as Gibson does. Remember that for Gibson affordances imply complementarity of the object and the subject. Ferraris asserts that "the forms, the signifiers and the uses are by a large part already present in the world, waiting only to be evoked by a human or an animal" (Ferraris, 2013b: 12). However, this "by a large part" is the most important step the theory has to work out. Two questions remain unanswered: 1) can the complementarity implied in affordances be worked out while not falling back to correlationism and 2) what is the theory of the ontological passage from determinations object has to the affordances it offers, given that it offers different affordances to different agents. However one answers these questions, positive realism breaks with the Kantian paradigm of associating holistic theories of the source of determination with anti-realism. From the Kantian point of the view, environment and complementarity that ties subject and object in the case of the enactment of affordability could only be understood as correlationist. Ferraris' insistence against such reading brings him closer to Hegel's position of holistic yet not antirealist theory of the source of determination.

Note how ontologically ambitious the notion of affordances is. According to Ferraris, "A cavern affords different types of beings, and serves as a refuge precisely because it has certain characteristics and not others" (Ferraris, 2014b: 55). This means that the modesty of reality as resistance is now replaced by a much bolder ontological claim: Reality is the source of determination and has a recognizable structure that affords us to interact with it in some ways while making the interaction in other ways impossible. While unamendability still contained the possibility that reality is completely foreign and indifferent to us, affordances imply the meaningfulness of being (if by meaningfulness we understand certain "readability" of being by humans and other subjects). Therefore, Ferraris claims that "in the environment, meaning "comes into being" - it is not at our complete disposition. Meaning is a modality of organization, where something is presented in some way. Yet, it does not ultimately depend on subjects" (Ferraris, 2014b: 55-56). In this way Ferraris finally discovers the way to speak about reality positively. This also seems to support the thesis that Ferraris' positive realism starts to drift towards a more Hegelian notion of a holistic source of determination. On the other hand, determination also becomes dynamic. Even if Ferraris does not provide

${ }^{19}$ Ferraris notion of environment seems to be very similar to Levi Bryant's notion of Regimes of attraction. See Chapter 5 of his Democracy of Objects (2011). 
a general theory of determination as Kant and Hegel do, the effectual nature of interactions between different determinations becomes evident. Not only do the objects "offer" affordances and send invitations (Ferraris, 2013b: 2133), they are determined in the environments in which they entangle themselves with other agents. In such context Ferraris even reminds that the etymology of the word "thing" points to its effectual nature: "Let's do not forget that italian "cosa" is derived from latin "causo" and that Greek word for "cosa" is "pragma", from which comes "prassi", "pragmatica", "pragmatismo" (Ferraris, 2013b: 13).

\section{Conclusions}

The analysis of Ferraris' notion of the source of determination naturally fell into three parts. First, I summarized his interpretation of Kant and the diagnosis of what, according to Ferraris, went wrong with Kant and postKantian philosophy. For Ferraris, the main point of dissatisfaction with Kant is Kant's "transcendental fallacy." According to Ferraris, in the first Critique, Kant simply treats experience and science as having identical structures. This presupposition enables Kant's thesis on conceptual schemes: for Kant, in order to experience the world, the intermediate intervention of conceptual schemes is necessary. According to Ferraris, Kantian unrestricted constructivism follows from this. Following such diagnosis of modern philosophy, Ferraris treats constructivism, and not correlationism, as the main opposition to his realism. The further analysis of constructivism showed that the opposite of constructivism, for Ferraris, is the claim that reality is not amorphous, but structured before any encounter with us. Furthermore, as the slipper experiment seeks to establish, this structure allows beings with altogether different conceptual capacities to experience, navigate in, and cope with the same world.

The second part, which follows from the first, tried to establish what the question of realism is really about for Ferraris. The analysis of the aforementioned slipper experiment allowed me to come to the conclusion that realism, for Ferraris, as for Kant and Hegel, is the claim that reality itself is the source of determination in the world. Another significant thing to note is that for Ferraris the question of reality is also tied to the question of a meeting between a subject and an object. He usually designates such meetings under the rubric of "an encounter" and emphasizes their practical character. Put differently, these meetings usually involve dealings, copings, and actions, not 
only the passive perception of an object by the subject. This means that reality is not only something that has structure and is the source of determination, but also something thought from the perspective of the meeting. This may sound trivial until we notice that other new realist alternatives offer different perspectives. For example, Meillassoux thinks reality from the theoretical perspective of the hyperchaos, while the perspective of the meeting is also not primary in Grant's rethinking of nature, where 'genesis' is the main concept. These two perspectives seem to be, if not fully, when at least much more theoretical than one Ferraris presents.

After two preliminary investigations, the third part dealt directly with Ferraris' notions of reality, where a more concrete notion of the source of determination is developed. This part attests that there is no fully worked out notion of reality Ferraris uses in all of his works. Rather, the rethinking of the notion is ongoing. However, I think that we can track a certain direction this rethinking is going. Ferraris started with the negative notion of reality as unamendability, which serves primarily as the pragmatic tool for the critique of constructivism. At this point he associates holistic theories of determination with anti-realism. The direction he is moving in the later works is that towards a more and more positive notion of reality. Up to this point, the most positive notion of reality Ferraris defends is that of reality as affordability. However, I wonder if 1) one can rethink the complementarity implied in affordances while not falling back into correlationism and 2) what is the ontological theory of the passage from determinations object has to the affordances it offers, given that it offers different affordances to different agents. What is more, the analyses uncovered two notions of the source of determination Ferraris operates. On the one hand, the negative realism seems to claim that it is the individual objects that are the sole sources of determination. This position is incompatible with both Kant's and Hegel's positions. At this stage, the only place where he defends the holistic theory of determination is the theory of social objects that is based on a version of weak constructivism. In other words, at this stage, Ferraris seems to link the holistic theory of determination with constructivism. On the other hand, positive realism seems to defend the holistic theory of determination which, while still being incompatible with Kant's offer, gets much closer to Hegel's notion of the absolute as the source of determination. 


\section{THE QUESTION OF THE SOURCE OF DETERMINATION AS THE PROBLEM OF REALISM: TWO PARADIGMS, TWO PROBLEMS}

In this thesis, the investigation into the question of determination in the three paradigms of continental philosophy uncovered three models of the source of determination. First, there is the atomic model of the source of determination, according to which objects indifferent to each other are the sources of determination. The analysis showed that Ferraris' early notion of reality as unamendability could be interpreted along these lines. More generally, such notion could be seen as the model of pre-Kantian realism. However, the analysis also showed that both Kant and Hegel rejected such notion while Ferraris moved from it in his later writings because he was unable to produce any positive notion of reality starting from it. Therefore, I will treat only two other options investigated in the thesis as philosophically plausible and promising.

The analysis also showed that there are at least two ways how to interpret Kant's position that it is the subject who is the source of determination. On the one hand, one could claim that this position constitutes Kant's subjectivism: for Kant, it is a subject who constructs experience. Of course, such reading would admit that every rational subject constitutes experience by employing the same categories, but nonetheless, it would maintain that this qualification does not enable Kant to escape subjectivism. This seems to be the direction that Ferraris' interpretation of Kant takes. Hegel criticisms of Kant's idealism as onesided and some of his remarks demonstrate that he sometimes also treat Kant as a simple subjectivist. On the other hand, one could claim that for Kant the source of determination is not the subject as such but the transcendental subjectivity. Indeed, the concrete rational subject only finds himself constituted by transcendental subjectivity. Such notion of the source of determination treats determination holistically: Determination is constituted through the objective realm of the system of categories (the transcendental subjectivity) and not only through the concrete acts of concrete rational subjects indifferent to a bigger whole of determinations. In this thesis, I defend this interpretation of Kant. The absolute idealists saw this tendency in Kant as one of the possibilities to be further developed in their own thought.

I also showed that Hegel also holds the holistic theory of the source of determination: for him, the source of determination is the absolute. I argued that for Hegel his notion of the absolute is at once against Kant and the continuation of Kant's efforts: On the one hand, Hegel argues that the subject 
cannot be the source of determination because the subject itself is only constituted in the opposition to the object, and, therefore, the source of determination must be a bigger whole that encompasses both the subject and the object; on the other hand, this bigger whole (that Hegel calls the absolute) is established as the condition of the possibility of the experience. In this sense, Hegel (as other absolute idealists) saw his work as continuous with Kant's transcendental philosophy.

In such situation, the question arises: what is the difference between Hegel's and Kant's holistic notions of the source of determination? I think that the essential difference lies in the fact that the absolute must encompass both the constitution of a subject and that of an object. According to Kant, the transcendental subjectivity constitutes only experienced determinations. Kant insists on the fact that even if we cannot know the thing-in-itself or discern what in experience comes from the transcendental subjectivity and what from the sensibility, the distinction between spontaneity and receptivity must remain untouched. In this way, the space for the speculation of what lies beyond experience, in the great outdoors, to use Meillassoux's phrase, remains. Contrary, Hegel's absolute is the source of determination of both an object and a subject, of receptivity and spontaneity. In other words, the Absolute is the source of determination of mental, ideal and material, and not only of mental and ideal as Kant's transcendental subjectivity. However, Hegel's absolute should not be seen as some metaphysical entity or ground but rather the whole of all relations and determinations contingently evolving in history. It is for this reason that Logic and Encyclopedia neither start nor ends with the subject. If Kant's question is what kind of subject must exist for experience to be possible, Hegel's question is how must being as the whole be constituted for rational beings to emerge and think being?

It is at this critical juncture where we must place Ferraris' positive realism and his notion of affordances. It is clear that Ferraris defends positive realism because he was unable to produce a positive notion of reality starting from the notion of reality as unamendability. However, should we treat his notion of affordances and its dependence on the notion of environment as a disguised return to the post-Kantian idealism according to which the primary source of determination is the objective structure prior to the constitution of a concrete human subject but nonetheless tied to the subjective? This seems to be the case because the environment seems to be the environment of a given subject: The same material state of affairs could be two completely different environments for two different subjects (consider Agamben's dragonfly). However, this is precisely the conclusion Ferraris wants to avoid. If that is the case, then we have to read Ferraris' environment and affordances along the 
lines of Hegelian absolute idealism: The environment is prior to the subject; it is the primary source of determination, even if the subject emerges out of it and later becomes a power that can determine things in its own right. The conclusion I've reached in this thesis is that there are simply not enough concrete commitments in Ferraris' text to determine which of these interpretations is more valid.

In a broader context, Hegelian absolute idealism seems to be the lessexplored option in the post-Kantian philosophy. According to Kant, the source of determination is the transcendental subjectivity, the objective structure that is prior to a concrete rational subject but nonetheless essentially tied to rational subjects. Looking from this perspective, most conceptual innovations after Kant seem to be essentially Kantian: be it history, the unconscious, the will to power, passive syntheses, Dasein, the clearing, language, discursive practices, the Real or the text. All these figures are the notions of the source of determination prior to the constitution of any concrete subject nonetheless essentially tied to human subjectivity.

Another problem that this thesis uncovered concerns the notions of determination that the three authors operate with. Although in Positive realism Ferraris is less straightforward on his notion of determination, Kant, Hegel and Ferraris all hold the holistic differential theories of determination. On the one hand, they all treat a concrete determination to be constituted only in a larger web of determinations, be it the transcendental subjectivity, the absolute, or the environment. The positivist view of determination, according to which determination is composed of atomic autonomous bits of determination is rejected by all three thinkers.

A more problematic part of the theories of determination defended by Kant and Hegel is their differential nature. According to Kant, a determination is the equilibrium of the opposite forces. For Hegel, a determination is the colimitation of reality and negation. The question arises if a determination is composed of something already determined? That is to say, are Kant's opposite forces and Hegel's reality and negation already determined? And, what is more, is the positive force in Kant or the negation in Hegel also constituted by two different forces? Does the logic of opposition go all the way down? These questions indicate that Kant's and Hegel's notions of determination anticipate some of the problems later extensively discussed in the so-called philosophies of difference. 


\section{CONCLUSIONS}

In this thesis, I have treated Kant's theory of the source of determination as the model of the later post-Kantian paradigm. Contrary to many accounts prevalent today, Kant sees his aim as one of establishing the conditions of 'real' meeting between a subject and an object in the experience. In other words, he does not seek to enclose us in our subjectivity, but to get us in touch with the objective. For Kant, the source of determination is the transcendental subjectivity, not a concrete human subject. This means that "meeting" conditions established by Kant only apply to those, who "could be"/"have" transcendental subjectivity. In Kant's system, this de facto leaves only humans as capable of "the meeting." However, there is an objectivist tendency in Kant's philosophy: The transcendental subjectivity is prior to a concrete human subject and in this sense could be said to be objective. However, it is essentially tied to human subjectivity. Therefore, critics are right to point out that Kant's revolution is more Ptolemaic than Copernican.

Kant thinks determinations as intensive magnitudes. Intensive magnitudes are constituted by the opposition between the opposing forces (Realität and Negation). This means that forces constitute determinations qua qualities. Determinations are not primal or atomic. Kant's notion of reality is dynamical and not a substantialist one. At the same time, it strongly emphasizes the physical layer of reality. Transcendental subjectivity constitutes qualities well below the threshold of human sensibility (as in the case of magnetic and electric phenomena). Finally, Kant thinks the question of realism in the realism-idealism opposition. For Kant, idealism concerns the ontological status of determinations. Kant considers himself an idealist because he claims that determinations given to human subjects only exist in experience and not in the world apart from the human subjects. Also, there is a tendency in Kant to associate ontological individualism with realism and holistic theories of the source of determination with anti-realism.

I analyzed Hegel's theory of the source of determination as an example of the first wave of the critics of Kantian subjectivism, as an example of the absolute idealist thought. Hegel's notion of the absolute helps him to rethink the question of the source of determination and overcome Kant's limitation of knowledge to experience ("double bind"). Hegel follows a standard absolute idealist critique of Kant and maintains that the possibility of a meeting between a subject and an object can only be explained from the standpoint of the absolute (a bigger whole). When it comes to determination, neither subject nor object could be the origin (ontologically or explanatory wise), because 
they only emerge in opposition between them in experience. Hegel argues that the entire Kantian enterprise is built on the premise that there is a separation between a subject and the absolute, which remains forever unreachable. Hegel rejects such presupposition in favor of the thesis of ontological continuity. Therefore, for Hegel, the meeting has always already happened, the absolute "is in and for itself already with us."

In Science of Logic, he treats Realität as determination of the absolute. There, Hegel's analysis of determination establishes the threefold notion of reality. First, reality is first and the most basic determination and as such is the beginning of Hegel's theory of determination. Hegel's notion of reality is the notion of the determination of the logical, the mental, the ideal, and not only, or first of all, of the material. Second, reality, which is composed of the mixture of it and negation, introduces a real difference into the absolute. Therefore, reality is the beginning of the multitude in Logic. Reality is the beginning of both the individuation and relationality in the development of the absolute. Third, in reality, the negation, and with it the relational side of reality, is hidden. We are immanent to the absolute. Hegel's notions of the absolute and reality show that for him the opposition of idealism is not realism, but positivism - the claim that the world is composed of self-sufficient individuals as the sources of determination. Therefore, Hegel challenges the Kantian tendency to equate holistic theories of the source of determination with anti-realism. Precisely the opposite, for him the way to construct a postKantian realist ontology is to adopt a holistic theory of determination. In this way, Hegel's notion of reality transcends the opposition between correlationism and realism.

I presented Ferraris' new realism as the second alternative to the Kantian paradigm. Ferraris treats constructivism, and not correlationism, as the main opposition to his realism. The further analysis of constructivism showed that for him the opposite of constructivism is the claim that reality is not amorphous, but structured before any encounter with us. Furthermore, as the slipper experiment seeks to establish, this structure allows beings with altogether different conceptual capacities to experience, navigate in, and cope with the same world. The same analysis allowed me to come to the conclusion that realism for Ferraris is the claim that reality itself is the source of determination in the world.

There is no fully worked out notion of determination Ferraris uses in all of his works. However, I traced the three stages of development of his notion of the source of determination. Ferraris started with the negative notion of reality as unamendability, which serves primarily as the pragmatic tool for the critique of constructivism. At this stage, he seems to treat individual objects 
as sources of determination. The direction he is moving in the later works is towards a more and more positive notion of reality. Up to this point, the most positive notion of reality Ferraris defends is that of reality as affordability. However, I wonder if 1) one can rethink the complementarity implied in affordances while not falling back into correlationism and provide 2) the theory of the ontological passage from determinations object has to the affordances it offers, given that it offers different affordances to different agents.

Negative realism seems to claim that it is the individual objects that are the sole sources of determination. Such position is incompatible with both Kant's and Hegel's positions. At that stage, the only place where he defends the holistic theory of determination is the theory of social objects that, in turn, is based on a version of weak constructivism. In other words, at that stage, Ferraris seems to strongly link the holistic theory of determination with constructivism. On the other hand, positive realism seems to defend a holistic theory of determination. This position can be interpreted either as the return to the post-Kantian paradigm or as the position much closer to that of Hegel. The thesis did not find conclusive arguments as to which interpretation is more plausible.

The analysis of Ferraris', Kant's and Hegel's philosophies revealed the different oppositions in which these thinkers think the problem of realism. However, it also revealed that they all share an understanding what the question of realism is about. 


\section{BIBLIOGRAPHY}

Agamben, G., 2004, The Open: Man and Animal, Stanford: Stanford University Press.

Agamben, G., 1990, The coming community, London: University of Minnesota Press.

Allais, L., 2015, Manifest reality: Kant's idealism and his realism, London: Oxford University Press.

Allison, H., 1983, Kant's Transcendental Idealism: An Interpretation and Defense, Michigan: Yale University Press.

Baranovas. R., 2019, Why Kant is a weak conceptualist, in: Problemos 95, p.81-93, Vilnius: Vilniaus universiteto leidykla.

Beiser, C.F., 2002, German Idealism: the Struggle Against Subjectivism, 1781-1801, Cambrigde: Harvard University Press.

Brassier, R., 2010, Concepts and Objects, in: Speculative Turn: Continental Materialism and Realism, ed. Bryant L., Harman G., Srnicek N., p. 47-65, Re.prres.

Brassier, R., 2007, Nihil Unbound: Enlightenment and Extinction, New York: Palgrave Macmillan.

Braver, L., 2007, A Thing of This World: A History of Continental AntiRealism, Evanston: Northwestern University Press.

Bryant, L. R., 2011, The Democracy of Objects. London: Open Humanities Press.

Bubbio, P., D., De Cesaris, A., Pagano, M., Weslati, H., 2019, Hegel, Logic and Speculation, London: Bloomsbury Academic.

Burbidge J.W., 2008, Historical dictionary of Hegelian philosophy, Plymouth: Scarecrow Press. 
Catren G., 2010, Outland Empire: Prolegomena to Speculative Absolutism, in: Speculative Turn: Continental Materialism and Realism, ed. Bryant L., Harman G., Srnicek N., p. 334-367, Re.prres.

DeLanda M., 2013, Intensive Science and Virtual Philosophy, London: Bloomsbury Academic.

Deleuze, G., 1984, Kant's Critical Philosophy: The Doctrine of the Faculties, London: The Athlone Press.

Di Martino, L., 2012, Between "new realism" and "weak thought": Umberto Eco's "negative realism" and the discourse of late Postmodern Impegno, Quaderni d'italianistica, Volume XXXIII, No. 2, p.189-218.

Eco U., 2012, Di un realismo negativo, in: Bentornata realtà: Il nuovo realismo in discussione, ed., De Caro, M., Ferraris M,. Torino: Einaudi.

Eco U., 2015, Some Remarks on New Realism, in: Journal of Philosophical Research, Special Supplement, p. 387-395.

Ennis, P.J., 2011, Continental realism, Hants: Zero Books.

Esposito R., 1988, Communitas: The Origin and Destiny of Community, Stanford: Stanford University Press.

Ferraris M., 2014b, Documentalità: Perché è necessario lasciar tracce, Roma: Laterza.

Ferraris M., 2015, Ding an Sich, in: Das neue Bedürfnis nach Metaphysik, ed. Gabriel. M., Hogrebe W., Speer A., p. 119-132, Berlin: De Gruyter.

Ferraris M., 2016, Emergenza, Torino: Einaudi.

Ferraris M., 1997, Estetica Razionale, Milano: Raffaele Cortina.

Ferraris M., 2013a, Goodbye, Kant!: What Still Stands of the Critique of Pure Reason, Albany: State University of New York Press.

Ferraris M, 2014a, Manifesto of New Realism, Albany: State University of New York Press. 
Ferraris M, 2014c, New Realism as Positive Realism, in: Meta: Research in Hermeneutics, Phenomenology, and Practical Philosophy, Special Issue 2014, p. 172-213.

Ferraris M., 1998, Non ci sono gatti, solo interpretazioni, in: Diritto, Giustizia, Interpretazione, ed. Vattimo G., Derrida J., Roma: Laterza.

Ferraris M, 2013c, On New Realism, in: Kairos. Revista de Filosofia \& Ciência 8, p. 45-65.

Ferraris M., 2013b, Realismo Positivo, Torino: Rosenberg\&Sellier.

Fichte J.G., 1982, Science of Knowledge, Cambridge: Cambridge University Press.

Gabriel M., 2011, Transcendental Ontology: Essays on German Idealism, London: Continuum.

Gibson, J.J., 2015, The Ecological Approach to Visual Perception, New York: Psychology Press.

Giladi P., Hegel's Philosophy and Common Sense, In: The European Legacy Vol. 23, No. 3, p 269-285.

Giovanelli, M., 2010, Reality and Negation - Kant's Principle of Anticipations of Perception, London: Springer.

Grant I.H., Dunham J., Watson, S., 2014, Idealism: The History of a Philosophy, London: Routledge.

Grant I.H., 2006, Philosophies of Nature After Schelling, Cornwall: Continuum.

Grüne, S., 2011. Is there a Gap in Kant's B Deduction?, in: International Journal of Philosophical Studies 19 (3): 465-490.

Guyer P., 1987, Kant and the Claims of Knowledge, Cambridge: Cambridge University Press. 
Hanna, R., 2011. Kant's Non-Conceptualism, Rogue Objects, and The Gap in the B Deduction. In: International Journal of Philosophical Studies 19 (3): 399-415.

Harman G., 2013, Bells and Whistles: More Speculative Realism, Croydon: Zero Books.

Harman G., 2019, Object-Oriented Ontology: A New Theory of Everything. London: Pelican.

Harman G., 2011, The Quadruple Object. Winchester/Washington: Zero Books.

Hegel, G.W.F., 1997, Dvasios fenomenologija, Vilnius:ALK/Pradai.

Hegel G.W.F., 1977b, Difference between Fichte's and Schelling 's System of Philosophy, Albany: State University of New York Press.

Hegel G.W.F., 1977a, Faith and Knowledge, Albany: State University of New York Press.

Hegel, G.W.F., 2018, The phenomenology of spirit, translated by Pinkard T., New York: Cambridge University Press.

Hegel G.W.F., 2010, The Science of Logic, Cambridge: Cambridge University Press.

Hegel G.W.F., 1982, Who thinks abstracly?, in Kaufmann W., Hegel: Texts and Commentary, Indiana: University of Notre Dame Press.

Heidegger M., 2001, Being and Time, New York: HarperCollins Publishers.

Heidegger M., 1997, Kant and the problem of Metaphysics, Bloomington: Indiana University Press.

Heidegger M., 1982, The basic problems of phenomenology, Bloomington: Indiana University Press. 
Henrich D., 1989, Kant's Notion of a Deduction and the Methodological Background of the First Critique, in: Kant's Transcendental Deductions: The Three "Critiques" and the "Opus Postumum", ed. E. Förster, Stanford: Stanford University Press, p.29-46.

Henrich D., 1994, The Unity of Reason: Essays on Kant's Philosophy, Cambridge: Harvard University Press.

Hyppolite J., 1997, Genesis and structure of Hegel's "Phenomenology of Spirit”, Evanston: Northwesteren University Press.

Houlgate S., 2005, The Opening of Hegel's Logic: From Being to Infinity, Indiana: Purdue University Press.

Inwood, M., 2017, A Hegel Dictionary, Oxford: Blackwell Publishers Ltd.

Johnston A., 2018, A New German idealism: Hegel, Zizek, and dialectical materialism, New York: Columbia University Press.

Kant, I., 1992, Attempt to introduce the concept of negative magnitudes into philosophy, in: Theoretical philosophy, 1755-1770, ed. Walford, D., New York: Cambridge University Press.

Kant, I., 1998, Critique of Pure Reason, translated by Guyer, P., and Wood, W.A., Cambridge: Cambridge University Press.

Kant, I., 1956, Kritik der reinen Vernunft, Hamburg: Verlag von Felix Meiner.

Kant, I., 2004, Prolegomena to Any Future Metaphysics: That Will Be Able to Come Forward as Science, Cambridge: Cambridge University Press.

Kleist, v.H., Letter of 22 March 1801 to Wilhelmine von Zenge, in: The Broken Jug. Manchester: Manchester University Press, 1977.

Kneller J., 2007, Kant and the power of imagination, Cambridge: Cambridge University Press.

Longuenesse, B., 1998, Kant and the capacity to judge: sensibility and discursivity in the transcendental analytic of the Critique of pure reason, Princeton: Princeton University Press. 
Malabou, C., 2005. The Future of Hegel. Plasticity, Temporality and Dialectic. London, New York: Routledge.

McTaggart J.E., 1910, A commentary on Hegel's Logic, London: Cambridge University Press.

Meillassoux, Q., 2008. After Finitude. An Essay on the Necessity of Contingency. London: Continuum.

Morton, T., 2013, Hyperobjects: Philosophy and Ecology After the End of World, Minneapolis: The University of Minnesota Press.

Nancy J-L., 1998, Hegel: The Restlessness of the Negative, London: University of Minnessota Press.

Nancy J-L., 1986, The Inoperative community, London: University of Minnessota Press.

Pippin R., 2018, Hegel's Realm of Shadow's, Logic as Metaphysics in "The Science of Logic", Chicago: University of Chicago Press.

Poma, A., 1997, The critical philosophy of Hermann Cohen, Albany: State University of New York Press.

Sabolius, K., 2014, Quentinas Meillassoux ir radikali meno (ne)galimybe, in: Problemos 85, p. 153-166. Vilnius: Vilniaus universiteto leidykla.

Schwarz, W., 1987, Kant's Categories of Reality and Existence, in: Philosophy and Phenomenological Research, Vol. 48, No. 2, pp. 343-346.

Sebold R., 2014, Continental anti-realism: a critique, New York: Rowman \& Littlefield International.

Vattimo, G., 2016, Of Reality: The Purposes of Philosophy, New York: Columbia University Press.

Winfield, R,D., 2012, Hegel's Science of Logic: a critical rethinking in thirty lectures, Plymouth: Rowman \& Littlefield Publishers. 
Šerpytytė R., 2012a, Nihilizmas ir naujieji realizmas, in: Problemos 82, p.7-17, Vilnius: Vilniaus universiteto leidykla.

Šerpytytė R., 2012b, Nihilizmas ir tikrove: spekuliatyvusis realizmas nihilizmo banalizavimas?, in Problemos 81, p. 7-16. Vilnius: Vilniaus universiteto leidykla.

Šerpytyte R., 2015, Ontologija ir nihilizmas. Hegelio scena ir užkulisiai, in: Ontologijos transformacijos: medijos, nihilizmas, etika, ed. Sodeika, T., Vilnius: Vilniaus universiteto leidykla.

Šerpytytė R., 2019, Tikrovès spektrai. Vakaru nihilizmas tarp diagnozès ir teorijos, Vilnius: Vilniaus universiteto leidykla.

Šliogeris A., 1985, Žmogaus pasaulis ir egzistencinis mastymas, Vilnius: Mintis. 


\section{LIST OF PUBLICATIONS}

Baranovas. R. 2019. Why Kant is a weak conceptualist. Problemos 95, 81-93.

Baranovas. R. 2019. Realität, Hegel's idealism and common sense. Hegeljahrbuch. Vol. 2019. Iss.1, 253-259, https://doi.org/10.3790/hgjb.2019.1.253.

Baranovas. R. 2020. Virtuality and the problem of agency in objectoriented ontology. Open philosophy, 3(1), 233-241. Doi: 10.1515/opphil2020-0106.

Baranovas. R. 2021. Po Kanto: naujajo realizmo ir absoliučiojo idealizmo alternatyvos. In: Apie tikrovę, ed. Sabolius k., Lapas, Vilnius: 2021, 132-171. 
NOTES 
NOTES 
NOTES 
Vilniaus universiteto leidykla

Saulètekio al. 9, III rūmai, LT-10222 Vilnius

El.p.: info@leidykla.vu.lt,www.leidykla.vu.lt

Tiražas 15 egz. 